\title{
Design, Properties and Recent Application of Macrocycles in Medicinal Chemistry
}

\author{
Philipp Ermert*
}

\begin{abstract}
Macrocyclic compounds have recently received increasing attention in drug discovery as these compounds offer the potential to modulate difficult targets and to access novel chemotypes. Approaches towards libraries of macrocyclic compounds based on modular organic synthesis and applications of these technology platforms to find and improve biologically active compounds are introduced in this minireview. Alternatively, lead compounds may be obtained by truncation and modification of macrocyclic natural products. Selected medicinal chemistry programs are discussed, illustrating a macrocyclization approach toward ligands with improved properties. The design of such ligands is often informed by X-ray crystal structures of protein-ligand complexes. Efforts to understand cellular permeability and oral bioavailability of cyclic peptides and non-peptidic macrocycles are summarized.
\end{abstract}

Keywords: Library $\cdot$ Macrocycle drug $\cdot$ Membrane permeability $\cdot$ Modular synthesis $\cdot$ Oral bioavailability

\section{Introduction}

Macrocycles have received increasing attention in drug discovery over the past 15 years as these compounds offer potential to modulate difficult targets such as proteinprotein interactions with large, shallow (featureless) binding sites or proteases, which recognize rather large substrates. Several technology platforms to generate libraries of macrocyclic compounds have been developed in the last decade, including approaches based on modular organic synthetic assembly of building blocks as well as biochemical (e.g. m-RNA display) and biological (e.g. phage display) approaches. Macrocyclic natural products like for example largazole (Fig. 12) or sanglifehrin A (Fig. 13) inspired the synthesis of simplified analogs. More and more frequently, macrocyclization is applied in medicinal chemistry programs as a standard strategy to improve the properties of compounds as well as to generate novel chemotypes. These efforts are reflected in the publication of a large number of research papers summarized in a series of review articles covering the field. ${ }^{[1]}$ In the

${ }^{\star}$ Correspondence: Dr. P. Ermert recent past, macrocyclic natural products or derivatives thereof but also synthetic de novo designed macrocyclic compounds were approved by the FDA or are in clinical trials (Fig. 1).[1e,2]

Many macrocycles are "beyond rule of five' compounds. This chemical space was traditionally associated with reduced cell permeability and bioavailability. Therefore, over the last few years, significant work

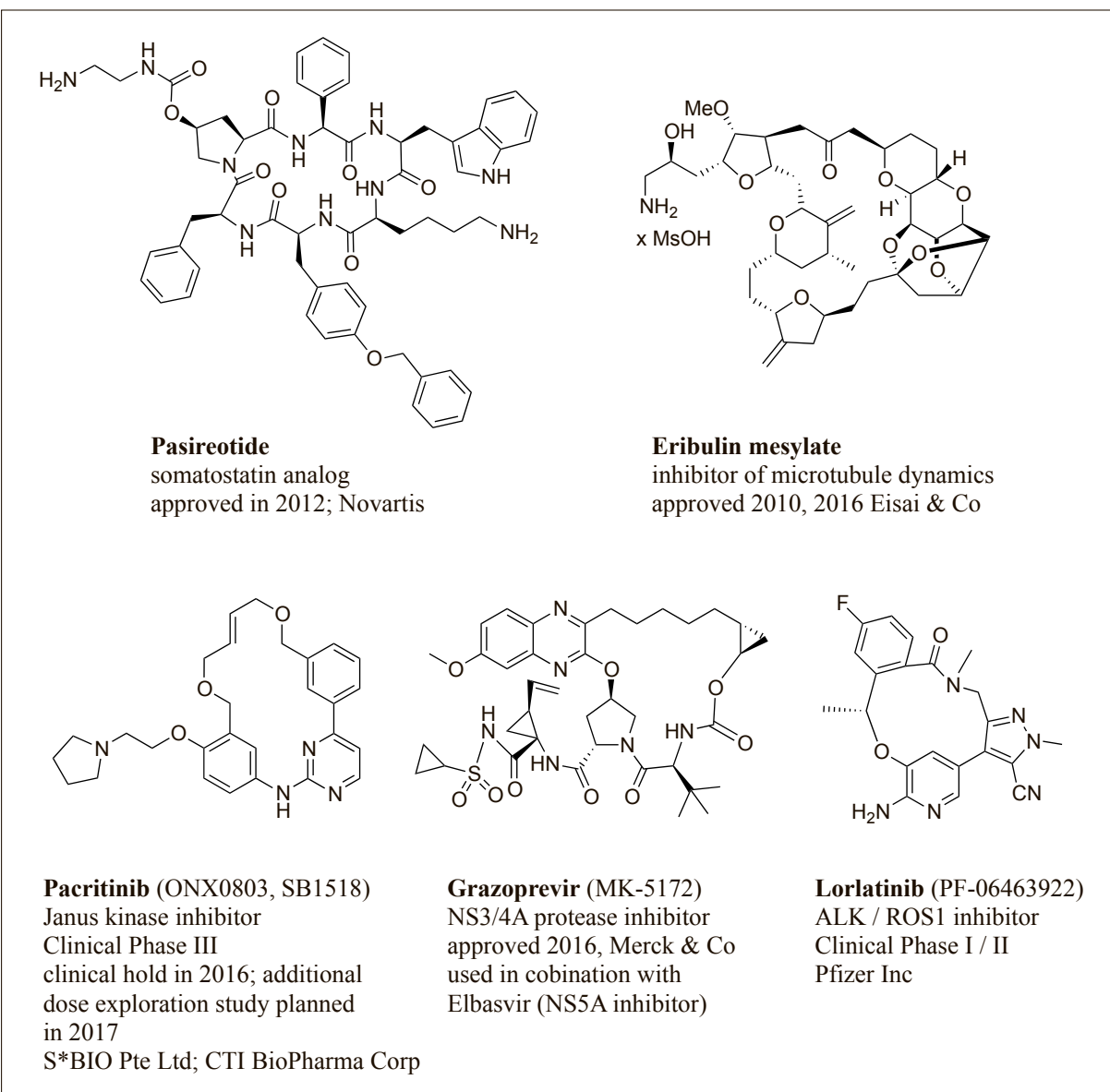

Fig. 1. Macrocyclic drugs which were approved or are in clinical trials: Pasireotide ${ }^{[2 a]}$ is a representative of the class of cyclic peptide drugs with modified side chains; Eribulin ${ }^{[2]}$ is a simplified synthetic analog of the complex natural product Halichondrin B; Pacritinib ${ }^{[1]}$, Grazoprevir ${ }^{[1,2 c]}$ and Lorlatinib ${ }^{[2,2 e]}$ represent de novo designed orally available macrocycles. 
was dedicated to the investigation of the properties of these compounds. ${ }^{[3]}$ Sets of cyclic peptides as well as non-peptidic macrocycles have been studied to understand the factors on which permeability and oral availability depend. The potentially favorable impact of macrocyclization on pharmacokinetic properties like passive permeability and stability (translating into improved bioavailability) suggest the consideration of macrocyclic prodrugs. Early examples comprise the conversion of linear peptides into bio-cleavable macrocyclic structures; the concept found recent application to non-peptidic thrombin inhibitors.

\section{Synthesis of Macrocyclic Compounds}

In the present article the discussion of the generation of libraries of macrocyclic compounds is limited to chemical synthesis, covering platforms for modular assembly of building blocks and approaches based on multicomponent reactions. The latter recently found broader application in the ring-closing step. Products obtained by chemical synthesis can be used in any screening format and their up-scale is readily achieved.

DNA-encoded synthesis, phage display or mRNA display techniques will not be discussed. These latter techniques have been introduced in a review article by Dougherty et al..$^{[1 \mathrm{~m}]}$ They offer the advantage to access very large (limited to $10^{9}$ $10^{13}$ compounds $\left.{ }^{[1 \mathrm{~m}]}\right)$ and diverse libraries of peptidic compounds. The methods provide compounds with relatively high MW and large polar surface area as pointed out by Yudin; ${ }^{[4]}$ the presence of tags may limit the screening application.

\subsection{Macrocyclization Reactions}

Many reaction types have been employed in the ring-closing step to obtain macrocyclic products; a detailed overview is provided in recent reviews by Marsault and Peterson. ${ }^{[1 \mathrm{~b}, 5]}$ Macrolactam and macrolacton formation, ring-closing metathesis and click reactions are used particularly frequently. This was explained by ready accessibility of the linear precursors, applicability of the transformations in solution and on solid support, availability of a variety of reagents and reaction conditions as well as tolerance of other functional groups. ${ }^{[1 b]}$ Classical difficulties sometimes occurring in the synthesis of (often rather strained) macrocyclic compounds comprise (cyclo) oligomerization of the linear precursor and epimerization of labile stereocenters prior to cyclization. Occasionally the generation of new chirality elements leading to the formation of stereoisomers is observed.
Oligomerization, e.g. the formation of cyclic dimers can be controlled by dilution and slow addition of the linear precursor to the reagent or catalyst. ${ }^{[6]}$ In addition, the choice of solvent ${ }^{[6 a, d]}$ and temperature (higher temperatures favoring the cyclomonomer $)^{[6 a, b]}$ have been reported to be important (e.g. conversion of $\mathbf{1}^{[6 a]}$, Scheme 1).

The cyclization of $\mathbf{4}$ (Scheme 2) was described by Boger et al. to be very sensitive to the conditions applied; 5 (62-63\%) was obtained as major product if EDCI/ $\mathrm{HOBt}$ in $\mathrm{DMF} / \mathrm{CH}_{2} \mathrm{Cl}_{2} 2: 8$ or FDPP/ DMAP in DMF were used; ring closure with epimerization was however observed with PyBOP/DMAP in DMF or in DMF/ $\mathrm{CH}_{2} \mathrm{Cl}_{2}$ 2:8 affording epi-5 (60\%) almost exclusively. ${ }^{[6 \mathrm{~d}]}$

The success in the head-to-tail cyclization of peptides was found to depend on ring size and on point of cyclization; ring closure in the synthesis of cyclic tetrapeptides and pentapeptides for example can go along with cyclooligomerization or epimerization. Structure-inducing building blocks bringing the reactive ends in proximity have been broadly applied to favor the ring-closing reaction. ${ }^{[7]}$

Occasionally, stable atropisomers result from macrocyclization. ${ }^{[8]}$ This was observed for instance in a series of macrocyclic farnesyl transferase (FTase) inhibitors described by scientists at Merck. ${ }^{[9]}$ The optical antipodes (enantiomeric conformers) of cyclophane $\mathbf{6}$ were resolved by chiral HPLC and kinetic data for racemization in DMSO have been determined: a half-life of (-)-6 of $60 \mathrm{~min}$ at $100{ }^{\circ} \mathrm{C}$ or $8.4 \mathrm{~min}$ at $120^{\circ} \mathrm{C}$ and an activation energy $\mathrm{E}$ of 28.4 $\mathrm{kcal} / \mathrm{mol}$ for the inter-conversion of (-)-6 and (+)-6 were reported (Fig. 2).

Compound (R)-8 (Fig. 2) was prepared in the course of an optimization of factor VIIa inhibitors by BMS scientists. ${ }^{[11,12]}$ Inhibitor $(R)-\mathbf{8}$ with an additional methyl group at the meta position of the phenyl glycine moiety, shows fivefold improved potency compared with $(R)-7$ and was reported to exist as a 1:1 mixture of conformational isomers. Priestley et al. proposed the presence of atropisomers due to hindered rotation of the unsymmetrically substituted phenylglycin aryl group (see below, section 3.1.1 for a detailed discussion and additional examples). ${ }^{[1,12]}$

Ring closure engaging an $S_{N}$ Ar reaction, displacing the fluorine atom of $\mathbf{9}$ afforded the rather strained (14-membered) para-cyclophane $\mathbf{1 0}$ as a mixture of atropisiomers; Joullié et al. then converted $\mathbf{1 0}$ by reduction and deamination into 11 (Fig. 2). [13]

At room temperature stable and separable rotamers of compounds containing tertiary amide groups in the macrocyclic scaffold are rarely observed; examples comprise the natural cyclopeptides sanguinamide $\mathrm{B}^{[14]}$ (not shown) and ceratospongamide. ${ }^{[15,16]}$ Trans,trans-

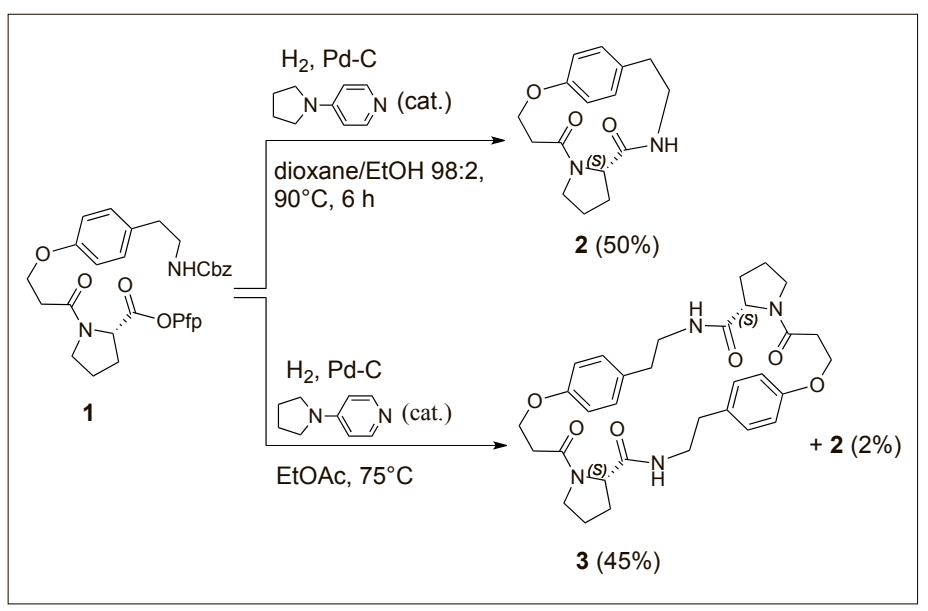

Scheme 1. Formation of cyclo-monomer or cyclo-dimer depending on reaction conditions as reported by Schmidt and coworkers. ${ }^{[6 a]}$

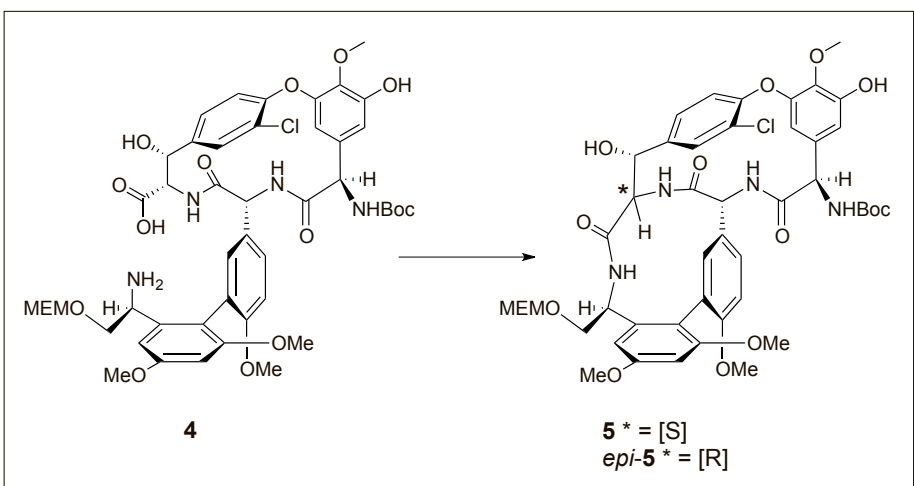

Scheme 2 .

Cyclization result depends on conditions: $\mathrm{EDCl} / \mathrm{HOBt}$, DMF/ $\mathrm{CH}_{2} \mathrm{Cl}_{2} 2: 8$ or FDPP/ DMAP in DMF, 5 (6263\%); PyBOP/DMAP, DMF or DMF/ $\mathrm{CH}_{2} \mathrm{Cl}_{2}$ 2:8, epi-5 (60\%). ${ }^{[\mathrm{Gcd}]}$ 
Fig. 2. Macrocyclic farnesyl transferase (FTase) inhibitor $\mathbf{6}^{[9,10]}$ and factor VIla inhibitor $(R)-8^{[11,12]}$ exist as mixture of atropisomers; the paracyclophane $10^{[13]}$ was obtained as a mixture of atropisomers.

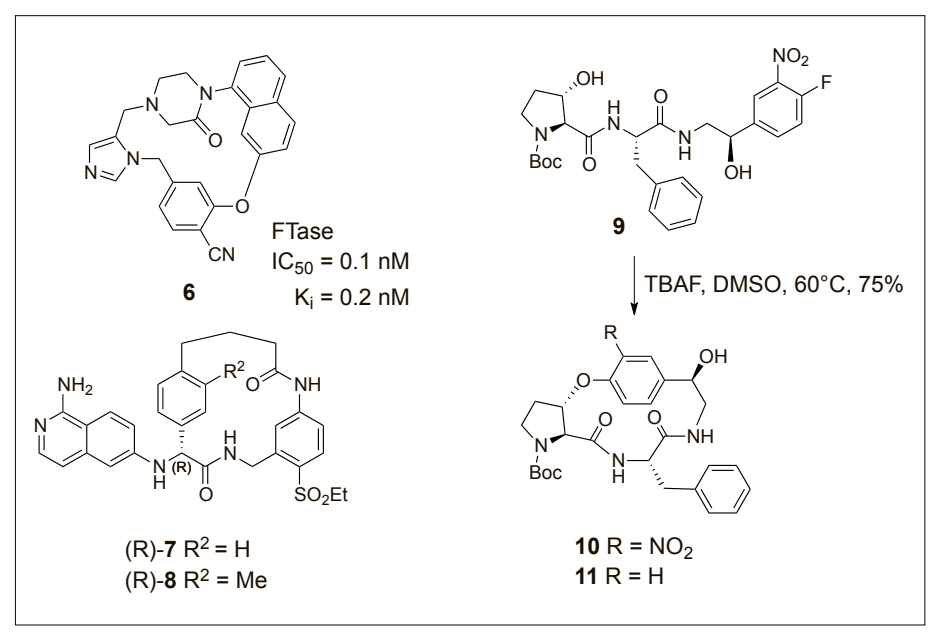

ceratospongamide (12; Scheme 3) and cis, cis-ceratospongamide (13) are modified cyclic heptapeptides isolated from a marine alga/sponge symbiont. The two proline residues control the conformation of the macrocycle. The stable (at ambient temperature) conformational isomers can be separated by HPLC. ${ }^{[15]}$ In agreement with the different three-dimensional structures, the rotamers exhibit different biological activities. The trans,trans-isomer 12 was described to be an inhibitor of transcriptional activation induced by IL- $1 \beta$ (expression of secreted phospholipase A2 was inhibited with $\left.\mathrm{IC}_{50}=32 \mathrm{nM}\right) .{ }^{[15,16]}$ The cis-cis-isomer 13 (the major component of the natural cyclo-heptapeptide[16a]) was inactive. Deng et al..$^{[15]}$ reported the transformation of either isomer into a 5:1 mixture of 12 and 13 upon heating in DMSO at $175^{\circ} \mathrm{C} \cdot{ }^{[17]}$ Depending on the synthetic access, different distributions of the isomers were obtained (Scheme 3): Ring closure between the thiazole carboxylic acid and L-phenylalanine and subsequent cyclodehydration of the allo-threonine residue was reported to provide the cis,cis-product 13 exclusively. ${ }^{[15,16 \mathrm{~b}]}$ If the cyclization was performed in the presence of the oxazoline moiety, mixtures of cis, cis-product $\mathbf{1 3}$ (major) and trans,trans-product $\mathbf{1 2}$ were obtained. ${ }^{[15]}$

\subsection{Macrocycle Libraries by Modular Organic Synthesis}

Progress in synthetic methodologies, miniaturization, and automation allowed the synthesis of libraries of macrocyclic compounds for hit identification. Modular architecture of macrocycle libraries is important to synthesize significant numbers of compounds and to also facilitate rapid hit amplification and optimization. Based on synthetic organic chemistry, a variety of platforms have been elaborated over the last two decades.

Technologies giving access to libraries of peptide-derived macrocycles, which mimic an entire functional epitope of a protein, include the protein epitope mimetic approach and the peptide stapling strategy.

Polyphor's PEMfinder ${ }^{\circledR}$ technology $^{[18]}$ provides cyclopeptide-like molecules (general formula 14, Fig. 3), composed of a conformation-inducing template and a peptide chain of 4-20 amino acids. PEMfinder $^{\circledR}$ compounds mimic $\beta$-hairpin and $\alpha$-helical functional epitopes of proteins, important exposed structural motifs involved in many protein-protein interactions. The versatile PEMfinder ${ }^{\circledR}$ technology offers many possibilities to modulate activity, selectivity and ADME properties by varying ring size, amino acid building blocks (including non-natural amino acids, amino acid isosteres) and also the template. The PEMfinder ${ }^{\circledR}$ technology provided, among others, POL3026 (15), a potent CXCR4 antagonist, ${ }^{[18 a, b]}$ and POL7001
(16), a novel Pseudomonas aeruginosa selective antibiotic, targeting LptD, a $\beta$-barrel protein involved in transporting lipopolysaccharide from the periplasma to the outer membrane. ${ }^{[18 c]}$ POL3026 was further developed into Balixafortide (POL6326), which is in Phase Ib clinical trial for combination therapy in advanced metastatic breast cancer. POL7001 was developed into Murepavadin (POL7080), which completed Phase II trials and represents the first member of a new class of outer membrane targeting antibiotics (OMPTA). ${ }^{[18 d]}$ A further program to generate potent and selective protease inhibitors yielded POL6014,[18d] a reversible inhibitor of human neutrophil elastase $\left(\mathrm{K}_{\mathrm{i}}=\right.$ $1.4 \mathrm{nM}$ ), which entered clinical development for treatment of cystic fibrosis.

Verdine and coworkers used alkyl tethers to stabilize $\alpha$-helices. ${ }^{[19]}$ Key components to enhance helicity of peptides are $\alpha$-methylated amino acids in $(R)$ - or $(S)$ configuration, bearing olefinic side chains of variable length. After their incorporation into peptides at the $\mathrm{i}-$ and $\mathrm{i}+4$ or $\mathrm{i}+7$ position they are covalently linked engaging olefin metathesis. The technology was applied to generate stabilized $\alpha$-helix mimetics of p53 (SAH-p53) peptides, which exhibit high affinity for MDM2.[20] The technology is commercially exploited by Aileron Therapeutics with ALRN-6924, a MDM2/MDMX antagonist for p53 cancer therapy in clinical evaluation. [21]

Approaches to prepare arrays of macrocyclic scaffolds with reduced number of peptidic bonds have been independently developed by Tranzyme (MATCH $\left.{ }^{\mathrm{TM}}\right)$,

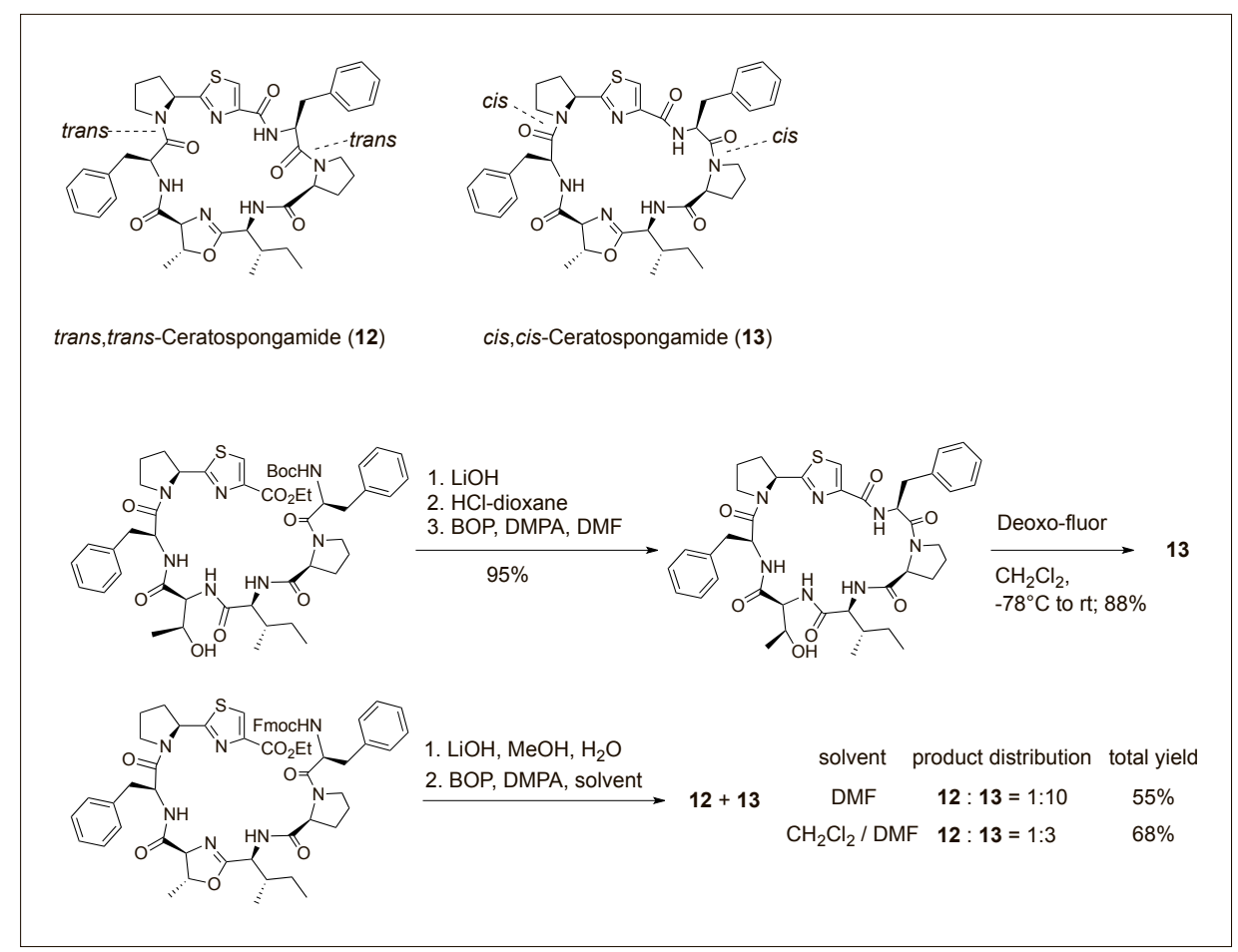

Scheme 3. Stable conformational isomers of ceratospongamide. ${ }^{[1,16]}$ 
the Broad Institute (DOS) and Polyphor (MacroFinder ${ }^{\circledR}$ ). The use of variable modules (building blocks) provides access to different scaffolds. All three technologies allow all stereoisomers of a given scaffold to be obtained. Late stage derivatization of lateral functional groups provides further amplification of the structural diversity of the products. In order to synthesize larger numbers of final products, suitable building blocks must be accessible in multi-gram quantity. Usually, some of the building blocks need to be prepared to adapt to the needs defined by the synthetic strategy (e.g. protective group pattern). The ring closure is often the most critical step. Robust cyclization conditions are of key importance to avoid loss of material in this late step.

The application of Tranzyme's approach $\left(\mathrm{MATCH}^{\mathrm{TM}}\right)^{[22]}$ allowed the discovery and development of potent and selective ghrelin agonist 18 (Fig. 4). [1b,22,23] The approach was based on the general formula $\mathbf{1 7}^{[22]}$ combining a tripeptide sequence and a tether to accomplish a macrocyclic structure which was intended to constrain the pharmacophore motif of peptidergigc GPCR ligands. Starting from ghrelin agonist $\mathbf{1 8}$ hit to lead optimization led to $\mathbf{1 9}$ (TZP-101, Ulimorelin), which was evaluated in Phase III clinical trials for the treatment of post-operative ileus and acute gastroparesis. The clinical evaluation was discontinued after failing to meet efficacy endpoints. ${ }^{[24]}$

Scientists at the Broad Institute developed a diversity-oriented approach to access macrocyclic compounds with natural product-like complexity. Libraries were assembled using a build/couple/pair (B/C/P) strategy. Suitable building blocks are synthesized ('build' phase) and combined to give the linear precursor ('couple' step), which were cyclized ('pair' phase). ${ }^{[25]}$ The modular synthesis approach allows to generate libraries of macrocyclic compounds as well as to perform efficient medicinal chemistry follow-up programs to optimize initial hit compounds. This was illustrated by the identification of the 12-membered macrocyclic hedgehog pathway inhibitor robotnikinin (20; Scheme 4) ${ }^{[26]}$ and its optimization, ${ }^{[27]}$ which comprised the synthesis of analogs with alternative aminoalcohol linkers, methylation of the macrocycle $\mathrm{N}$-atom, inversion of the configuration in position 2, attachment of substituents to various positions as well as variation of lateral substituents in given positions. The effort provided inhibitor $\mathbf{2 1}$ with oxygen and nitrogen atoms in reverse positions in the macrocycle and the phenyl substituent in position 2 replaced by a 4-chlorophenyl group. ${ }^{[27]}$ In contrast to robotnikinin, which binds to the Sonic Hedgehog (Shh) protein, 21 is a Smoothened antagonist. [27]

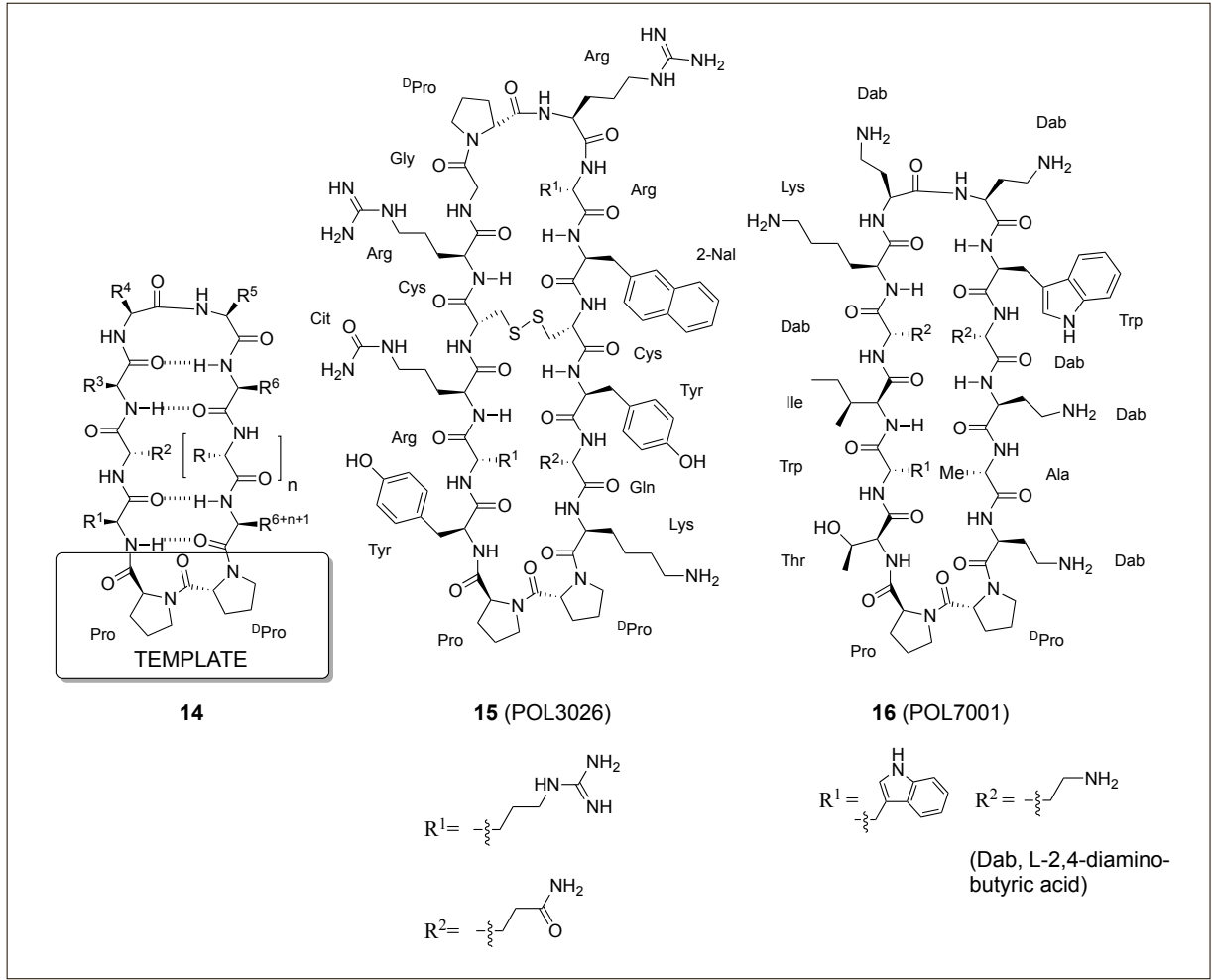

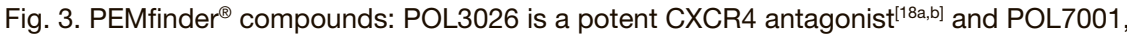
a $P$. aeruginosa selective antibiotic. ${ }^{[18 \mathrm{c}, \mathrm{d}]}$

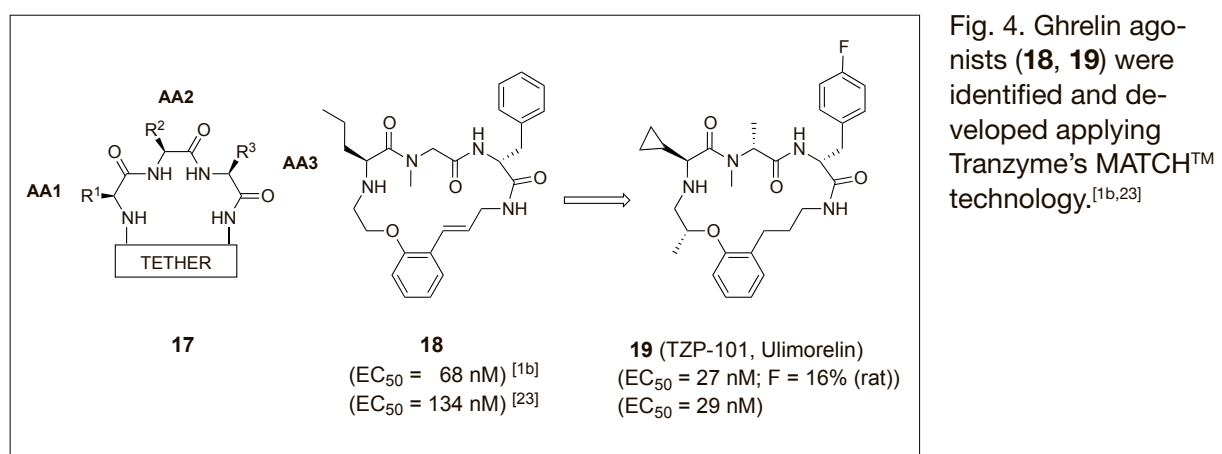

The application of the DOS platform to the identification and improvement of novel macrocyclic antimalarial agents was reported more recently by the Schreiber group. ${ }^{[28]}$ Development of an SAR around the original lead ML238 (22; Fig. 5) ${ }^{[28 a]}$ led to the close analog $\mathbf{2 3}$ which was reported to show good potency, improved solubility, lowered hERG binding and reduced plasma protein binding, but still only limited microsomal stability. The activity of 23 was investigated in vivo. ${ }^{[28 \mathrm{~b}]}$

The MacroFinder ${ }^{\circledR}$ platform (Fig. 6) was developed independently at Polyphor Ltd. The approach is based on non-peptidic macrocycles in a molecular weight range of 400 to $800 \mathrm{Da}$; 12 - to 30-membered macrocyclic rings are represented. Conformation-inducing elements like proline, ortho-, meta-, or para-substituted aromatic building blocks or biaryl building blocks are integrated into a macrocyclic backbone. Currently, the MacroFinder ${ }^{\circledR}$ library comprises $c a .20^{\prime} 000$ unique, HPLC-purified individual compounds, which were obtained by modular assembly of chiral and achiral building blocks in high throughput using mixed solution phase/solid phase synthesis process engaging parallel synthesis robots or applying a split-pool approach. Ring-closure reactions were achieved most often by lactam formation or metathesis. The stereoisomers of a given scaffold of the MacroFinder ${ }^{\circledR}$ library are often represented and always accessible. Each scaffold is represented at least in a set of 10-20 compounds, intending to generate hit families rather than singleton hits. A constant set of substituents is represented in all scaffolds. The robust synthetic methodologies behind allow rapid hit amplification and facilitate medicinal chemistry programs. Screening of a subset of the initial MacroFinder ${ }^{\circledR}$ library and hit follow-up allowed the identification of 24 (Fig. 6) a potent motilin receptor an- 


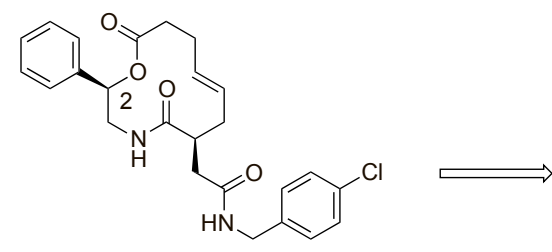

Robotnikinin (20)

$\mathrm{IC}_{50}>25 \mu \mathrm{M}$

max. inhibition $=47 \%$
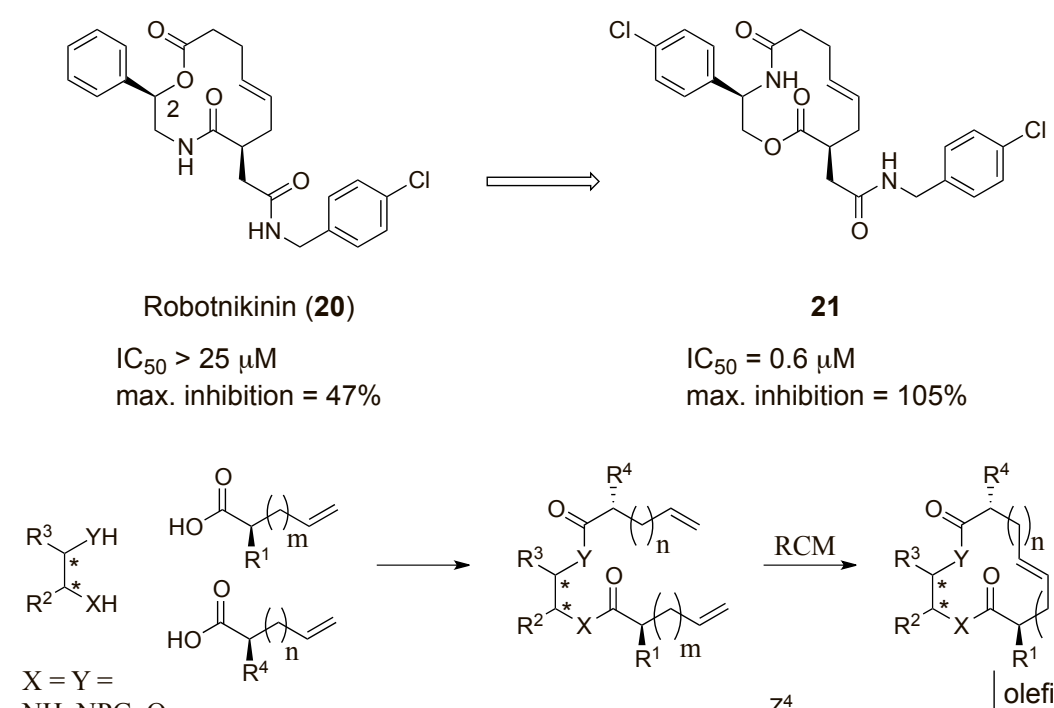

21

$\mathrm{IC}_{50}=0.6 \mu \mathrm{M}$

max. inhibition $=105 \%$

$\mathrm{NH}, \mathrm{NPG}, \mathrm{O}$

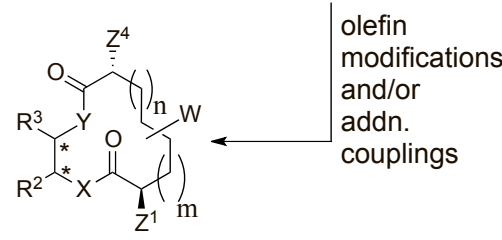

Scheme 4. Hedgehog pathway inhibitors identified by Schreiber and colleagues at the Broad Institute. ${ }^{[26,27]}$ Half-maximal inhibitory concentrations were determined in the Shh-induced C3H10T1/2 alkaline phosphatase assay; maximal inhibition relative to cyclopamine.

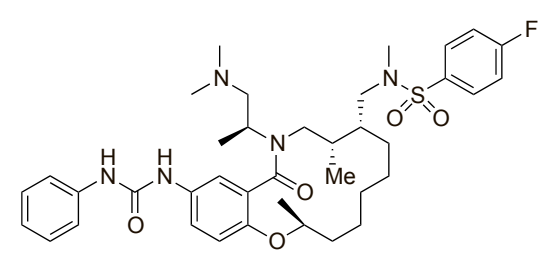

22 (ML238)

blood-stage malaria, $\mathrm{GI}_{50}=0.54 \mathrm{nM}$

solubility (PBS) $<5 \mu \mathrm{M}$

hERG (displacement control $\left.{ }^{\star}\right)$ at $\left.10 \mu \mathrm{M}\right): 95 \%$ LogD (HPLC): 4.1

microsomal stability (\% remaining at $1 \mathrm{~h}$ ): $<5 \%$ plasma protein binding: $99 \%$ bound

*) $\left[{ }^{3} \mathrm{H}\right]$-astemizole

Fig. 5. Antimalarial compounds discovered and improved applying the DOS platform of the Broad Institute. ${ }^{[28]}$

tagonist after only two fast optimization rounds.

While the DOS library and the MacroFinder ${ }^{\circledR}$ library were developed to access general, structurally diverse arrays of macrocyclic compounds, Myers and colleagues most recently presented a platform for target-oriented modular assembly of macrolide antibiotics. ${ }^{[29]}$

In Myers' approach, ${ }^{[29 a]}$ macrolide scaffolds are obtained by assembling building blocks (e.g. 25-32; Scheme 5) in a convergent 17-step synthesis. ${ }^{[30]}$ Variation of the

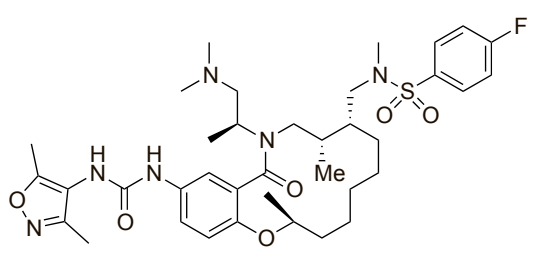

23

blood-stage malaria, $\mathrm{GI}_{50}=4.2 \mathrm{nM}$

hERG (displacement control $\left.{ }^{\star}\right)$ at $\left.10 \mu \mathrm{M}\right): 13 \%$ LogD (HPLC): 2.9

microsomal stability (\% remaining at $1 \mathrm{~h}$ ): $8 \%$ plasma protein binding: $92 \%$ bound solubility $(\mathrm{PBS})>100 \mu \mathrm{M}$ modules allows access to alternative scaffolds; diversification at late stage by conversion of suitable functional groups introduced in the course of the synthesis allows increasing the number of derivatives obtained per scaffold. The azido group present in the macrolide intermediates $\mathbf{3 4}$ and 36 for example, was further derivatized by copper-mediated azide alkyne cycloaddition; the Alloc-protected amine present in 36 was converted into amides after deprotection. The thermolysis conditions applied in the key cyclization step (e.g. conver- sion of the hydroxyl-dioxolenone $\mathbf{3 3}$ into 34) were reported to be quite general and applicable to variable scaffolds. The synthesis platform allows the preparation of compounds that could not be obtained by semisynthesis (chemical modification of erythromycin, which is obtained by fermentation).

\subsection{Multicomponent Reactions as Ring-closing Step}

As an alternative approach for the efficient synthesis of sets of macrocyclic compounds, multicomponent reactions were employed in the ring-closing step. Recent illustrations comprise the Ugi reaction starting from an isocyano carboxylate, an aldehyde and an amine reported by Dömling[31] or Yudin's reaction ${ }^{[32]}$ engaging amphiphilic aziridin aldehydes in an isocyanate-based multicomponent reaction. Wessjohann and Rivera engaged electron-poor phenols as acid component in a cyclative Ugi/Smiles reaction. ${ }^{[33]}$ The synthesis of oxadiazole-containing analogs of cyclic peptides was described by Yudin. [34]

Multicomponent reactions (MCRs) might also be used to assemble linear cyclization precursors as exemplified for the Petasis reaction ${ }^{[35]}$ (combining an aniline, glyoxylic acid and a phenylboronic acid building block) in the context of the synthesis of factor VIIa inhibitors (see below, section 3.1.1, Fig. 7). Isocyanide-based MCR found application to generate complex linear precursors, which were then cyclized in a subsequent step engaging, among other transformations, amide coupling, ${ }^{[36]}$ ring-closing metathesis ${ }^{[37]}$ or $\mathrm{Cu}$ mediated alkyne/azide cycloaddition. ${ }^{[38]}$

Cyclic products can be obtained by direct use of the Ugi-MCR starting with bifunctional building blocks. In their pioneering work, Failli et al. described in 1979 the head-to-tail cyclization of a linear hexapeptide 37 by reaction with isobutyraldehyde and cyclohexyl isocyanide to the cyclopeptide 38, which was obtained as a separable mixture of diastereomers (Scheme 6). ${ }^{[39]}$ Poor control of the configurational outcome of the Ugi reactions is well documented. ${ }^{40]}$ Smaller rings are difficult to access by this method; the corresponding reaction starting from triglycine 39 exclusively gave the cyclodimer 40. Yudin related the difficulty in head-totail cyclization of small peptides in an Ugi reaction to the slow transannular attack in the intramolecular acylation step (Mumm rearrangement of the initially formed adduct). ${ }^{[32]}$

The utilization of the Ugi reaction to cyclize via side chain functional groups of linear peptides (side-chain to side-chain and side-chain to termini cyclization) has been only recently investigated by Vasco et al. ${ }^{[41]}$ As compared with the head-to-tail 
module 2
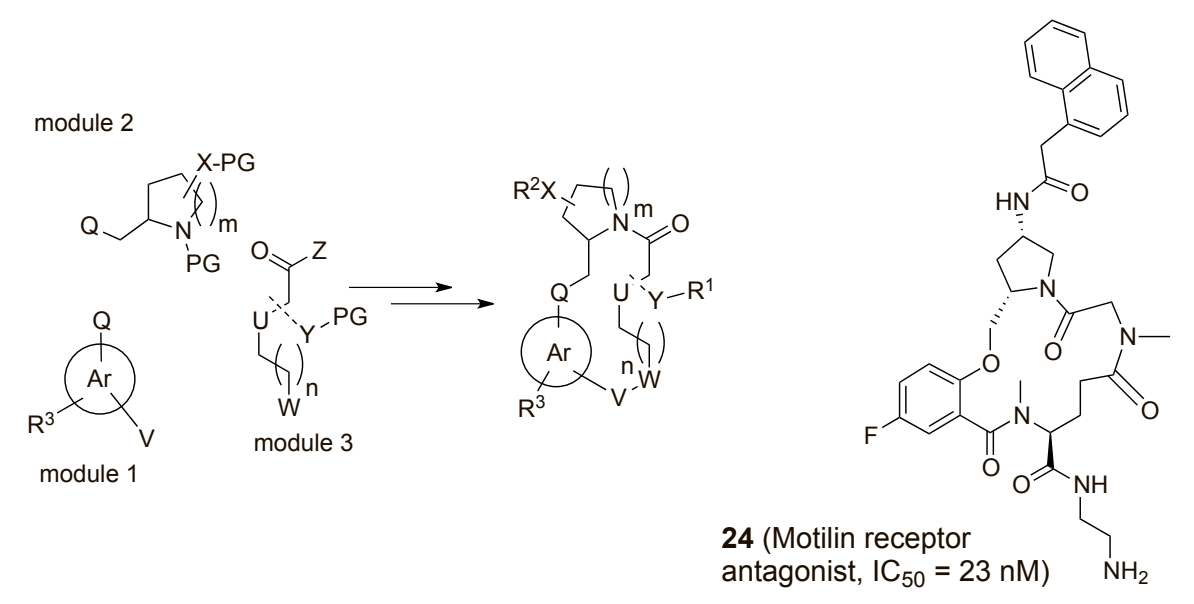

Fig. 6. MacroFinder ${ }^{\circledR}$ platform allows modular assembly of chiral and achiral building blocks in high throughput; prototype compound 24.

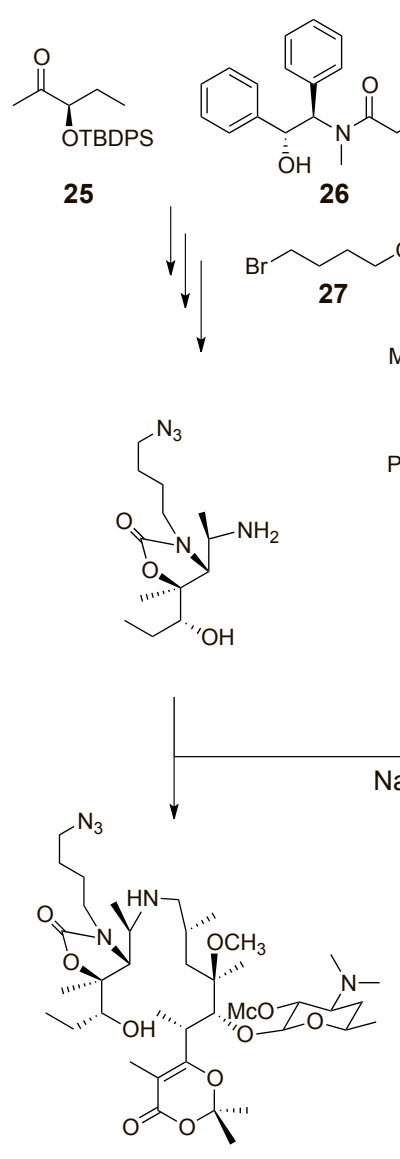

33

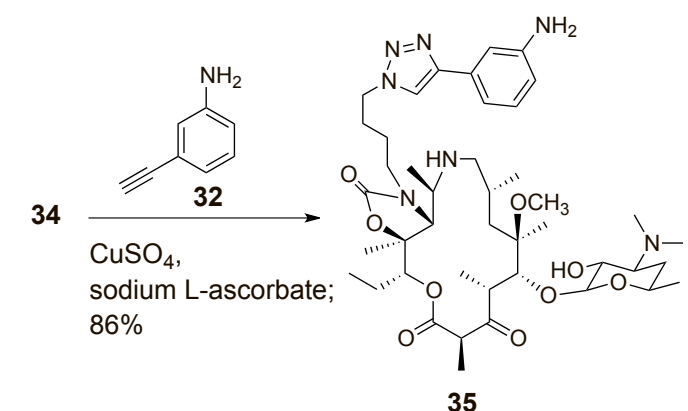

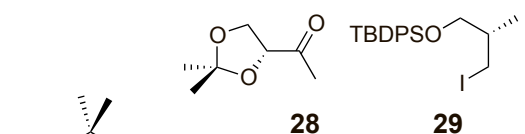

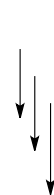

31

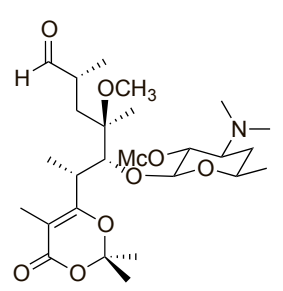

$\mathrm{c}=1 \mathrm{mM}$; $94 \%(1.9 \mathrm{~g}$ scale $)$
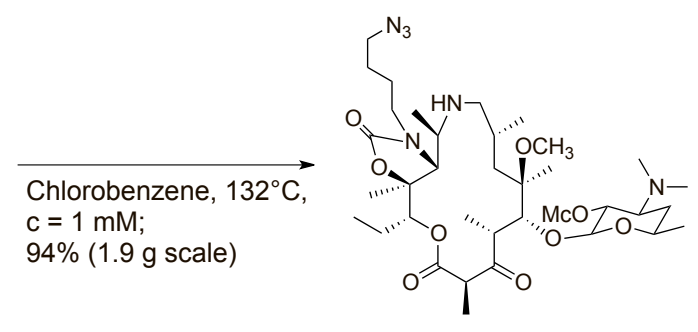

34
Chlorobenzene, $132^{\circ} \mathrm{C}$

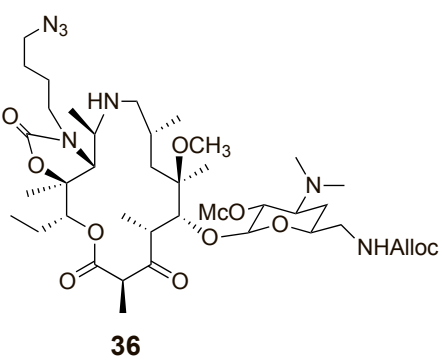

Scheme 5. Target-oriented modular synthesis: Myers convergent assembly of macrolide antibiotics. ${ }^{[29 a]}$

cyclization, better results were obtained using the flexible Glu and Lys side chains as acid and amine component. Yields of $c a$. $60 \%$ were reported for most transformations (e.g. 41 and 42; Scheme 7); head to Glu-side-chain cyclization (43) was found to produce lower yields and incomplete conversion.

The carboxylic acid component can be replaced by an electron-poor phenol. In a recent example Morejon et al. reported the synthesis of $\mathrm{N}$-aryl bridged cyclic peptides 45 by the Ugi-Smiles MCR starting from peptide 44 with C-terminal 3-nitrotyrosine residue, $n$-dodecyl isocyanide and formaldehyde or isobutyraldehyde (Scheme 8$)$. ${ }^{33]}$ The transformation can be performed in solution and on resin. Although the products contain an ortho-nitro substituted tertiary aniline moiety, no atropisomerism was observed. The reaction with isobutyraldehyde afforded two diastereomers. Remarkably small rings like the 13-membered para-cyclophan $\mathbf{4 6}$ are accessible by this method.

In the preceding examples, the ring closure goes along with the incorporation of an additional variable exocyclic moiety. If an $\alpha$-isocyano- $\omega$-carboxylate is used as bifunctional building block, the variable structural motifs provided by the aldehyde and the amine component both end up as independent side chains directly attached to the macrocyclic scaffold. This is illustrated by the conversion of isocyano dodecylcarboxylate (47) with isobutyraldehyde and benzyl amine, providing 16-membered macrocycle $\mathbf{4 8}$, as described by Dömling and coworkers. ${ }^{[31]}$ Comparable results were reported for $\alpha$-isocyano- $\omega$-carboxylates with additional amide (not shown) or urea (49) groups (Scheme 9).

Yudin and coworkers ${ }^{[32,40,42]}$ reported macrocyclization of linear peptides with an N-terminal proline residue (52) by treatment with tert.-butyl isocyanide and the amphoteric aziridine aldehyde 51 ${ }^{[43]}$ in trifluoroethanol (Scheme 10). Yudin's reaction deviates from the conventional Ugi reaction with a mono-functionalized aldehyde in the intramolecular rearrangement; the transannular attack of an amino group is replaced by the attack of the 'extra(macro)cyclic' aziridine-N-atom. Three additional atoms are introduced in the peptide backbone leading to products 53 with an aziridine moiety and an exocyclic amide group (11 examples; yields 73-88\%). ${ }^{[32]}$ Unlike a conventional Ugi reaction, the aziridine aldehyde mediated transformation provided peptidomimetic macrocycles with excellent diastereoselectivity. The reaction proceeds with high stereoselectivity; the $(S)$-configured aldehyde $\mathbf{5 1}$ undergoes macrocyclization with peptides with an $\mathrm{N}$-terminal L-amino acid. 
The method also allows access to medium sized rings and smaller macrocycles in good yield as documented with examples of 9 or 12-membered rings. ${ }^{32]}$ The aziridine ring present in the products $\mathbf{5 3}$ can be opened by treatment with nucleophiles allowing the incorporation of further diversity. ${ }^{[32,40,44]}$ Competing reaction pathways have been described. Depending on the configuration of the aziridine aldehyde and the linear peptide ${ }^{[32,44 b]}$ and on the length of the latter ${ }^{[42,44 b]}$ predominant formation of linear products has been reported occasionally. The substrate dependent reactivity allowed Yudin and coworkers to derive a plausible reaction path. ${ }^{[42]}$

The reaction of pentapeptide $\mathbf{5 4}$ with propionaldehyde and ( $\mathrm{N}$-isocyanimino)triphenyl-phosphorane, which allows to assemble macrocyclic oxadiazole-containing peptide analogs (Scheme 11), was also developed by Yudin and coworkers. [34] The diastereomeric products 55 and $\mathbf{5 6}$ were obtained in $68 \%$ yield. These authors described 27 structurally diverse examples (variation of peptide substrate and aldehyde; yields ranging from $13 \%$ to $68 \%$, ring size $15,18,21,24)$; most often two diastereomeric products were obtained. ${ }^{[34]}$ Substrates with sarcosine in the position adjacent to the N-terminal proline provided the macrocycle as a single diastereomer. (In the aziridine aldehyde mediated cyclizations, the reaction failed with $\mathrm{N}$-methyl amino acids in the second position).

\section{Macrocyclization as Approach to Improve Compound Properties}

Pre-organization of a molecule in the active conformation is the basis of an entropic advantage leading to improved binding. This intuitive concept is applied in nature by converting peptidic strands into cyclic structures by formation of disulfide bridges. Early synthetic applications comprise the preparation of macrocyclic mimics of terminal loops or helices of peptidic GPCR ligands. ${ }^{[1 \mathrm{k}]}$ Recently, macrocyclization has been frequently applied in medicinal chemistry programs as a strategy to improve the properties of compounds. Design of macrocyclic inhibitors on the basis of structural information obtained from X-ray crystal structures of proteinligand complexes was successful in providing compounds with improved potency and selectivity, as compared to acyclic controls. Often macrocyclization also went along with an improvement of the pharmacokinetic properties. In 2016, this was exemplified by numerous case studies, e.g. by enzyme inhibitors targeting factor VIIa serine protease, or Mer receptor tyrosione kinase. Potent and selective macrocyclic inhibitors of MTH1 nudix phosphohydro-

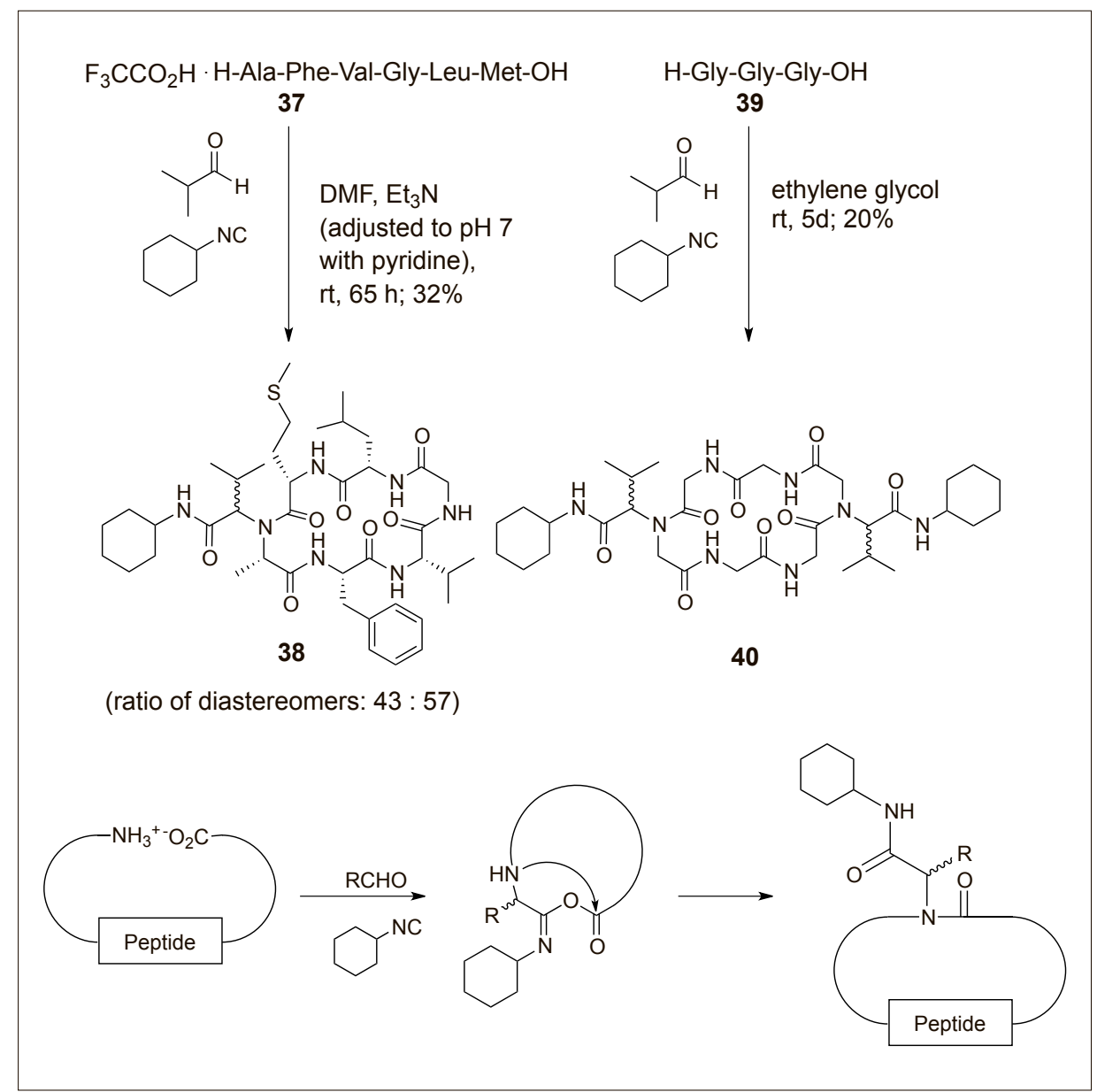

Scheme 6 . Head to tail cyclization of a linear hexapeptide $\mathbf{3 7}$ afforded $\mathbf{3 8}$ by reaction with isobutyraldehyde and cyclohexyl isocyanide; the corresponding reaction starting from triglycine 39 exclusively gave the cyclodimer $40 .{ }^{[39]}$

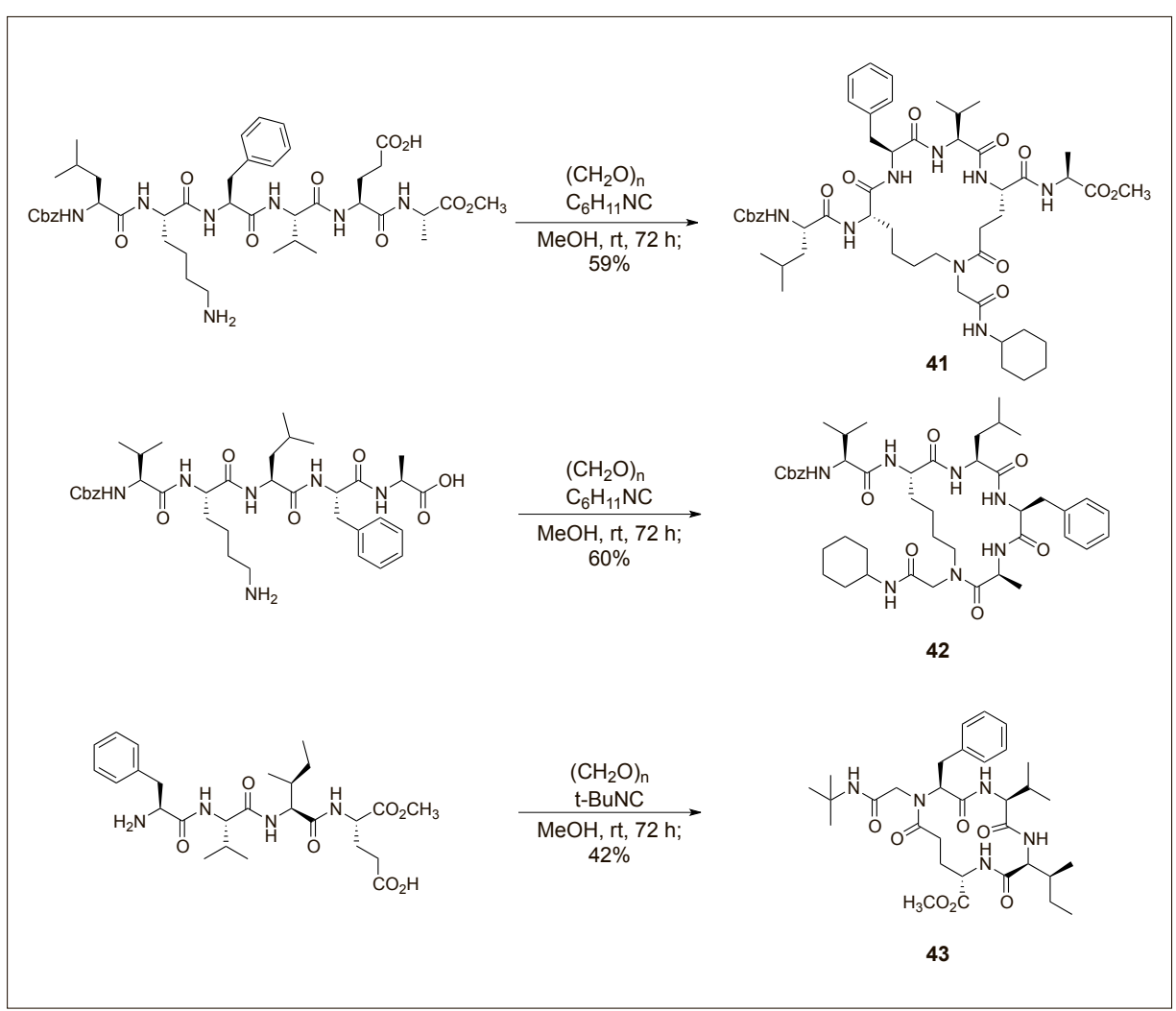

Scheme 7. Ugi reaction to cyclize over side chain functional groups of linear peptides. ${ }^{[4]}$ 


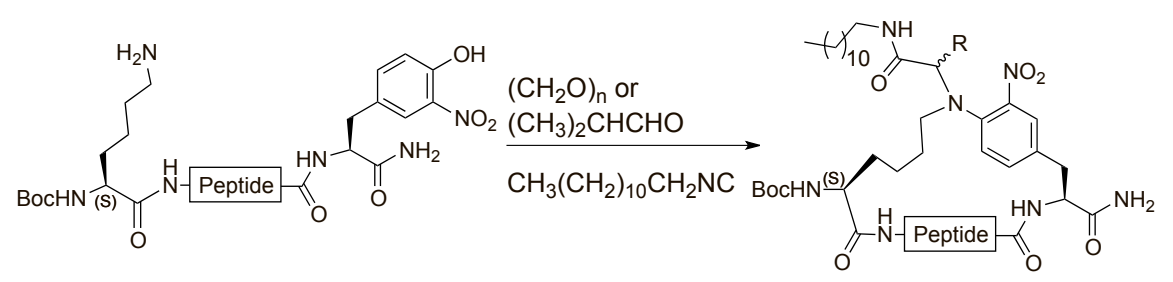

44<smiles>CC(C)[C@H](NC(=O)C(N)Cc1ccccc1)C(=O)NC(Cc1ccc(O)c([N+](=O)[O-])c1)C(N)=O</smiles>

$\left(\mathrm{CH}_{2} \mathrm{O}\right)_{n}$, $\mathrm{CH}_{3}\left(\mathrm{CH}_{2}\right)_{10} \mathrm{CH}_{2} \mathrm{NC}$ $\mathrm{CH}_{3} \mathrm{OH}, \mathrm{rt}, 48 \mathrm{~h}$ (c = $25 \mathrm{mM}$ ); $67 \%$

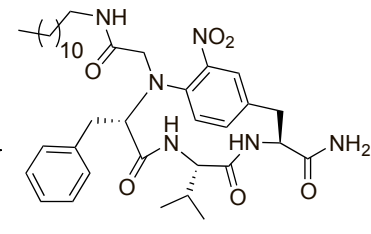

46

Scheme 8. Ugi-Smiles multicomponent reaction applied to form macrocycles. ${ }^{[33]}$

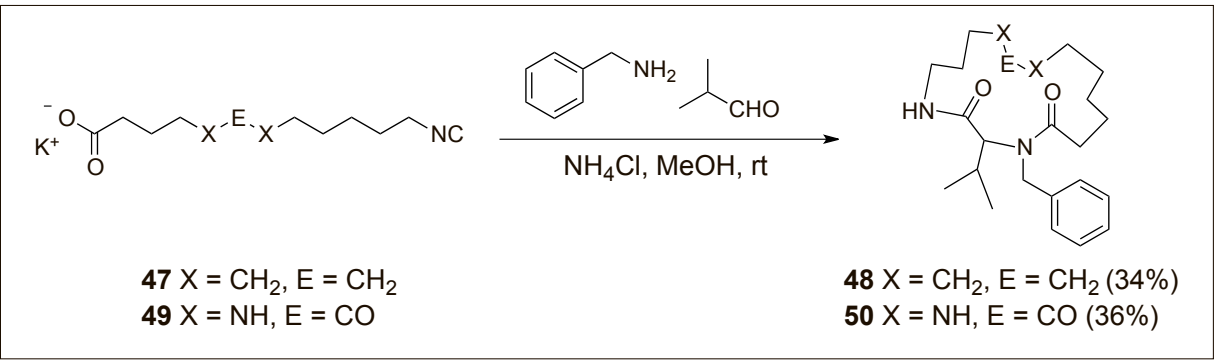

Scheme 9. Ugi cyclization engaging $\alpha$-isocyano- $\omega$-carboxylates. ${ }^{[31]}$

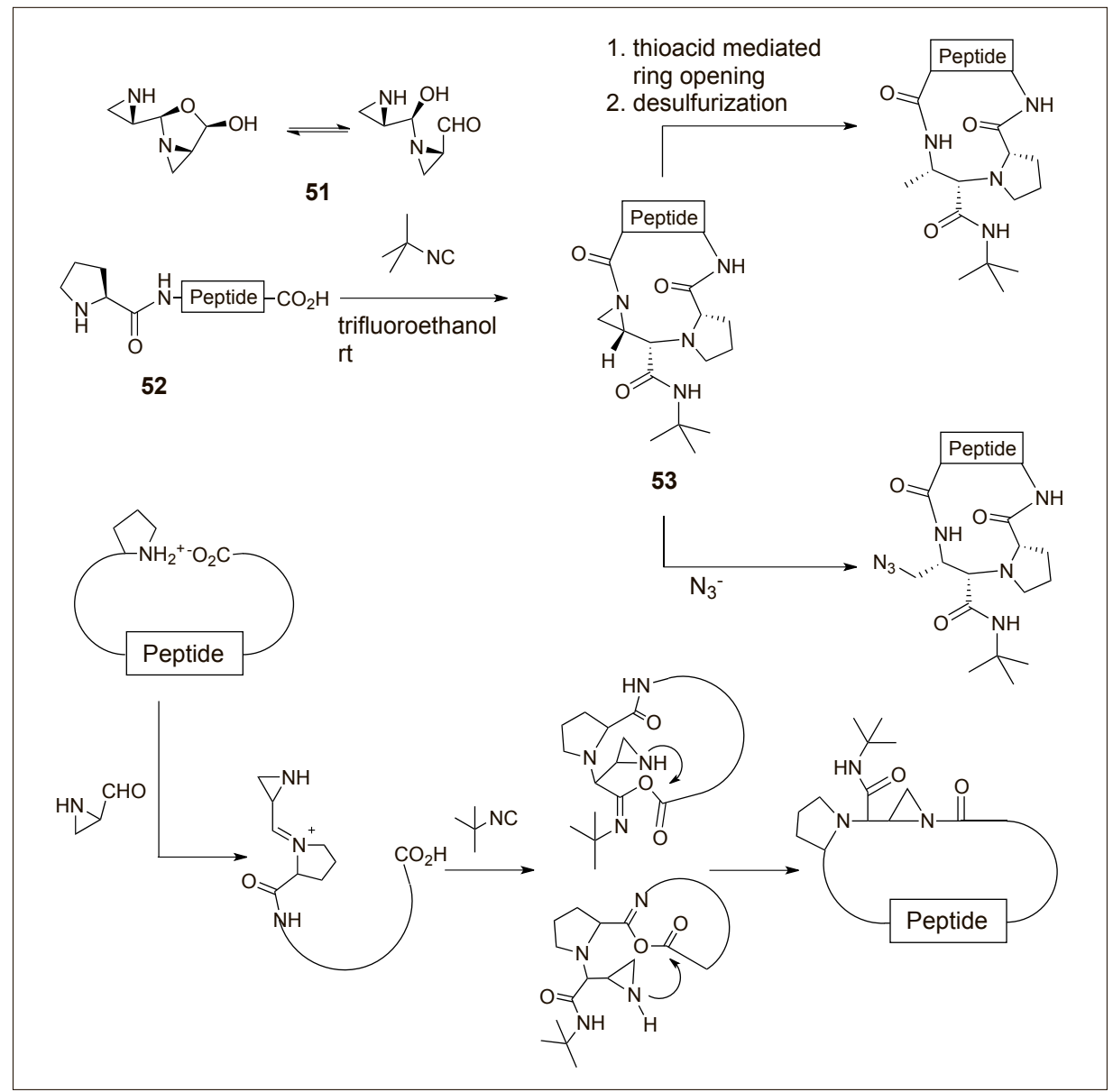

Scheme 10. Yudin's variant of the Ugi reaction engaging the amphoteric aziridine aldehyde $\mathbf{5 1}$ allows to cyclize peptides. ${ }^{[32,42]}$ lase allowed elucidation of the role of this target in carcinogenesis. Further examples comprise compounds acting on proteinprotein interactions (PPIs), e.g. macrocyclic IL-17A antagonists.

\subsection{Examples from Medicinal Chemistry Programs}

\subsubsection{Inhibitors of Coagulation Factor VIla}

The coagulation factor VIIa (FVIIa) is a serine protease. Upon vessel injury, association with the tissue factor (TF, a membrane-bound glycoprotein) results in formation of a catalytically competent $\mathrm{TF} /$ FVIIa complex. ${ }^{[11]}$

Small molecule inhibitors of FVIIa often contain a benzamidine group, which was replaced by a 1-amino isoquinoline moiety in the pyrrolidin phenylglycin amide lead 57 (Fig. 7) described by Priestley et al. from Bristol-Myers Squibb. ${ }^{[11]}$ A crystal structure of $\mathbf{5 7}$ in complex with FVIIa revealed the proximity of the acetanilidoand the phenyl group and suggested to link these substituents to get a macrocyclic inhibitor. The 15- to 17-membered macrocycles 58-61 were synthesized to evaluate the optimal linker. Against TF/FVIIa, inhibitor 60 was found to be the most potent of the four compounds and to be 11-fold more potent than the acyclic analog 62 . The activity was attributed to the $(R)-\mathbf{6 0}$ isomer $\left(\mathrm{K}_{\mathrm{i}}=400 \mathrm{nM}\right)$ after separation of the enantiomers. TF/FVIIa inhibitors $(R)$ 7, $(R)-63$ and $(R)-8\left(\mathrm{~K}_{\mathrm{i}} 1.6\right.$ to $\left.8.0 \mathrm{nM}\right)$, analogs of $(R)-60$ with an alkyl sulfone substituent attached to the anilide moiety, were found to be equally potent as the lead structure $57\left(\mathrm{~K}_{\mathrm{i}}=8 \mathrm{nM}\right)$. Compared with the 2 to 10 -fold more potent benzamidine analog $(R)-64$, the 1 -amino isoquinoline derivatives displayed improved selectivity against a panel of serine proteases.

Compound $(R)-8$, with an additional methyl group at the meta position of the phenyl glycine moiety, showed a 5-fold improved potency compared to $(R)-7$ and was reported to exist as a 1:1 mixture of conformational isomers. The BMS group proposed the presence of atropisomers due to hindered rotation of the unsymmetrically substituted phenylglycin aryl group. ${ }^{[11,12]}$

An 11-fold improved potency upon incorporation of a methyl group in this position was reported for the related macrocyclic carbamates 65 and 66 (Fig. 8, Table 1). ${ }^{[12]}$ Compound $\mathbf{6 6}$ also exists as a 1:1 mixture of atropisomers (two species observed in the ${ }^{1} \mathrm{H}-\mathrm{NMR}$ spectrum; that the two sets of signals were due to a pair of interconverting conformers was demonstrated using an NOE-difference experiment $\left.{ }^{[12]}\right)$. On the basis of NMR experiments, an activation energy of $12.4 \mathrm{kcal} /$ mol was determined for the phenyl ring 
flip; the half-life of a rotameric state of compound 66 is $c a .30 \mathrm{~min} .{ }^{[12]}$

Introduction of a methyl group in the benzylic position of the linker in $(R)$ configuration gave 67, which is 4-fold more potent than $\mathbf{6 5}$. Introduction of this benzylic methyl group allowed to lock the adjacent phenyl ring into the desired atro- pisomer (with the methyl group pointing into the S2 pocket of FVIIa); $\mathbf{6 8}$ adopts a single macrocycle conformation in solution. ${ }^{[12]}$ Blocking rotation is a strategy to overcome the conformational heterogeneity caused by atropisomerism. ${ }^{[8]}$ Compared to 66 , inhibitor 68 has a significantly improved potency. The $\mathrm{N}$-methylated amide
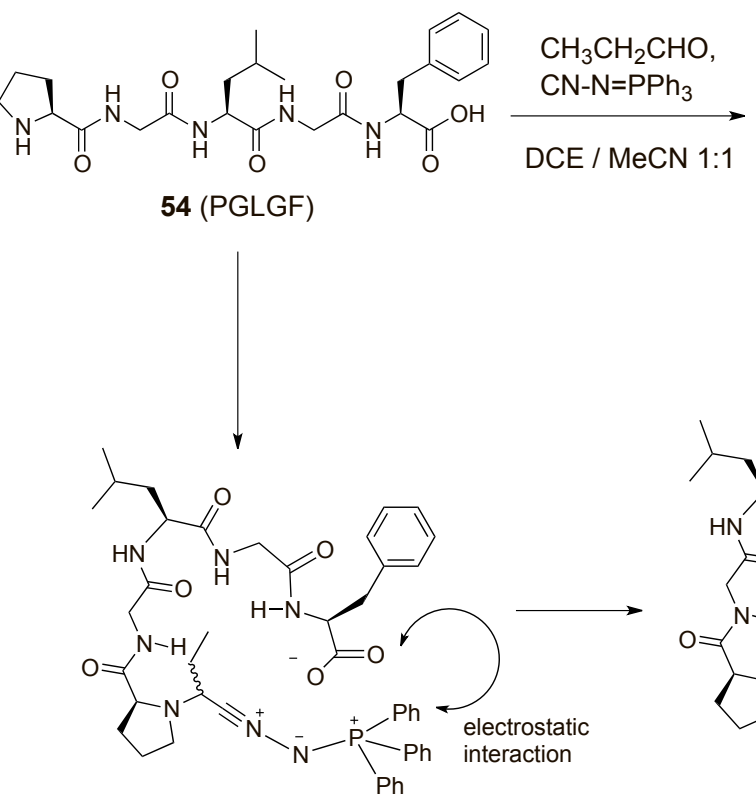

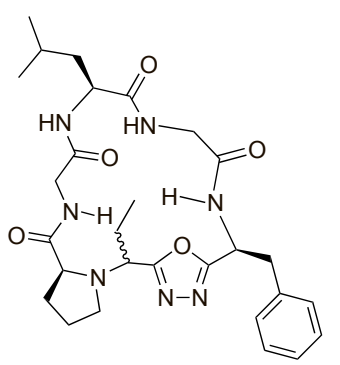

$55(50 \%)$ [S]-isomer $56(18 \%)[R]-$ Isomer

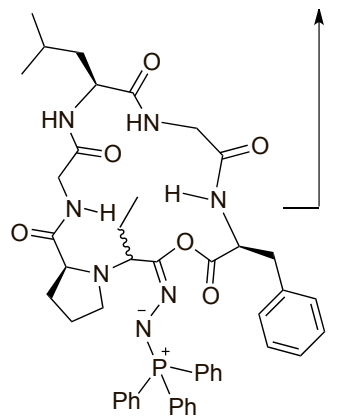

Scheme 11. Yudin's synthesis of cyclic oxadiazole containing peptides. ${ }^{[34]}$

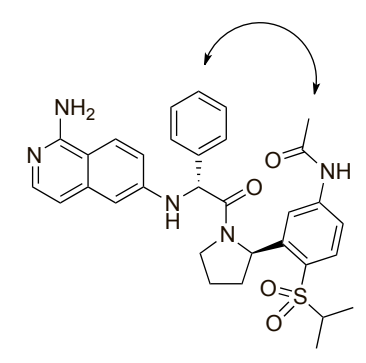

57 TF/FVIla $K_{i}=8.0 \mathrm{nM}$

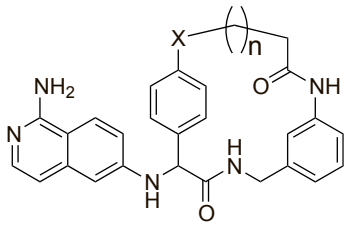

$58 X=0, \quad n=2$

$59 \mathrm{X}=\mathrm{CH}_{2}, \mathrm{n}=2$

$60 \mathrm{X}=\mathrm{CH}_{2}, \mathrm{n}=1$

$61 \mathrm{X}=\mathrm{CH}_{2}, \mathrm{n}=0$

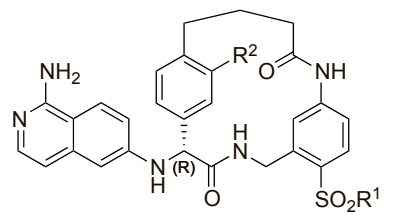

(R)-7 $\mathrm{R}^{1}=\mathrm{Et}, \mathrm{R}^{2}=\mathrm{H}$ TF/FVIIa $\mathrm{K}_{\mathrm{i}}=8.0 \mathrm{nM}$

(R)-63 R $\mathrm{R}^{1}=\mathrm{i}-\mathrm{Pr}, \mathrm{R}^{2}=\mathrm{H}$ TF/FVIIa $\mathrm{K}_{\mathrm{i}}=5.2 \mathrm{nM}$

(R)-8 $R^{1}=E t, R^{2}=M e$ TF/FVIIa $\mathrm{K}_{\mathrm{i}}=1.6 \mathrm{nM}$
(R)-64

TF/FVIla $\mathrm{K}_{\mathrm{i}}=0.7 \mathrm{nM}$

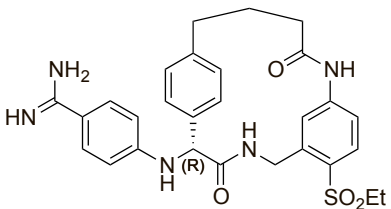

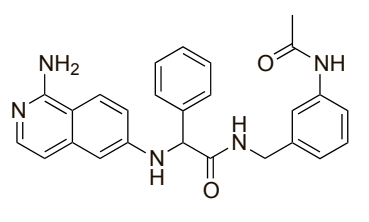

62

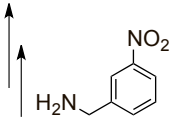

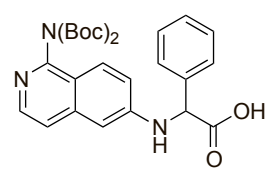

Petasis

69 is as potent as 68 . Both compounds exhibit, as compared to the parent compound 65, improved selectivity over a number of serine proteases; the selectivity over tissue kallikrein was found to be still limited (Fig. 8, Table 1).[12] Zhang et al. reported that further development of the compound by introduction of a cyclopropylsulfonyl group at the anilide moiety provided the highly potent compound $\mathbf{7 0}$ with good selectivity over the panel of serine proteases including tissue kallikrein. ${ }^{[45]}$ Fluorination at the 4-position of the aminoisoquinoline ring led to 71, which exhibited improved permeability and oral availability in dog (Fig. 8, Table 2). ${ }^{[4]}$ Pharmacokinetic studies were performed in dog, as compound 71 exhibited better metabolic stability in dog than in rodents. Compound 71 inhibited thrombus formation with $\mathrm{EC}_{50}=360$ $\mathrm{nM}$ in a rabbit model of electrically induced carotid arterial thrombosis (ECAT). Because of the poor rodent metabolic stability and pharmacokinetics the compound was not further advanced. [45]

\subsubsection{IL-17A Antagonists}

The cytokine IL-17A is important in host defense against infections and is implicated in inflammatory and immune disorders. Secukinumab, a monoclonal antibody against IL-17A has been approved by the FDA for the treatment of psoriasis. An oral therapy is not available; no small molecule IL-17A antagonists were advanced into clinical trials. ${ }^{[46]}$ Scientists at Pfizer recently described macrocyclic IL-17A inhibitors $\mathbf{7 5}$ and $\mathbf{7 6}$ which were developed on the basis of structural information obtained by crystallization of a complex of IL-17A and the acyclic inhibitor 72 (Fig. 9, Table 3).[46] Inhibitors like compound 72 were first disclosed by Ensemble Therapeutics Co. ${ }^{[47]}$

Antagonist 72 binds to IL-17A with a $\mathrm{K}_{\mathrm{D}}$ of $0.66 \mu \mathrm{M}$ in surface plasmon resonance (SPR) measurements and blocks the interaction of IL-17A and its receptor IL-17RA $\left(\mathrm{IC}_{50}=1.14 \mu \mathrm{M}\right.$ in fluorescence energy transfer (FRET) assay).[46b] The 15-residue high affinity peptide HAP (73) was identified through phage display screening (initially providing peptide sequence 74) and subsequent optimization. HAP (73) was reported to inhibit IL-17A signaling in a cell-based functional assay with an $\mathrm{IC}_{50}$ of $17 \mathrm{nM}$. $^{46 a]}$ The structure of a complex of IL-17A dimer stabilized with anti-IL17A $\mathrm{F}_{\mathrm{ab}}$ and two molecules of peptide 73 was solved. ${ }^{[46 a]}$ In absence of anti-IL17A $F_{a b}$ no crystals were obtained.

Direct co-crystallization or soaking of

Fig. 7. Coagulation factor TF/Vlla inhibitors: Amide-bridged macrocycles. ${ }^{[11]}$ 72 into crystals of the cytokine failed to provide a protein-ligand complex, which was attributed to protein rearrangement going along with inhibitor binding.[46b]

Competitive binding experiments by SPR

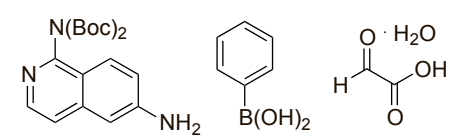


demonstrated that inhibitor $\mathbf{7 2}$ and HAP (73) bind to different sites of IL-17A and that the presence of $\mathbf{7 3}$ increases the onrates of 72, indicating that HAP (73) stabilizes a conformation of the cytokine to which ligand $\mathbf{7 2}$ binds readily. The determination of the structure of a complex of 72, IL-17A dimer, anti-IL-17A $\mathrm{F}_{\mathrm{ab}}$ and the high affinity peptide antagonist HAP (73) revealed that the acyclic inhibitor $\mathbf{7 2}$ binds in a central pocket at the dimer interface and adopts a U-shaped conformation bringing the fluorophenyl alanine side chain and the terminal dimethyl amide in close proximity (distance $5.7 \AA$ ). The relevance of the crystal structure in solution was confirmed with covalent reactive probes. ${ }^{446 \mathrm{~b}]}$

NMR experiments revealed that the bound conformation is not populated in solution. ${ }^{[46 b]}$ To reduce the entropic penalty of the binding, the design of macrocyclic inhibitors was considered by Liu and colleagues. Inhibitors 75 and 76 (Fig. 9) exhibited improved affinity for IL-17A and significantly improved activity in the FRET assay. ${ }^{[46 \mathrm{~b}]} \mathrm{X}$-ray structures of IL$17 \mathrm{~A}$ in complex with the macrocyclic inhibitors demonstrated that $\mathbf{7 2 , 7 5}$ and $\mathbf{7 6}$ bind in the same mode; the linker and the modified terminal amide group made additional contacts. ${ }^{[46 \mathrm{~b}]}$

The IL-17A example illustrates the importance of structural information as basis of inhibitor design particularly well. Significant conformational shifts of the apo IL-17A dimer relative to the complex with small molecule inhibitors were observed. Slow on-rates also indicate that inhibitor binding goes along with significant protein rearrangement. The flexible and thus unpredictable nature of the protein made inhibitor design a difficult task. Structural information for ligand design is particularly important where there are significant conformational changes in the protein.

\subsubsection{MTH 1 Inhibitors}

MTH1 belongs to the enzyme family of Nudix (Nucleoside diphosphate linked to $\underline{X}$ ) phosphohydrolases. MTH1 catalyzes the hydrolysis of oxidized nucleotides such as 8-oxo-dGTP and thereby prevents their incorporation into DNA.

Improved affinity for the target through reduced conformational entropy loss has been postulated ${ }^{[1 \mathrm{a}, \mathrm{c}]}$ as an advantage of macrocyclization. This intuitive view can be illustrated for example by the cyclic MTH1 inhibitor 79, which was found by Kettle et al. at AstraZeneca to be 1000-fold more potent than the linear compound $\mathbf{7 7}$ (Fig. 10). ${ }^{[48]}$ These authors noticed the close proximity of methoxyethyl side chain and the N(1)-benzyl group in the bound conformation of $\mathbf{7 7}$ and speculated this conformation unlikely to be predominant in solution. Restriction of the motion

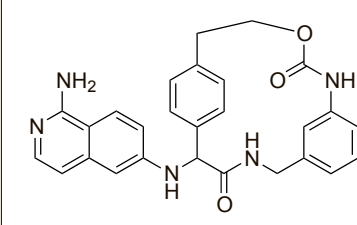

65

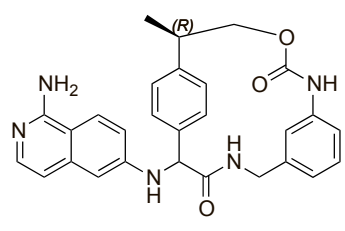

67

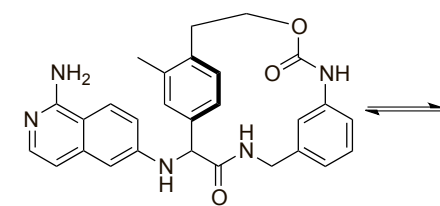

66

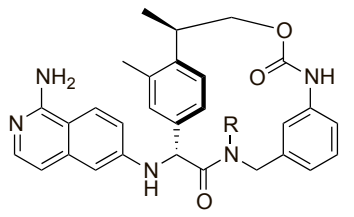

$68 \mathrm{R}=\mathrm{H}$

$69 \mathrm{R}=\mathrm{CH}_{3}$
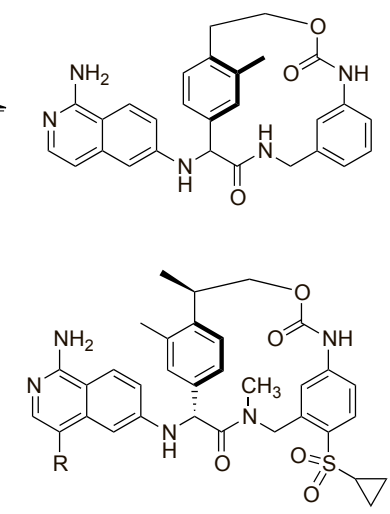

$70 \mathrm{R}=\mathrm{H}$

$71 \mathrm{R}=\mathrm{F}$

Fig. 8. Coagulation factor TF/VIla inhibitors: Carbamate-bridged macrocycles. ${ }^{[12,45]}$

Table 1. $\mathrm{K}_{\mathrm{i}}$ values: [nM]. ${ }^{\mathrm{T} T F} / \mathrm{VIla}$ assay was performed at $25^{\circ} \mathrm{C}$; ${ }^{\mathrm{b}} \mathrm{TF} / \mathrm{VIl}$ a assay was performed at $37^{\circ} \mathrm{C} \cdot{ }^{[12,45]}$

\begin{tabular}{|c|c|c|c|c|c|c|}
$\mathbf{C p d}$ & TF/FVIIa & FXa & FXIa & Thrombin & Trypsin & $\begin{array}{c}\text { Tissue } \\
\text { Kallikrein }\end{array}$ \\
\hline & & & & & & $\mathbf{K}_{\mathbf{i}}$ \\
\hline $\mathbf{6 5}$ & $510^{\mathrm{a}}$ & 610 & 5700 & $>13000$ & 3500 & 35 \\
\hline $\mathbf{6 6}$ & $46^{\mathrm{a}}$ & 2600 & 10800 & $>13000$ & 4500 & 6 \\
\hline $\mathbf{6 7}$ & $140^{\mathrm{a}}$ & 4500 & 9100 & 4700 & $>6200$ & 25 \\
\hline $\mathbf{6 8}$ & $1.4^{\mathrm{a}}$ & $>13300$ & $>14200$ & $>11500$ & $>10000$ & 25 \\
\hline $\mathbf{6 9}$ & $1.3^{\mathrm{a}} / 20^{\mathrm{b}}$ & $>10000$ & $>10000$ & $>10000$ & $>10000$ & $36 / 21$ \\
\hline $\mathbf{7 0}$ & $0.16^{\mathrm{b}}$ & 1800 & 2300 & 3800 & 450 & 270 \\
\hline $\mathbf{7 1}$ & $0.43^{\mathrm{b}}$ & & & & & 650 \\
\hline
\end{tabular}

Table 2. Permeability, metabolic stability and oral availability; ${ }^{a} \mathrm{dose}: 1 \mathrm{mg} / \mathrm{kg} .{ }^{[45]}$

\begin{tabular}{|c|c|c|c|c|c|c|}
\hline \multirow[t]{3}{*}{ Cpd } & PAMPA & \multicolumn{3}{|c|}{ microsomal stability } & $\mathbf{F}$ & $\mathbf{F}$ \\
\hline & Pc & & & & in $\operatorname{dog}^{a}$ & in rat \\
\hline & {$[\mathrm{nm} / \mathrm{s}]$} & human & dog & $\begin{array}{c}\text { Rat } \\
\text { (mouse) }\end{array}$ & $\%$ & $\%$ \\
\hline 69 & 13 & & & & & \\
\hline 70 & 50 & $>120$ & 110 & 12 & 1 & \\
\hline 71 & 900 & 45 & 26 & $1.9(3.1)$ & 40 & $<5$ \\
\hline
\end{tabular}

of the flexible chains of $\mathbf{7 7}$ might go along with a large entropic penalty which could be reduced by preorganization of the molecule in the bioactive conformation through macrocyclization.

So far indeed, only limited experimental work is available, comparing thermodynamic data of macrocyclic and linear ligands. ${ }^{[49,50]}$ An entropic advantage for the binding of a macrocycle over a flexible linear control could not be generally demonstrated. The nature and the flexibility of linker, parts of the macrocycle, not directly interacting with the target and the ring size, were found to influence the partitioning of enthalpy and entropy of binding. [49c,50]

With a reported $\mathrm{IC}_{50}$ value of $0.3 \mathrm{nM}$, 78 is 1700 -fold more potent than the lin- 
ear analog 77. The replacement of a linker $\mathrm{CH}_{2}$-group with an oxygen atom (affording 79) led to 1000 -fold increase in potency while maintaining the lipophilicity (Table 4). ${ }^{[48]}$ The affinity of $\mathbf{7 7}, \mathbf{7 8}$ and $\mathbf{7 9}$ for MTH1 was measured by surface plasmon resonance (SPR) and the results confirmed those of the enzymatic assay (Table 4). The macrocyclic inhibitors $\mathbf{7 8}$ and $\mathbf{7 9}$ showed significantly longer residence times $\left(t_{1 / 2}>\right.$ $1 \mathrm{~h})$ than the acyclic control 77, which rapidly dissociated.

Macrocyclization led to improved oral bioavailability (79: $\mathrm{F}=64 \%$ in rat) but had little effect on clearance, volume of distribution and half-life which is quite short for 79 as well as for 77 (Table 5). ${ }^{48]}$

Inhibitor 79 is selective and was found to be inactive against 267 kinases although the compound contains an aminopyrimidine moiety. The compound was also profiled in a panel of 153 pharmacological targets without observation of notable activities.

Using a whole cell thermal stabilization assay, Kettle et al. assessed 77, 78 and 79 to their ability to penetrate cells and to bind to MTH1 and found a good correlation between activity in the enzyme assay and cellular target engagement. ${ }^{[48]}$ The potent and selective MTH1 inhibitors $\mathbf{7 8}$ and 79 were further tested in panel of tumor cell lines and found to have an effect on viability only at top concentration tested in case of $\mathbf{7 8}$ or no effect in case of $\mathbf{7 9}$, indicating that MTH1 has no essential role for cancer-cell survival. ${ }^{[48]}$ As pointed out by Kettle et al., this is in contrast to observations with other small molecule MTH1 inhibitors, which were reported to display broad anti-proliferative activity. ${ }^{[48]}$

\subsubsection{Mer Receptor Tyrosine Kinase Inhibitors}

Mer receptor tyrosine kinase (MerTK) belongs to the TAM (Tyro3, Axl, MerTK) kinase family. Elevated expression of MerTK is observed in various human tumor cells. It has a role in promoting antiinflammatory responses in the innate immune system (thus suppressing the antitumor immune responses). Inhibitors of MerTK might therefore provide therapeutic effects against MerTK expressing tumors. ${ }^{[51,52]}$

Zang et al. described UNC2025 (80, Fig. 11), a potent $\left(\mathrm{IC}_{50}=0.74 \mathrm{nM}\right)$, orally available $(\mathrm{F}=100 \%$, mice $)$ inhibitor of MerTK, which exhibited also a comparably potent activity against Fms-like tyrosine kinase 3 (Flt3; $\left.\mathrm{IC}_{50}=0.8 \mathrm{nM}\right){ }^{[51]}$ Flt3 is a cytokine receptor, expressed at the surface of hematopoietic progenitor cells. The Flt3 gene is frequently mutated in acute myeloid leukemia. Inhibitor $\mathbf{8 0}$ was assessed against a panel of 305 kinases at a concentration of $100 \mathrm{nM}$ (> 100-fold

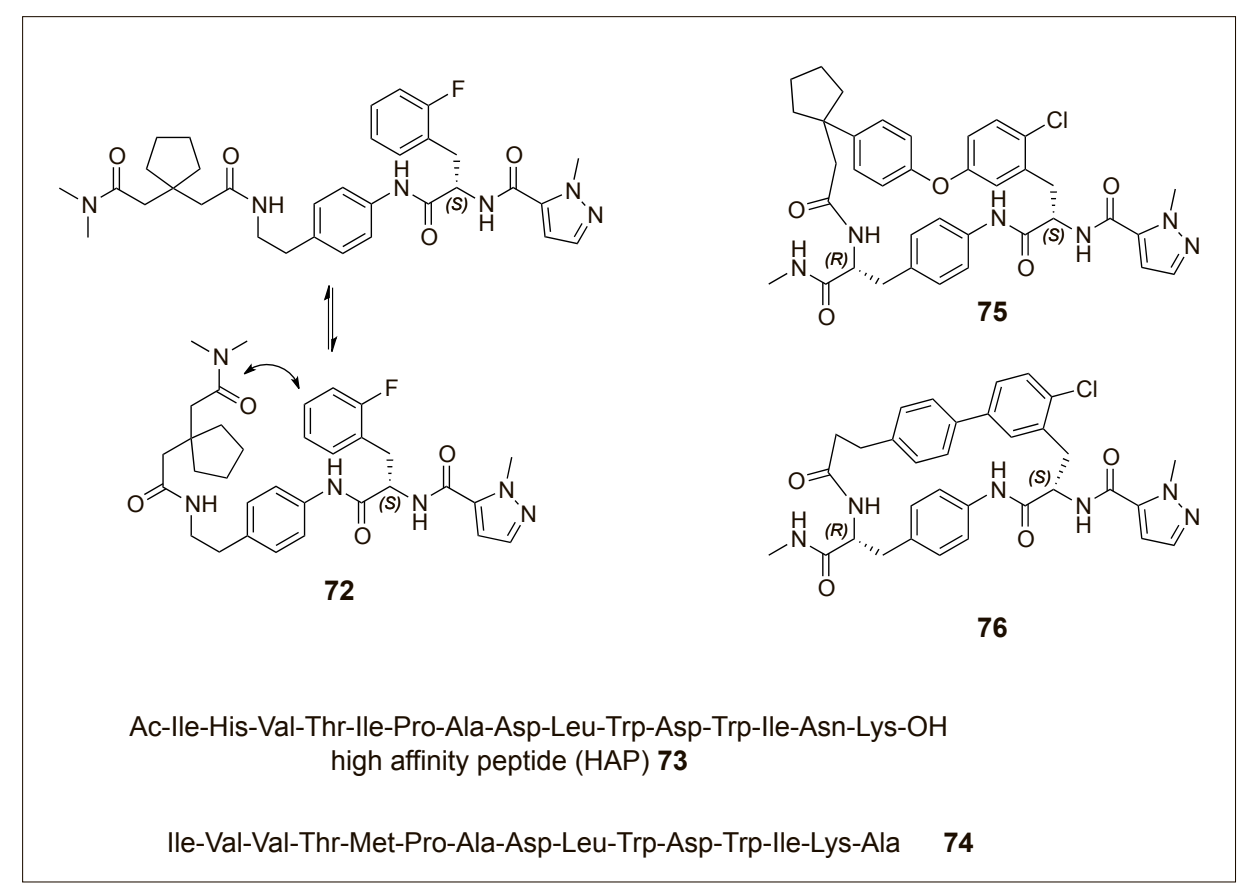

Fig. 9. Macrocyclic and peptidic IL17A antagonists. ${ }^{[46]}$

Table 3. Affinity and potency data of macrocyclic IL-17A antagonists $\mathbf{7 5}$ and $\mathbf{7 6}$ in comparison with the acyclic compound 72 and the high affinity peptide (HAP) $73 .{ }^{[46]}$

$$
\text { hIL-17A }
$$

\begin{tabular}{|c|c|c|c|c|c|}
\hline Cpd & MW & $\begin{array}{c}\text { SPR binding } \\
\mathrm{K}_{\mathrm{D}}[\mathrm{nM}]\end{array}$ & $\mathbf{k}_{\text {on }}$ & $\mathbf{F R E T}$ & Keratinocytes \\
\hline $\mathbf{7 2}$ & 604 & 660 & $2.6 \cdot 10^{3}$ & 1140 & $>10$ \\
\hline $\mathbf{7 3}$ & 1861 & 0.9 & & 0.8 & \\
\hline $\mathbf{7 5}$ & 628 & 199 & $1.3 \cdot 10^{3}$ & 34 & 0.54 \\
\hline $\mathbf{7 6}$ & 612 & 141 & $3.1 \cdot 10^{3}$ & 9 & 0.38 \\
\hline
\end{tabular}

Fig. 10. MTH1 inhibitors: Compound 77 was reported to bind at the site of the base of 8-oxodGTP and to form hydrogen bonds with Asp119 and Asp120. The methoxyethyl side chain and the N(1)-benzyl group are in close proximity with a distance of $3.5 \AA$ (X-ray crystal structure by Kettle et al. ${ }^{[48)}$ ). NMR experiments suggested that the side chain of $\mathbf{7 7}$ is very flexible in solution. Macrocyclization by Mitsunobu arylether synthesis resulted in $\mathbf{7 8}$ and $\mathbf{7 9}$.

MerTK $\left.\mathrm{IC}_{50}\right)$. For 66 kinases an inhibition $>50 \%$ was found at this concentration. Included in the top 10 kinases were Flt 3 and the TAM family members Axl and Tyro3.
An X-ray structure of the related deriv-

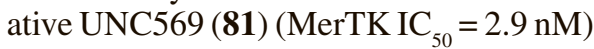
in complex with MerTK kinase domain revealed a close spatial proximity of the bu- 
Table 4. Potency of $\mathbf{7 7 , 7 8}$ and $\mathbf{7 9}$ in enzymatic assay and affinity in SPR; selected DMPK parameters as reported be Kettle et al. [48]; ain human microsomes.

\begin{tabular}{|c|c|c|c|c|c|c|}
\hline Cpd & $\begin{array}{c}\text { Enzyme } \\
\text { assay } \\
\text { IC }_{\mathbf{5 0}} \\
{[\mathrm{nM}]}\end{array}$ & $\begin{array}{c}\text { SPR } \\
\text { MTH1 } \\
\text { affinity } \\
\text { K }_{\mathrm{D}} \\
{[\mathrm{nM}]}\end{array}$ & $\begin{array}{c}\text { SPR residence } \\
\text { time } \mathbf{t}_{1 / 2} \\
{[\mathrm{~min}]}\end{array}$ & $\log D$ & $\begin{array}{c}\text { in vitro } \\
\text { clearance }^{\mathrm{a}}\end{array}$ & $\begin{array}{c}\text { Caco2 } \\
\mathbf{P}_{\text {app }} \text { AB } \\
{\left[\mathrm{x} 10^{-6} \mathrm{~cm} / \mathrm{s}\right]}\end{array}$ \\
\hline 77 & 536 & 440 & $<1$ & 2.6 & 35 & 5.2 \\
\hline 78 & 0.3 & 0.2 & 151.7 & 3.5 & 186 & 8.2 \\
\hline 79 & 0.5 & 0.4 & 81.2 & 2.4 & 48 & 3.2 \\
\hline
\end{tabular}

Table 5. Rat pharmacokinetics (dose: $3 \mu \mathrm{mMol} / \mathrm{kg}$ ) of macrocycle $\mathbf{7 9}$ and its acyclic analog $\mathbf{7 7}$ as reported by Kettle et al. ${ }^{[48]}$

\begin{tabular}{|c|c|c|c|c|}
\hline Cpd & $\mathbf{F}$ & clearance & $\mathbf{V}_{\text {dss }}$ & half life $\mathbf{t}_{\mathbf{1} / \mathbf{2}}$ \\
\hline & & {$[\mathrm{mL} / \mathrm{min} / \mathrm{kg}]$} & {$[\mathrm{L} / \mathrm{kg}]$} & {$[\mathrm{h}]$} \\
\hline $\mathbf{7 7}$ & $31 \%$ & 29 & 1.1 & 1.2 \\
\hline $\mathbf{7 9}$ & $64 \%$ & 26 & 0.8 & 1.3 \\
\hline
\end{tabular}

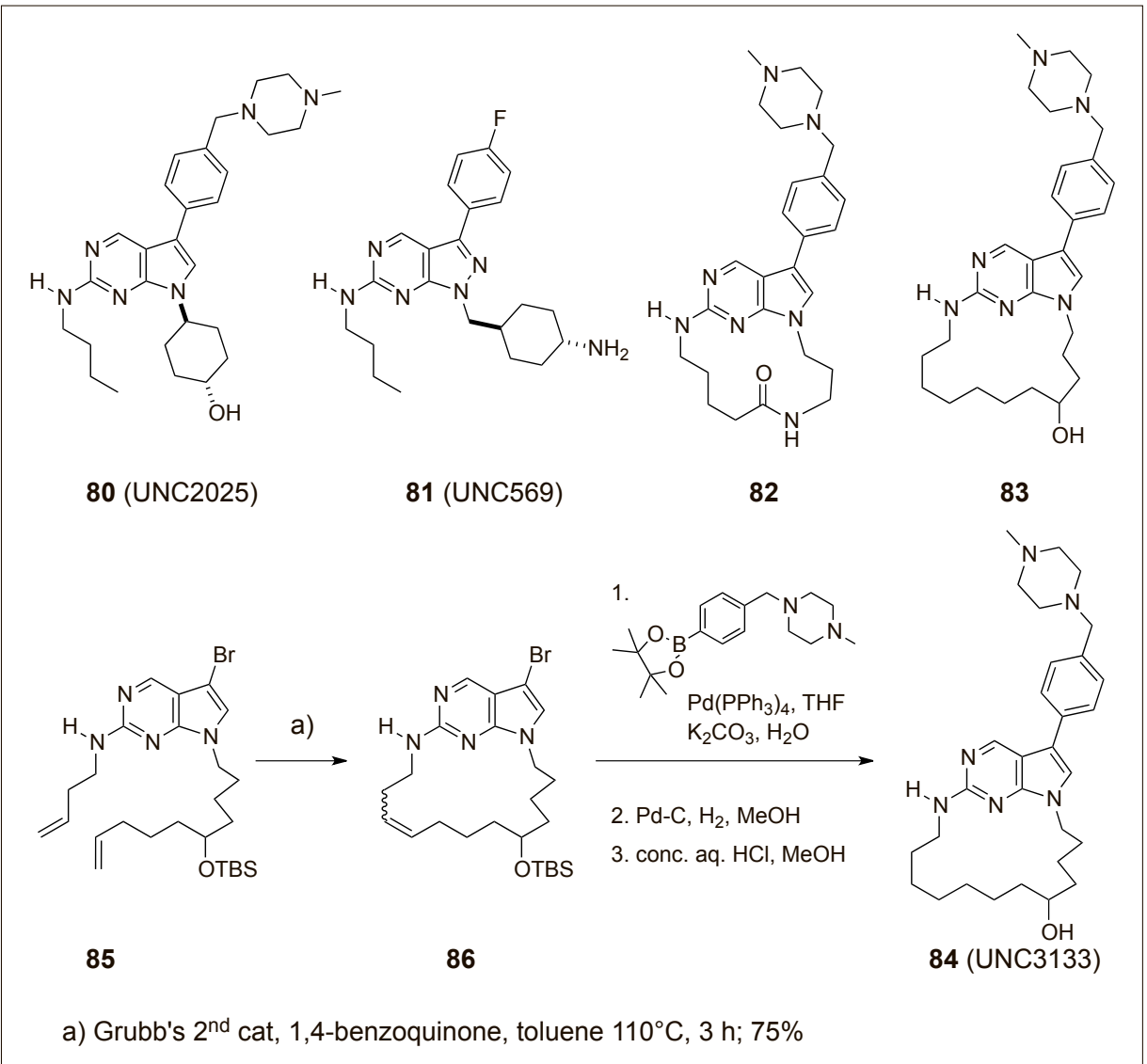

Fig. 11. Synthesis of 84 comprised ring-closing metathesis followed by Suzuki coupling, hydrogenation of the double bond and cleavage of the alcohol protective group. ${ }^{[52]}$

tyl chain and the cyclohexyl moiety, suggesting that these groups can be connected by a linker. ${ }^{[52]}$ Synthesis of $\mathbf{8 2}$ (MerTK IC $_{50}$ $=65 \mathrm{nM})$ and solution of the crystal structure of $\mathbf{8 2}$ in complex with MerTK kinase domain confirmed the hypothesis. ${ }^{[52 \mathrm{~b}]} \mathrm{A}$ variety of different linkers changing ring size, altering conformation, conformational flexibility and position of the hydrogen bond donor group resulted in two series of inhibitors, including $\mathbf{8 3}$ and UNC3133 (84). The (racemic) macrocyclic inhibitors 83 and 84 exhibit low nanomoloar potency against MerTK and Flt3. ${ }^{[52 b]}$ Inhibitor $\mathbf{8 4}$ was tested against a panel of 30 kinases at a concentration 100-fold above MerTK $\mathrm{IC}_{50}$. Unfortunately, the selectivity of $\mathbf{8 4}$ was found to be worse than that of $\mathbf{8 0}$; eight tyrosine and four serine/threonin kinases were inhibited with $>50 \%$. ${ }^{[52 b]}$ Selected activity and pharmacokinetic data of $\mathbf{8 0}$, 83 and 84 are depicted in Table 6.

\subsection{Lead Structures Derived from Natural Products}

Macrocyclic natural products may serve as starting points inspiring the synthesis of simplified analogs. The synthesis and biological evaluation of macrocyclic largazole and sanglifehrin analogs were very recently published.

\subsubsection{Simplified Largazole Analogs}

Histone deacetylase enzymes (HDAC) are zinc metalloenzymes which catalyze the cleavage of an acetyl group from lysine residues in histones and other substrates. ${ }^{[53]}$ HDAC proteins are also called lysine deacetylases (KDAC). Largazole (87; Fig. 12), a natural 16-membered macrocyclic depsipeptide isolated from a marine cyanobacterium, is a potent class I selective HDAC inhibitor. ${ }^{[54]}$ It is a prodrug; cleavage of the octanoyl group releases the largazole thiol $\mathbf{8 8}$ which is thought to coordinate $\mathrm{Zn}^{2+}$. The depsipeptide ring system acts as surface cap recognition group. ${ }^{53]}$ Several research groups described analogs of largazole; $[53 \mathrm{~b}, 55]$ very recently Reddy et al. ${ }^{[56]}$ synthesized simplified analogs with diverse $\mathrm{Zn}$-binding groups; the thiazolethiazoline portion was replaced by a proline dipeptide and the $\beta$-hydroxy acid by aspartate which resulted in a 13 -membered ring cyclic peptide. The C-terminal aspartate amide bond serves as an equivalent of the $\mathrm{C}-\mathrm{C}$ double bond. The most active compounds identified ( $\mathbf{8 9}$ and $\mathbf{9 0}$ ) were hydroxamic acids.

Almaliti et al. substituted the thiazolethiazoline fragment of largazole with alternative capping groups while maintaining the ring size and war head. ${ }^{[54]}$ Biological evaluation of the analogs 91-93 revealed that the bipyridyl analog 92 (the best compound of the series described) showed potency against HDACs comparable to that of largazole and an even elevated selectivity for class I HDACs over class II HDACs (Table 7). ${ }^{[54]}$ Analogs 91-93 were tested for antiproliferative activity on a NCI 60 cell line panel; Almaliti et al. found inhibitor 92 to be the most active compound with a profile similar to largazole; in a HCT116 cell growth inhibition assay 92 had a $\mathrm{GI}_{50}$ of $75 \mathrm{nM}$ (largazole: $\mathrm{GI}_{50}=$ $65 \mathrm{nM}){ }^{[54]}$ 
Table 6. Potency of linear $(\mathbf{8 0})$ and macrocyclic $(\mathbf{8 3}, \mathbf{8 4})$ inhibtors against selected kinases and in vivo pharmacokinetic parameters (mice; dose iv and po $3 \mathrm{mg} / \mathrm{kg}$ ). ${ }^{[51,52 \mathrm{~b}]}$

\begin{tabular}{|c|c|c|c|c|c|c|c|c|}
\hline Cpd & $\begin{array}{c}\text { MerTK } \\
\text { IC }_{50} \\
{[\mathrm{nM}]}\end{array}$ & $\begin{array}{c}\text { Axl } \\
\text { IC }_{50} \\
{[\mathrm{nM}]}\end{array}$ & $\begin{array}{c}\text { Tyro3 } \\
\text { IC }_{50} \\
{[\mathrm{nM}]}\end{array}$ & $\begin{array}{l}\text { Flt3 } \\
\text { IC }_{50} \\
{[\mathrm{nM}]}\end{array}$ & $\begin{array}{c}\text { Systemic } \\
\text { clearance } \\
{[\mathrm{mL} / \mathrm{min} / \mathrm{kg}]}\end{array}$ & $\begin{array}{r}\mathbf{V}_{\text {dss }} \\
{[\mathrm{L} / \mathrm{kg}]}\end{array}$ & $\begin{array}{c}\text { Half life } \\
\mathbf{t}_{1 / 2} \\
{[\mathrm{~h}]}\end{array}$ & $\mathbf{F}$ \\
\hline 80 & 0.74 & 14 & 17 & 0.8 & 9.2 & 2.3 & 3.8 & 100 \\
\hline 83 & 1.8 & 14 & 25 & 7.5 & & & & \\
\hline 84 & 3.0 & 17 & 31 & 6.8 & 106 & 6.8 & 1.6 & 16 \\
\hline
\end{tabular}

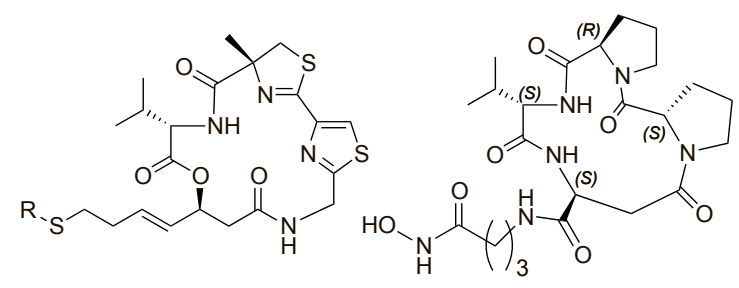

$87 \mathrm{R}=\mathrm{CO}\left(\mathrm{CH}_{2}\right)_{6} \mathrm{CH}_{3}$, Largazole

89

$88 \mathrm{R}=\mathrm{H}$
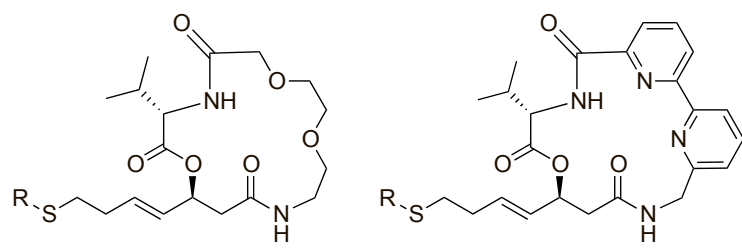

$92 \mathrm{R}=\mathrm{CO}\left(\mathrm{CH}_{2}\right)_{6} \mathrm{CH}_{3}$

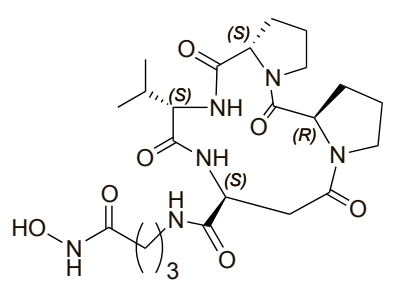

90

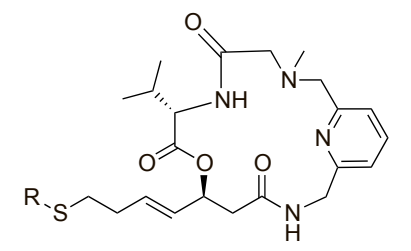

$93 \mathrm{R}=\mathrm{CO}\left(\mathrm{CH}_{2}\right)_{6} \mathrm{CH}_{3}$
Fig. 12. Largazole and simplified analogs. ${ }^{[54,56]}$

Table 7. IC ${ }_{50}$ values of largzole (87) and 92 against HDACs 1, 2 and 3 of class I and HDAC6 of class II. ${ }^{[54]}$

\begin{tabular}{|c|c|c|c|c|}
\hline Cpd & HDAC1 & HDAC2 & HDAC3 & HDAC6 \\
\hline & $\mathrm{IC}_{50}[\mathrm{nM}]$ & $\mathrm{IC}_{50}[\mathrm{nM}]$ & $\mathrm{IC}_{50}[\mathrm{nM}]$ & $\mathrm{IC}_{50}[\mathrm{nM}]$ \\
\hline Largazole (87) & 61 & 64 & 50 & 1400 \\
\hline $\mathbf{9 2}$ & 21 & 28 & 27 & 13000 \\
\hline
\end{tabular}

\subsubsection{Cyclophilin Inhibitors Based on Structural Simplification of Sanglifehrin A}

Sanglifehrin A (94, Fig. 13) is a bacterial 22-membered macrolactone natural product consisting of a tripeptide portion (valine-meta-tyrosine-piperazic acid) and an extended polyketide structure. It exhibits immunosuppressive properties and binds with nanomolar affinity to cyclophilin (Cyp) A, B and C. ${ }^{[57]}$

CypA is necessary for hepatitis $\mathrm{C}$ virus (HCV) replication. CypA binds to the viral protein NS5A and is a target for $\mathrm{HCV}$ treatment. Non-immunosuppressive CypA inhibitors are of interest to treat $\mathrm{HCV}$ infection. ${ }^{[57 a]}$
Selective oxidative cleavage of the $\mathrm{C}(26)-\mathrm{C}(27)$ double bond in the side chain was reported to give the aldehyde $\mathbf{9 5}$ which maintained the affinity for the cyclophilins but showed no immunosuppressive activity; ${ }^{[57 b]}$ the simplified derivative $\mathbf{9 8}$, which had the side chain at $\mathrm{C}(23)$ removed as well as the substituents in position 1417 , was reported to maintain micromolar affinity for cyclophilins. ${ }^{[57 b, c]}$

The analogs 96 and 97 (with substituents present in positions 14-17) have been described very recently by Steadman et al. and were found to be significantly more potent than 98 (Table 8). ${ }^{57 a]}$ X-ray crystal structures of 96 and 98 in complex with CypA determined by these authors revealed that the binding mode of the tripeptide portion (which is responsible for all direct hydrogen bonding interactions to CypA) is well conserved in both structures. The conformation of the nonpeptidic moiety was found to be different. Inhibitor 96 exhibits like sanglifehrin A and unlike 98, an intramolecular hydrogen bond between the amide $\mathrm{NH}$ of Val and the oxygen atom of the substituent at $\mathrm{C}(15)$. The thermodynamic parameters for the binding of 96 and 98 were compared (Table 9); the difference in affinity of the two compounds could be attributed to a difference in binding enthalpy. ${ }^{\text {[57a] }}$ (That the formation of an intramolecular hydrogen bond results in a favorable enthalpic contribution to $\Delta \mathrm{G}$ of binding was also observed by DeLorbe et al..$^{[50]}$ )

Steadman et al. also reported the synthesis and biological evaluation of analog 99 with a replacement of the diene group by a meta-substituted styryl group resulting in a further rigidified non-peptidic portion. [57a] Compound 99 was reported to bind in a new mode with the side chain of m-Tyr no longer making a hydrogen-bonding contact to His(126) and the styrene moiety undergoing a $\pi$-stacking interaction with the guanidinum side chain of $\operatorname{Arg}(55)$. The activity found for compound $\mathbf{1 0 1}$ confirmed that the $\mathrm{m}$-Tyr side chain is dispensable in the presence of the styryl linker. ${ }^{[57 a]}$

\section{Permeability and Oral Bioavailability of Macrocyclic Compounds}

Macrocyclic structure is a feature that is thought to confer permeability and oral bioavailability. This view is supported by the observation that macrocycles are enriched among orally available beyond rule of five compounds. ${ }^{[58]}$ Increased diffusion rates in solution $\left(\mathrm{CDCl}_{3}, \mathrm{D}_{2} \mathrm{O} / \mathrm{DMSO}-\mathrm{d}_{6}\right.$ 9:1 and DMSO- $\mathrm{d}_{6}$ ) have been reported by Bogdan et al., comparing macrocyclic compounds and linear controls engaging NMR spectroscopy. ${ }^{[59]}$ All investigated macrocyclic compounds were found to exhibit in all solvents modestly higher diffusion rates $\left(+5 \%\right.$ in $\left.\mathrm{CDCl}_{3}\right)$ than the linear controls. ${ }^{[59]}$ The lipophilicity of the selected compound pairs was reported to be druglike $(\log \mathrm{D} 0.5-2.5)$; examples of the cyclic structures 102a-105a and the corresponding linear compounds $\mathbf{1 0 2 b}-\mathbf{1 0 5} \mathbf{b}$ are depicted in Fig. 14.

As compared to the corresponding Nand C-terminal capped linear peptide $\mathbf{1 0 7}$ (Fig. 15), Rezai et al. observed for the macrocyclic peptide 106 increased diffusion across a phospholipid impregnated membrane. ${ }^{[60]}$ In a parallel artificial membrane permeability assay (PAMPA) apparent diffusion coefficients $\left(\mathrm{P}_{\mathrm{e}}\right)$ were determined; $106\left(\log P_{e}=-6.2\right)$ was found to be at least 
100-fold more permeable than $107(\log \mathrm{P}$ $<-8.1)$; for cyclosporine A (CsA) a $\log$ $\mathrm{P}_{\mathrm{e}}$ value of -6.6 was reported as a comparison. ${ }^{[60]}$ In $\mathrm{CDCl}_{3}$ (dielectric constant $4.8 ;[61]$ solvent used to mimic the center of a lipid bilayer (dielectric constant 4.0[60,62]) cyclic peptide $\mathbf{1 0 6}$ was found to adopt a conformation with two transannular hydrogen bonds between $\operatorname{Leu}(3)$ and $\operatorname{Tyr}(6)$. A H/D exchange experiment showed that only the amide $\mathrm{NH}$ of D-Leu(2) was exchanged within $19 \mathrm{~h}$, indicating that only this NH of $\mathbf{1 0 6}$ is solvent exposed. The example thus illustrates the important role of intramolecular hydrogen bonds in improving membrane permeability. For classical small molecules ${ }^{[63]}$ as well as for medium-sized ring-containing compounds at the border of rule of five ${ }^{[64]}$ intramolecular hydrogen bonds were also reported to improve membrane permeability.

\subsection{Cyclic Peptides}

Sets of cyclic peptides are comparatively easy to prepare by modular chemical synthesis. Large libraries of cyclic peptides can also be obtained by DNA-encoded synthesis or display technologies. Their role as important natural products, as well as the exceptional properties of cyclosporine A (a cyclic undecapeptide) motivated several research groups to investigate in more detail factors that influence cellular permeability and oral availability of cyclic peptides. A profound understanding of these factors might allow an improved design of libraries of cyclic peptides and beyond of other macrocyclic structures.

Structural motifs that influence the cellular permeability (and oral availability) of macrocyclic peptides have been investigated systematically. ${ }^{[65-78]}$ Removal of hydrogen bond donors by internalization (formation of intramolecular hydrogen bonds) or by N-methylation, shielding of polar contacts by side chains of $\beta$-branched amino acids or orientation of free $\mathrm{NH}$ groups into the center of bowl-shaped structures (steric occlusion; no desolvation required) and increased lipophilicity (more lipophilic, larger side chains) may result in better permeability. N-Methylation not only removes hydrogen bond donors but has also an influence on the conformational flexibility of a given scaffold as it reduces the energy difference between cis and trans peptide bonds. Kessler and coworkers found that 23 out of 30 mono-, di-, tri- and tetramethylated cyclic pentalanine peptides c-[D-Ala-(Ala) ${ }_{4}$ ] exhibit in DMSO-d 6 solution the presence of more than one conformer. ${ }^{[72]}$ Other structural motifs present in permeable cyclic peptides comprise heterocycles (e.g. thiazole and oxazole rings in natural products, ${ }^{[79]}$ oxadiazoles in synthetic peptide analogs, ${ }^{[34,80]} \gamma$-amino acids, (e.g $\beta$-hydroxy- $\gamma$-amino acids and

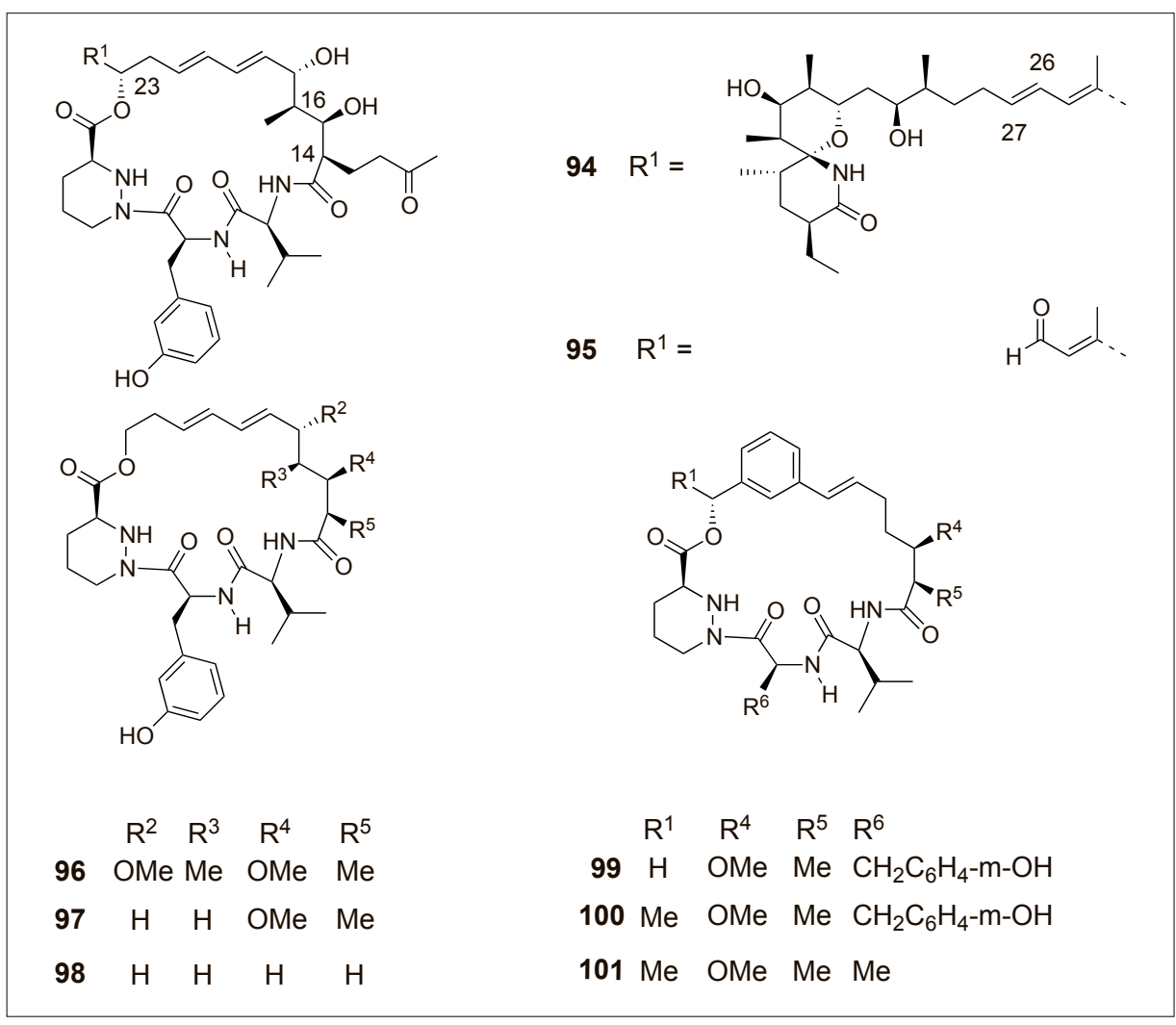

Fig. 13. Sanglifehrin A (94) and truncated analogs. ${ }^{[57]}$

Table 8. Biochemical and cellular potency of cyclophilin A inhibitors 96-101; CspA = cyclosporine A; data taken from Steadman et al. ${ }^{[57 a]}$

\begin{tabular}{|c|c|c|c|}
\hline Cpd & $\begin{array}{c}\text { TR-FRET } \\
\text { CypA binding }\end{array}$ & $\begin{array}{c}\text { PCV genotype 1b } \\
\text { functional assay }\end{array}$ & \begin{tabular}{c} 
replicon \\
\hline
\end{tabular} \\
\hline $\mathbf{9 6}$ & $\mathrm{K}_{\mathrm{D}}[\mathrm{nM}]$ & $\mathrm{K}_{\mathrm{i}}[\mathrm{nM}]$ & $\mathrm{EC}_{50}[\mathrm{nM}]$ \\
\hline $\mathbf{9 7}$ & 25 & 16 & 600 \\
\hline $\mathbf{9 8}$ & 65 & 65 & 240 \\
\hline $\mathbf{9 9}$ & 2600 & 795 & 4500 \\
\hline $\mathbf{1 0 0}$ & 64 & 14 & 320 \\
\hline $\mathbf{1 0 1}$ & 11 & 4 & 36 \\
\hline $\mathbf{C s p A}$ & 24 & 7 & 87 \\
\hline
\end{tabular}

Table 9. Thermodynamic data of inhibitors $96-98$ binding to cyclophilin A. ${ }^{[57 a]}$

\begin{tabular}{|c|c|c|c|} 
Cpd & $\Delta \mathbf{G}$ & $\Delta \mathbf{H}$ & $\mathbf{T} \Delta \mathbf{S}$ \\
& {$[\mathrm{kcal} / \mathrm{mol}]$} & {$[\mathrm{kcal} / \mathrm{mol}]$} & -9.97 \\
\hline $\mathbf{9 6}$ & -10.3 & -8.6 & 0.32 \\
\hline $\mathbf{9 7}$ & -9.5 & -7.0 & 0.93 \\
\hline $\mathbf{9 8}$ & -8.2 & & 1.2 \\
\hline
\end{tabular}

$\alpha, \beta$-unsaturated (vinylogous) amino ac$\left.\operatorname{ids}^{[81]}\right)$ and depsipeptide linkage. ${ }^{[79]}$

To identify cell-permeable cyclic hexapeptide scaffolds, Hewitt et al. synthesized an 1152-member split pool library (Fig. 16).[65] The predominantly very lipophilic compounds were prepared and screened in 12 sublibraries of 96 stereoisomers and 
$\mathrm{N}$-methyl analogs. The generic sequence was c-[Pro-(Xxx)-Tyr] with L-Pro and DPro in position 1, L-Leu, D-Leu, Me-L-Leu and Me-D-Leu in position 2-5 and L-Tyr in position 6. Sar and Gly were included in addition in positions 2 and 4 to obtain compounds with reduced lipophilicity. The 12 sublibraries were evaluated for passive permeability in a parallel artificial membrane permeability assay (PAMPA); compound flux over the artificial membrane was measured by LC-MS analysis. Hewitt et al. observed that sublibraries with comparably high representation of $\mathrm{N}$-methylated compounds or 'all-Leu' peptides were enriched with permeable compounds. Sublibraries with Gly or Sar residues were reported to be on average less permeable. Exceptions to the trends were reported like poorly permeable compounds with four N-methyl groups as well as non- $\mathrm{N}$-methylated compounds with high permeability. ${ }^{[65]}$ That there is no strict correlation of $\mathrm{N}$-methylation degree and permeability is in line with earlier findings of Kessler (see below). ${ }^{66,67]}$

Deconvolution strategies allowed Hewitt et al. to identify among other compounds the diastereomers 109 and 111 (Fig. 17) as well as 112 and 113 (Fig. 18). ${ }^{[65]}$ Both pairs of stereoisomers demonstrated the importance of the configuration in determining the conformation and thus the permeability. Compounds $\mathbf{1 1 2}$ and 113 differ in the configuration in position 3 which can be inverted without change in the backbone conformation or compromising permeability. Isomer 114, which differs from 112 in the configuration in position 3,4 and 5 is one of the least permeable compounds of the series. In variable temperature ${ }^{1} \mathrm{H}-\mathrm{NMR}$ experiments, the $\mathrm{NH}$ groups of $\mathbf{1 1 2}$ and $\mathbf{1 1 3}$ exhibit (unlike in 114) small temperature shift coefficients, which is consistent with the presence of intramolecular hydrogen-bonds and the relatively high cell permeability of these two isomers. The molecules adopt a bowlshaped conformation with the remaining $\mathrm{NH}$ pointing towards the center of the bowl.[65]

Diversifying the amino acid side chains by replacement of a single Leu residue in position 3, 4 or 5 of the permeable scaffold 113 with more polar amino acids were reported. ${ }^{[65]}$ Basic residues (Orn), hydrogenbond donors (Thr) or acceptors (4-Pal) led to poor permeability. The permeability was retained or improved if the lipophilicity was retained (substitution of Leu with Val, Phe, 2-Nal, Cha).

Kessler and coworkers ${ }^{[66]}$ studied the influence of $\mathrm{N}$-methylation on permeability; these authors synthesized and investigated 54 (out of 62 possible) $\mathrm{N}$-methylated (1-5 methyl groups) cyclic hexa-alanine c-[D-Ala-(Ala $\left.)_{5}\right]$ derivatives

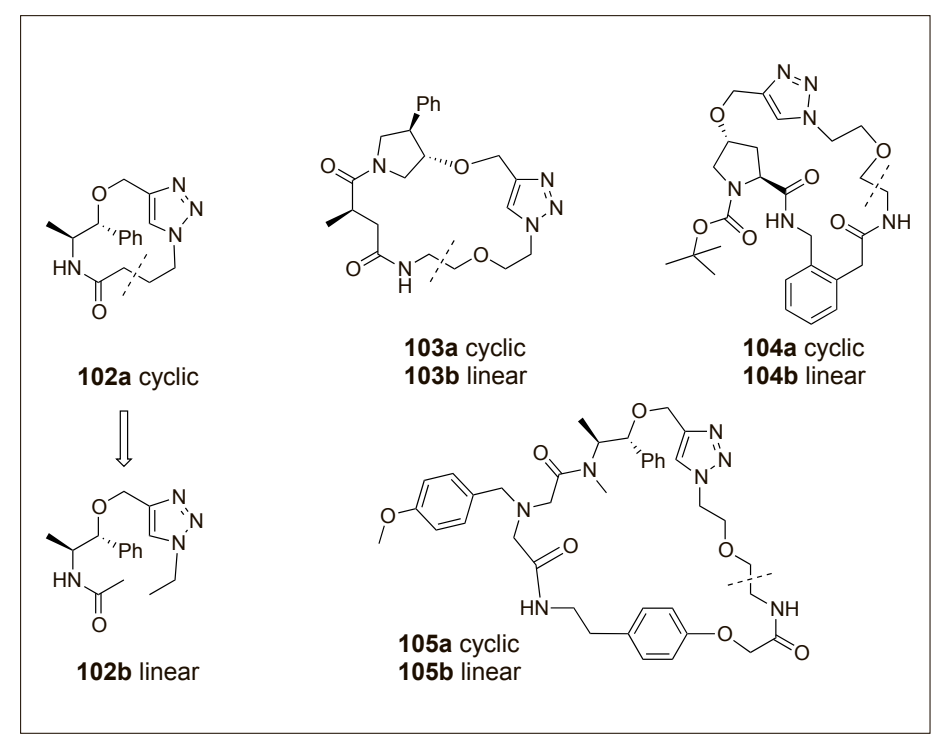

Fig. 14. Polyfunctional macrocyclic compounds 102a-105a were prepared engaging Cu-mediated alkyne/azide cycloaddition in the ringclosing step. The macrocycles and their acyclic equivalents 102b-105b cover the MW range $300-730$ and ring size 12 , 18, 21 and 29. The acyclic compounds, which are identical with regard to $\mathrm{MW}$ and functional groups represented were designed by cleavage of C-C bonds. ${ }^{[59]}$

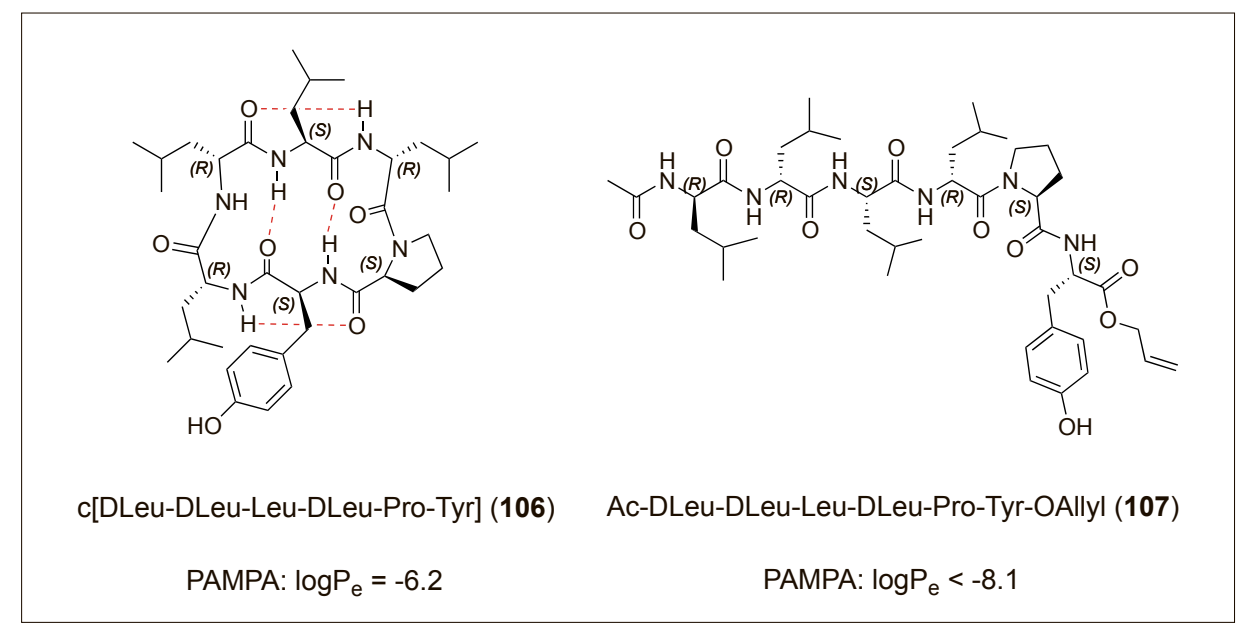

Fig. 15. In a parallel artificial membrane permeability assay (PAMPA) cyclic peptide 106 was found to be at least 100 -fold more permeable than the linear peptide $107 .{ }^{[60]}$

Fig. 16. 1152-member cyclopeptide split pool library of stereoisomers and $\mathrm{N}$-methyl variants described by Hewitt et al.; synthesis started with L-Tyr; residues in position 2 and 1 are unique in each sublibrary. ${ }^{[6]}$

Fig. 17. The well permeable diastereomers $\mathbf{1 0 9}$ and $\mathbf{1 1 1}$ differ only in the configuration at position 4. The most and the least permeable diastereomers 108/109 and 110/111 differ in the configuration at a single center in position 5. ${ }^{[65]}$
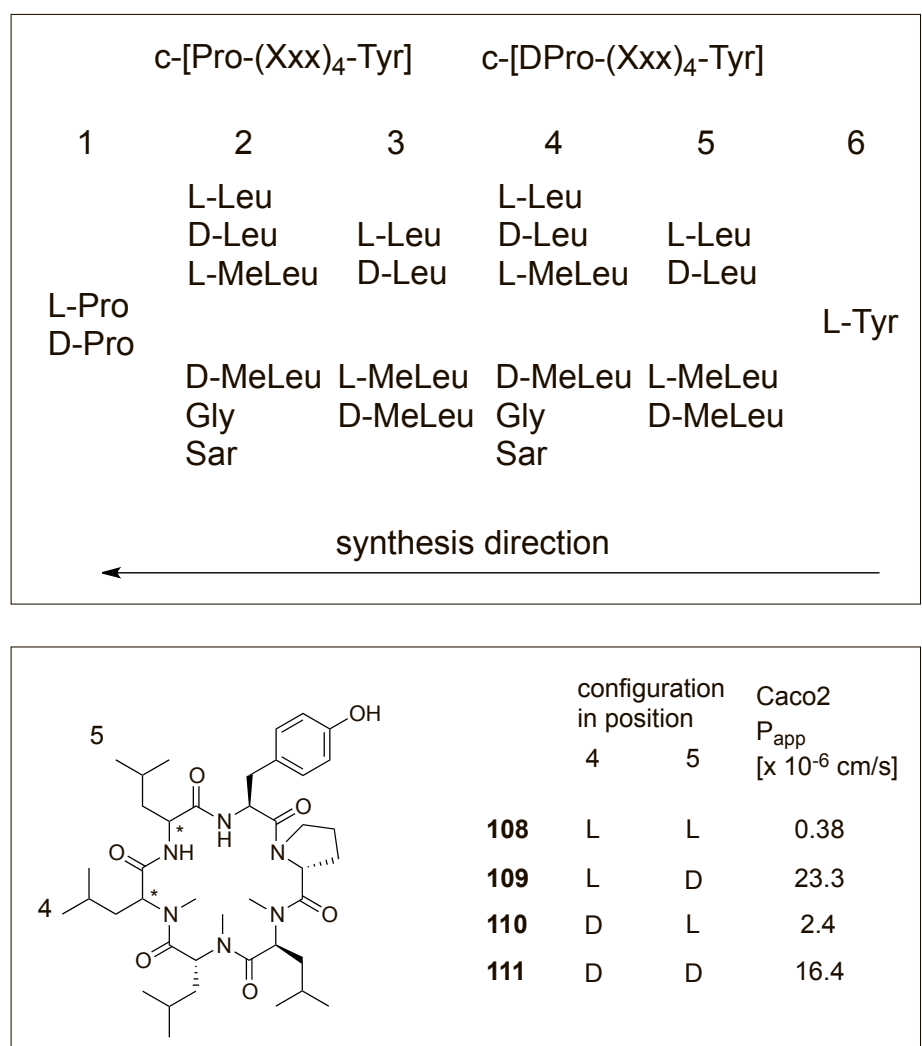
and evaluated their (intestinal) permeability. They found that most of the library members have poor permeability (Caco2 $\left.\mathrm{P}_{\text {app }}<1 \times 10^{-6} \mathrm{~cm} / \mathrm{s}\right)$; ten compounds exhibited good permeability (Caco $2 \mathrm{P}_{\mathrm{app}}>$ $\left.10 \times 10^{-6} \mathrm{~cm} / \mathrm{s}\right)$. No correlation was found between the number of $\mathrm{N}$-methyl groups and the permeability. ${ }^{[66,67]}$ The group of well permeable compounds comprised 4 bis-, 1 tris- and 5 tetra-N-methylated cyclic hexa-alanine derivatives, including compounds 115, 116 and 117 (Fig. 19). None of these peptides showed PAMPA permeability, which excludes passive transcellular pathway as consequence of increased lipophilicity as an explanation. The position of the N-methyl groups defines the conformation and thus the permeability. ${ }^{[68]}$ Peptides $\mathbf{1 1 5}$ and $\mathbf{1 1 6}$ showed similar $\mathrm{P}_{\text {app }}$ values in apical to basolateral and in basolateral to apical transport direction in the Caco2 assay.[66] Asymmetry would be a characteristic of carrier-mediated transport. On the basis of investigation of the compounds in several permeability models, Kessler and coworkers suggested facilitated diffusion (spontaneous passive transport of molecules across a cell membrane via specific carrier transmembrane proteins) as possible transport route. ${ }^{[66]}$

That chiral transport systems are involved in the case of these polar peptides was confirmed by comparing the permeability values of 115, 116 and 117 with the values of their optical antipodes ent-115, ent-116 and ent-117.[69] The pairs of enantiomers showed identical lipophilicities $\left(\log \mathrm{D}_{74}\right)$, and PAMPA permeability (log$\mathrm{P}_{\mathrm{e}}$ ) values but 4-9-fold differences in the Caco2 $\mathrm{P}_{\text {app }}$ values (Table 10). This result was interpreted as a proof for participation of an active transport pathway. ${ }^{[69]}$ The previously described passively permeable peptide 119[70] (Scheme 12) and its enantiomer ent-119 however exhibit comparable Caco 2 permeability. ${ }^{[69]}$

Cyclopeptide 119 was orally administered to rat $(10 \mathrm{mg} / \mathrm{kg})$ and exhibited $28 \%$ oral bioavailability. ${ }^{[70]}$ Slow H/D exchange in $\mathrm{CDCl}_{3}$ solution confirmed the presence of two intramolecular hydrogen bonds in 119. The trimethyl adduct 119 was obtained as a specific $\mathrm{N}$-methylation product by reaction of immobilized peptide $\mathbf{1 1 8}$ with $>95 \%$ selectivity. ${ }^{[70,71]}$

In line with findings reported for the cyclic penta-alanines, ${ }^{[72]}$ also for the cyclic hexa-alanines significant conformational changes were reported, depending on the position of the N-methylation. Peptides 115, 116 and 117 adopt a single conformation in solution. Peptide $\mathbf{1 1 6}$ possesses alltrans peptide bonds and to type II $\beta$-turns; 115 and 117, however, have one cis peptide bond and Type VI $\beta$-turn geometry along Ala(4)-Ala(5). ${ }^{[68]}$

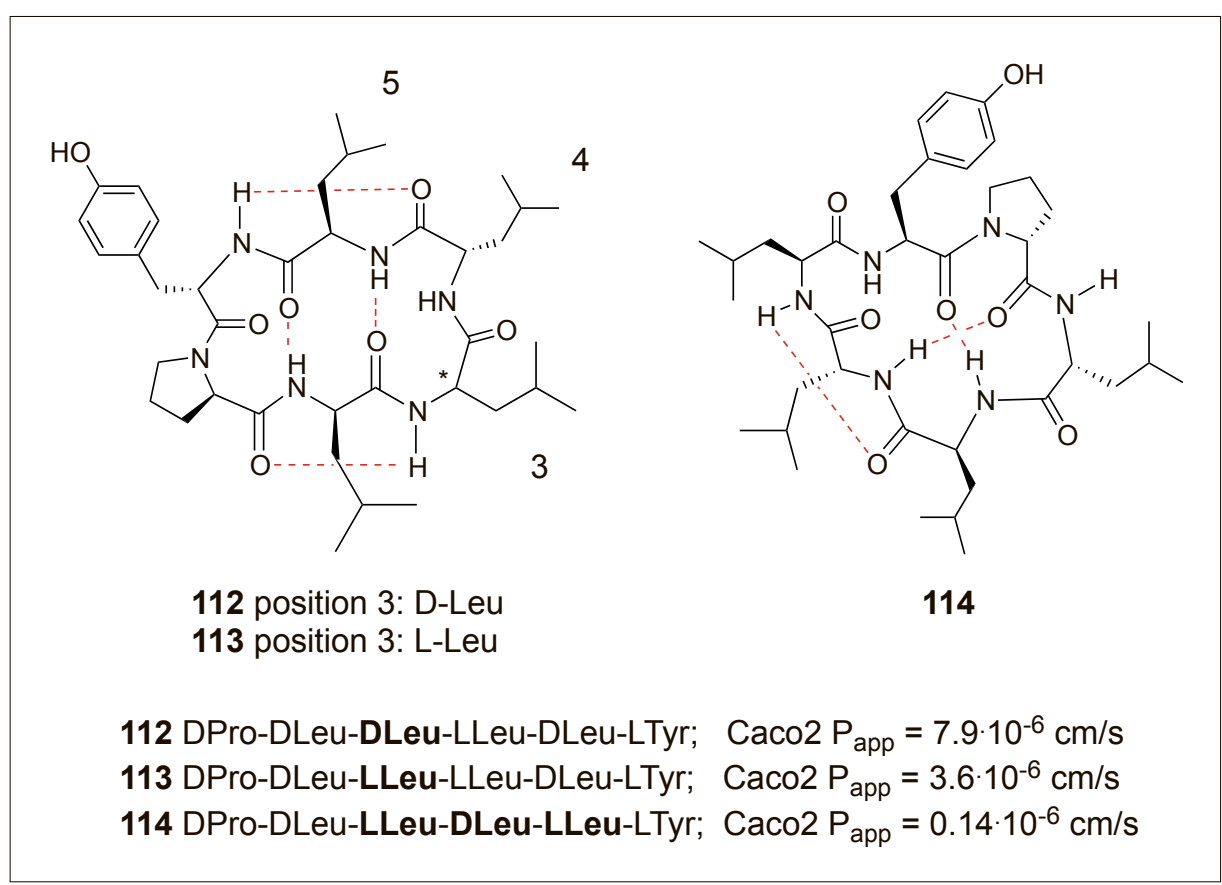

Fig. 18. 112 and $\mathbf{1 1 3}$ with two transannular and two extra-annular hydrogen bonds; $\mathbf{1 1 4}$ has two solvent-exposed amide $\mathrm{NH}$-groups. ${ }^{[65]}$

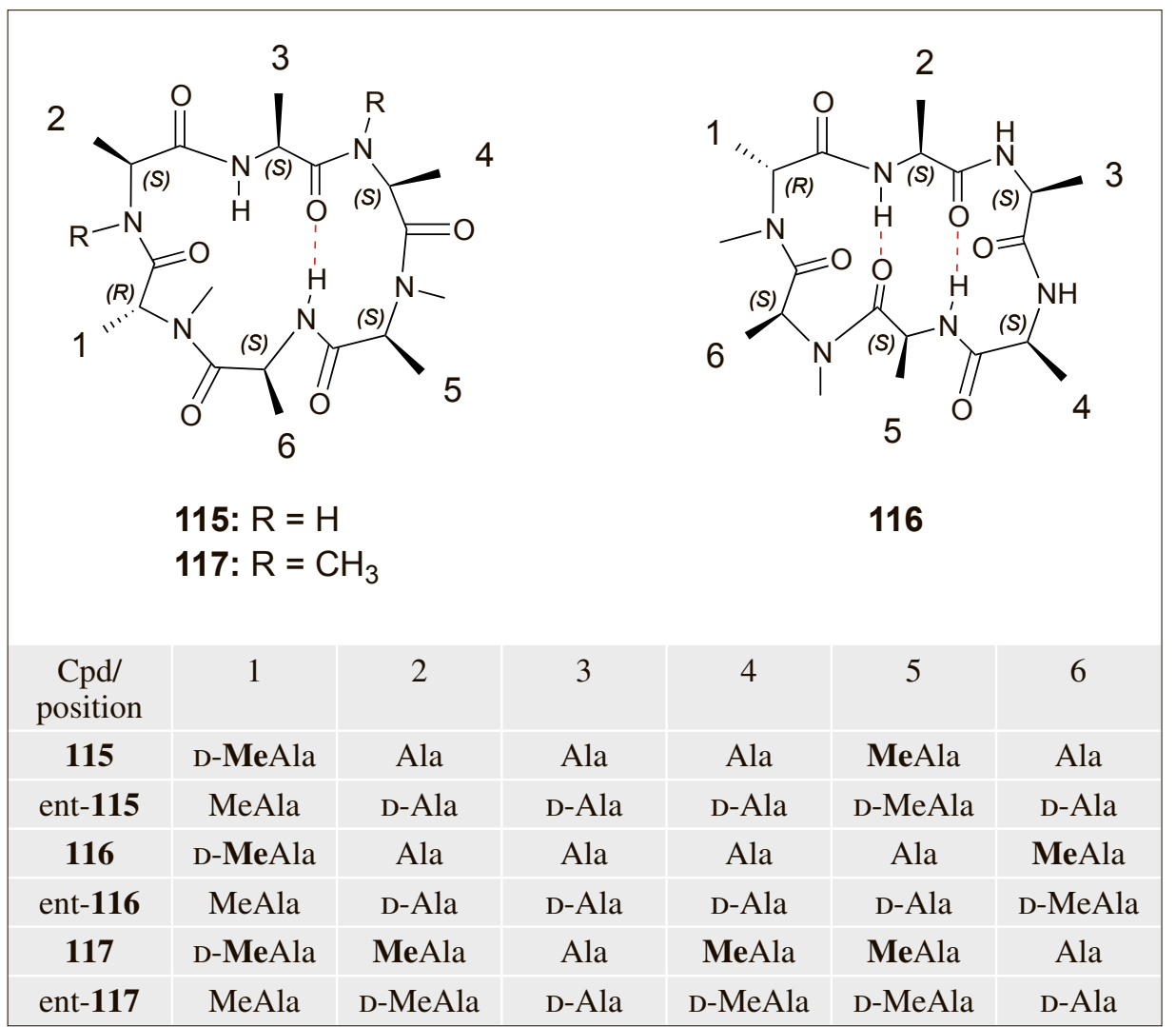

Fig. 19. Sequence of Caco2-permeable N-methylated cyclic hexa-alanines c-[D-Ala-(Ala) $\left.{ }_{5}\right]$ and their enantiomers. ${ }^{[66,69]}$

In summary, passive membrane permeability of cyclic peptides seems to depend on polarity of the side chains and more important on the conformation of the backbone. Rigid conformations with internalized or shielded hydrogen bond donors confer passive permeability. The configuration of the amino acids as well as the position of secondary and tertiary amide groups are key factors determining the conformation adopted by a cyclic peptide. Chiral transport systems are involved in the uptake of the more polar (N-methylated) cyclic hexa-alanines. Their cellular permeability is controlled by the position of $\mathrm{N}$-methyl groups rather than their number (and thus the lipophilicity increase). 
Kessler and coworkers studied the impact of multiple $\mathrm{N}$-methylation on the properties of model peptides with known biological activity, demonstrating that this approach may allow to improve oral bioavailability while retaining potency. ${ }^{[73]}$ Also this work not unexpectedly demonstrated that consequences of the substitution of the peptide $\mathrm{NH}$ by methyl group strongly depend on the position of the amide group within the cyclic peptide or in other words on the impact of the substitution on the conformation of the cyclic peptide.

The Veber-Hirschmann peptide c-[ProPhe-D-Trp-Lys-Thr-Phe] (120; Fig. 20) is a somatostatin receptor agonist with selectivity for receptor subtypes sst 2 and sst5. Systematic replacement of the amino acid residues of $\mathbf{1 2 0}$ with one or more corresponding $\mathrm{N}$ - $\alpha$-methyl amino acids resulted in 30 analogs. Out of these, seven compounds retained affinity toward the receptor subtypes in a range of $c a$. 3-70 $\mathrm{nM}$, underlining the importance of the $\mathrm{N}$-methyl position. ${ }^{[73 \mathrm{c}]}$ After oral administration to rats only the parent compound 120 and the analog 121 showed uptake into the blood; for $\mathbf{1 2 1}$ an oral bioavailability of $10 \%$ was determined. ${ }^{[73 c]}$ The sequence of N-alkylated and non-N-alkylated amino acids of $\mathbf{1 2 1}$ corresponds to that of the permeable hexa-alanine template 117.[68]

Two out of seven active compounds, cyclopeptides 121 (Fig. 20) and 122 (c[Pro-Phe-D-Trp-MeLys-Thr-MePhe]), showed increased $\mathrm{Caco} 2$ permeability compared with 120. Peptide 121 showed comparable permeability in $\mathrm{AB}$ and $\mathrm{BA}$ direction; Kessler and colleagues concluded that no active transport is involved. In rat serum, 120, 121 and 122 were reported to be stable. While $\mathbf{1 2 1}$ was found to be stable to intestinal enzymes, parent compound 120 was degraded. A comparison of the Caco 2 permeability of $\mathbf{1 2 1}$ and its enantiomer ent-121 revealed a 5-fold difference in $\mathrm{AB}$ direction $\left(1.53 \times 10^{-6} \mathrm{~cm} / \mathrm{s}\right.$ for 121 and $0.31 \times 10^{-6} \mathrm{~cm} / \mathrm{s}$ for ent-121), going along with an increased export ratio of 3.7 for ent-121 as compared with 1.0 for 121 (Table 11). ${ }^{[69]}$

Hewitt et al. failed to maintain permeability when replacing a Leu by amino acids with more polar side chains in the cyclic hexapeptide 113 (Fig. 18). ${ }^{65]}$ N-Methylated versions of the VerberHirschman peptide however exhibit Caco2 permeability although the compounds contain Lys and Thr.

The results suggest that simple $\mathrm{N}$-methylation to confer bioavailability to a biologically active cyclopeptide might not always be productive. N-Methylation might diminish activity by blocking interactions with the target protein or by forcing the cyclopeptide to adopt an inactive structure.

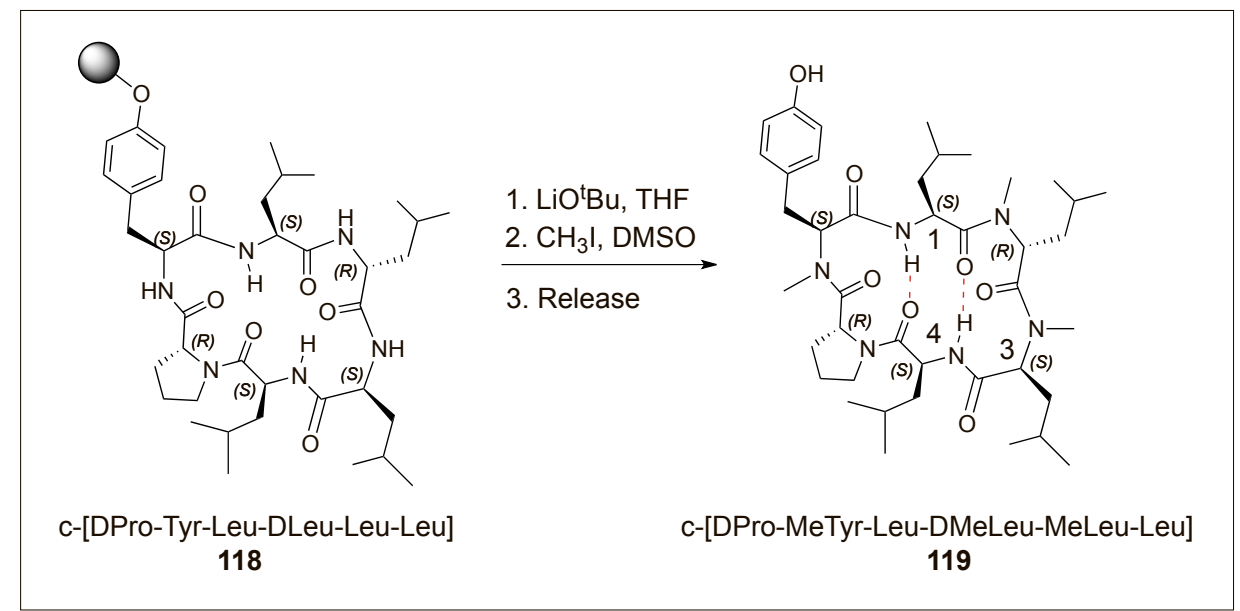

Scheme 12. Passively permeable cyclic peptide 119. ${ }^{[70]}$

Table 10. PAMPA $P_{e}$ in $\mathrm{cm} / \mathrm{s}$, determined at $\mathrm{pH} 7.4$; Caco2 $\mathrm{P}_{\text {app }}$ in $10^{-6} \mathrm{~cm} / \mathrm{s}$.

\begin{tabular}{|c|c|c|c|c|c|}
\hline Cpd & $\log D_{7.4}$ & $\begin{array}{c}\text { PAMPA } \\
\log _{\mathrm{e}}\end{array}$ & $\begin{array}{c}\text { Caco2 } \\
\mathbf{P}_{\text {app }} \text { AB }\end{array}$ & $\begin{array}{c}\text { Caco2 } \\
\text { efflux ratio }\end{array}$ & Reference \\
\hline 115 & & & ca. 20 & & {$[66,68]$} \\
\hline 115 & -1.0 & -8.2 & 0.2 & 0.8 & [69] \\
\hline ent-115 & -1.1 & -8.3 & 1.75 & 3.1 & [69] \\
\hline 116 & & & ca. 20 & & {$[66,68]$} \\
\hline 116 & $<-1.5$ & -8.3 & 0.15 & 1.0 & [69] \\
\hline ent-116 & $<-1.5$ & -8.2 & 1.34 & 2.6 & [69] \\
\hline 117 & & & ca. 20 & & {$[66,68]$} \\
\hline 117 & -0.8 & -7.0 & 0.56 & 1.9 & [69] \\
\hline ent-117 & -0.7 & -7.1 & 2.15 & 1.5 & [69] \\
\hline 119 & $>3$ & -4.4 & 16 & 1.5 & [69] \\
\hline ent-119 & $>3$ & -4.3 & 13 & 1.3 & [69] \\
\hline
\end{tabular}

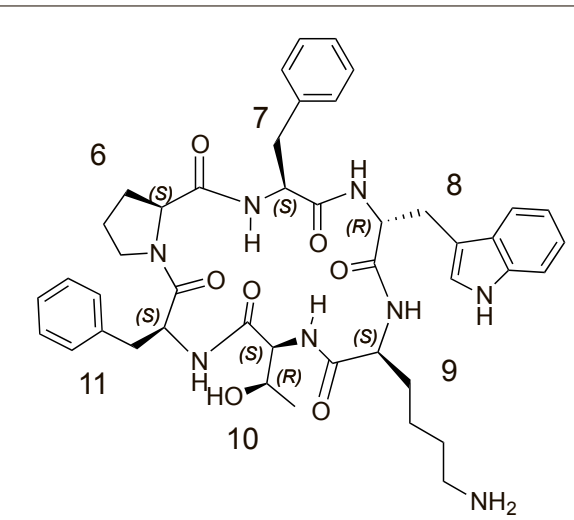

120

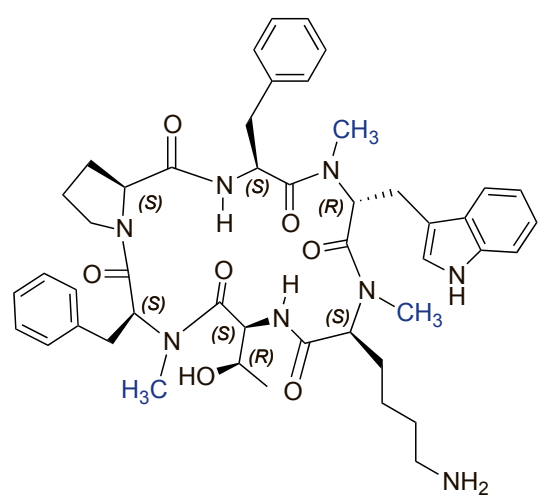

121 c-[Pro-Phe-MeDTrp-MeLys-Thr-MePhe]

117 c-[MeAla-Ala-MeDAla-MeAla-Ala-MeAla]
Fig. 20. Veber-Hirschmann peptide 120 and the $\mathrm{N}$-methylated analog 121; the numbering corresponds to the somatostatin position. ${ }^{[73 c]}$ 
Table 11. Affinity and permeability of the Veber-Hirschmann peptide $\mathbf{1 2 0}$ and the N-methylated analogs 121 and 122. ${ }^{[73 c]}$; Value reported by Marelli et al. ${ }^{[69]}$

\begin{tabular}{|c|c|c|c|c|c|}
\hline $\mathbf{C p d}$ & hsst2 & hsst5 & $\log \mathbf{D}^{*}$ & $\mathbf{C a c o 2} \mathbf{P}_{\text {app }}$ & F \\
\hline & $\mathrm{pK}_{\mathrm{D}}$ & $\mathrm{pK}_{\mathrm{D}}$ & & $\mathrm{x} 10^{-6} \mathrm{~cm} / \mathrm{s}$ & \\
\hline $\mathbf{1 2 0}$ & 8.01 & 7.82 & & $<1$ & \\
\hline $\mathbf{1 2 1}$ & 7.21 & 7.22 & 2.0 & $4.0(1.53)^{\mathrm{a}}$ & $9.9 \%$ \\
\hline
\end{tabular}
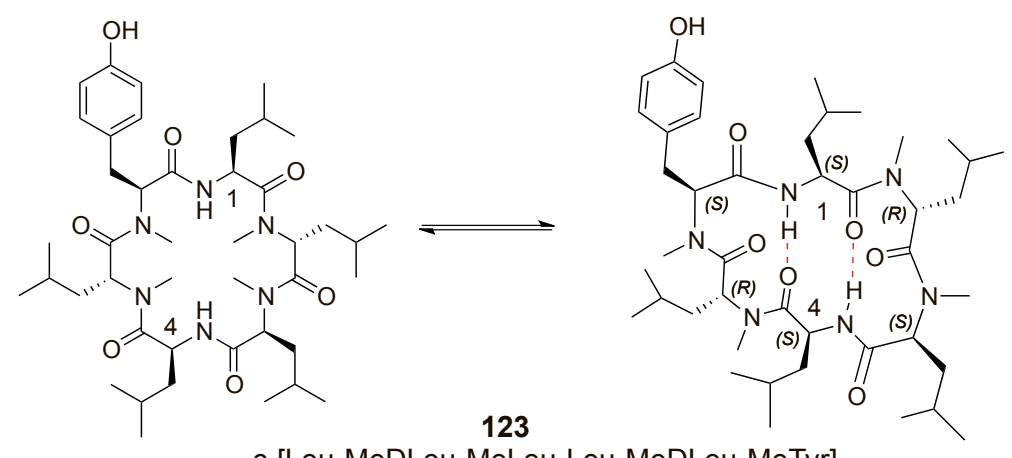

c-[Leu-MeDLeu-MeLeu-Leu-MeDLeu-MeTyr]

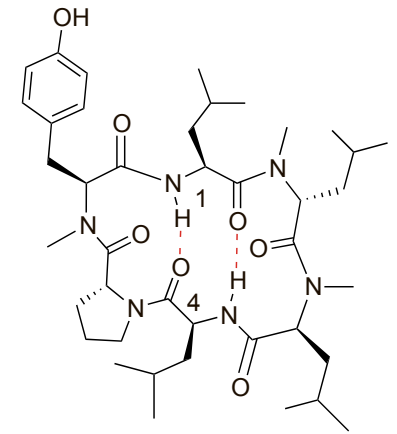

c-[Leu-MeDLeu-MeLeu-Leu-DPro-MeTyr] 119

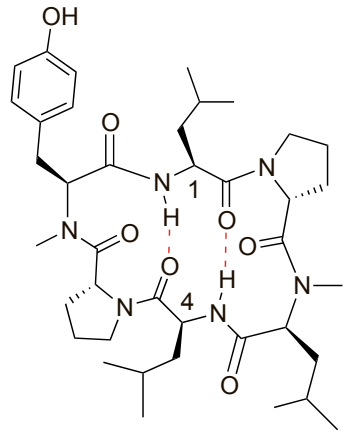

c-[Leu-DPro-MeLeu-Leu-DPro-MeTyr] 124

Fig. 21. 3D structure of three orally available cyclic hexapeptides 119,123 and 124 was investigated by Nielsen et al. ${ }^{[71]}$

Table 12. Passive permeability and oral bioavailability of 119,123 and 124 ; rat liver microsomal clearance $\mathrm{CL}_{\text {int }}$; oral bioavailability F: rat, dose $10 \mathrm{mg} / \mathrm{kg}^{[71]} \mathrm{CSA}$ : cyclosporine A. ${ }^{[7}$ Wite et al. ${ }^{[70 a]}$ reported F ca. 28\% (10 mg/kg, rats), Lewis et al. ${ }^{[70 \mathrm{~b}]}$ found $\mathrm{F} \mathrm{ca.} \mathrm{30 \%} \mathrm{(10} \mu \mathrm{M} / \mathrm{kg}$, mice).

\begin{tabular}{|c|c|c|c|c|c|}
\hline Cpd & $\begin{array}{c}\text { rotatable } \\
\text { bonds }\end{array}$ & MW & PAMPA P & $\mathbf{C L}_{\text {int }}$ & F \\
\hline & & {$[\mathrm{g} / \mathrm{mol}]$} & {$\left[10^{-6} \mathrm{~cm} / \mathrm{s}\right]$} & {$[\mu \mathrm{L} / \mathrm{min} / \mathrm{mg}]$} & \\
\hline $\mathrm{CsA}$ & & & & & $21 \%$ \\
\hline $\mathbf{1 2 3}$ & 12 & 785 & $<0.1$ & 19.1 & $18 \%$ \\
\hline $\mathbf{1 1 9}$ & 10 & 755 & 1.0 & 14.0 & $16 \%$ \\
\hline $\mathbf{1 2 4}$ & 8 & 725 & 6.8 & 7.3 & $30 \%$ \\
\hline
\end{tabular}

Nielsen et al. compared the three dimensional structure of three orally bioavailable cyclic hexapeptides 119, 123 and 124 (Fig. 21) with identical configuration and sequence of secondary and tertiary amide bonds. ${ }^{[71]}$ NMR experiments revealed that the structure of all three peptides in $\mathrm{CDCl}_{3}$ solution consists of an antiparallel $\beta$-sheet connected by two (type 1) $\beta$-turns at the ends. The structures determined for $\mathbf{1 1 9}$ and $\mathbf{1 2 4}$ in DMSO- $\mathrm{d}_{6}$ solution correspond to those determined in $\mathrm{CDCl}_{3}$. Peptide $\mathbf{1 2 3}$ in contrast was found to adopt in DMSO- $\mathrm{d}_{6}$ a ring-shaped structure with no transannular hydrogen bonds. Slow H-D exchange $\left(\mathrm{t}_{1 / 2}>700 \mathrm{~min}\right)$ was observed in $\mathrm{CDCl}_{3}$ for the Leu(1) and Leu(4) amide protons of 119, 123 and 124, indicating that both amide NHs are hydrogen bonded. In DMSO- $\mathrm{d}_{6}$, slow H-D exchange was observed for 119 and 124; in line with the determined structure rapid $\mathrm{H}-\mathrm{D}$ exchange $\left(\mathrm{t}_{1 / 2}<60 \mathrm{~min}\right)$ was reported for the amide protons of peptide 123.

The passive membrane permeabilities were determined in a PAMPA assay with the most rigid peptide 124 exhibiting the largest value; 124 showed also the best microsomal stability of the three compounds (Table 12).

Oral absorption of these cyclic peptides was studied in rats and compared with cyclosporine A (CsA). Plasma concentration curves showed more rapid absorption of 119 and 124 and slower uptake of 123 and CsA. Although in vitro passive permeabilities and metabolic stabilities of peptides 123 and $\mathbf{1 1 9}$ did not predict good pharmacokinetic profiles, both compounds showed oral availability. Nielsen et al. speculated that the less flexible peptides 119 and 124 might be transported by a shuttle. ${ }^{[71]}$ Marelli et al. ${ }^{[69]}$ reported for 119 and the enantiomer of 119 well comparable Caco2 permeabilities (119: $\mathrm{P}_{\text {ap }}=$ $16 \times 10^{-6} \mathrm{~cm} / \mathrm{s}$ efflux ratio 1.5 ; ent-119: $\mathrm{P}^{\text {app }}$ $=13 \times 10^{-6} \mathrm{~cm} / \mathrm{s}$ efflux ratio 1.3 ; Table 10 ) which would be in line with passive diffusion through the lipid bilayer rather than with involvement of a transporter protein.

Sanguinamide A (125, Fig. 22), ${ }^{[74]}$ a thiazole-containing cyclic heptapeptide with two prolyl amide bonds, was isolated from Hexabranchus sanguineus (sea slug, a marine invertebrate). Fairlie and colleagues reported the NMR spectroscopic characterization in DMSO- $\mathrm{d}_{6}$ solution and determined the conformation at the Phe(3)Pro(4) amide bond and at the Ile(5)-Pro(6) amide bond to be cis and trans. ${ }^{[75]}$ In solution the molecule forms an antiparallel $\beta$-sheet with a turn at each end. Two amide $\mathrm{NH}$ bonds participate in intramolecular hydrogen bonds. The compact molecule, which is orally available in rat (dose 10 $\mathrm{mg} / \mathrm{kg}, \mathrm{F}=7 \%$ ), violates three rule-of-five parameters. ${ }^{[75,76]}$

The effect of $\mathrm{N}$-methylation on permeability of sanguinamide A analogs was found by Lokey and coworkers to be position dependent. ${ }^{[77]} \mathrm{N}-$ Methylation of the exposed Phe(3)NH - to give analog 126 - resulted in improved permeability and - surprisingly - solubility (Fig. 22, Table 13). The conformation of the macrocycle (determined in $\mathrm{CHCl}_{3}$ ) was not changed and the intramolecular hydrogen bonds remained unaffected. N-Methylation of amides which participate in intramolecu- 


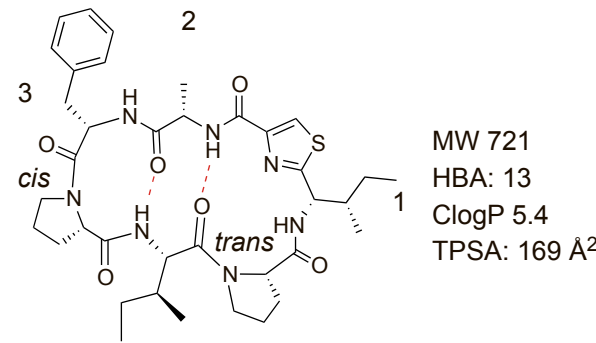

c[lle(Thz)-Ala(2)-Phe(3)-Pro(4)-Ile(5)-Pro(6)] Sanguinamide $A ; 125$

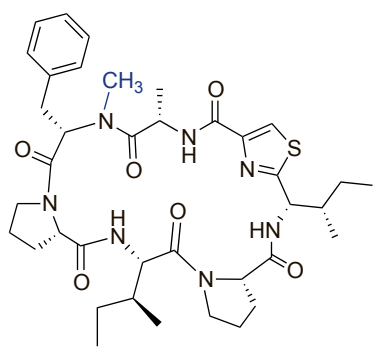

126

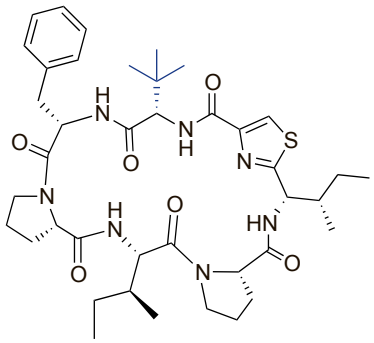

danamide F; 127

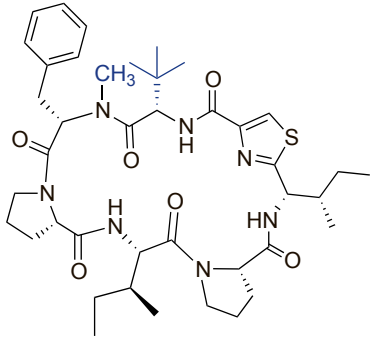

danamide $\mathrm{D} ; \mathbf{1 2 8}$

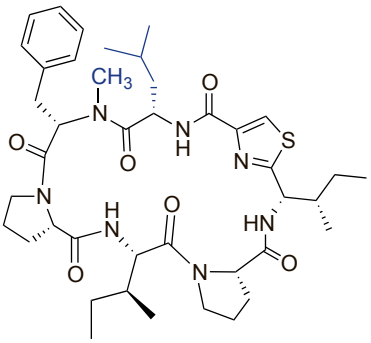

129

Fig. 22. Sanguinamide A and analogs; intramolecular hydrogen bonds indicated by dashed lines. ${ }^{[75-77]}$

Table 13. Permeability, thermodynamic solubility and oral availability of sanguinamide $A$ and analogs; oral bioavailability determined in rat (dose $10 \mathrm{mg} / \mathrm{kg}){ }^{[75-77]}$

\begin{tabular}{|c|c|c|c|c|c|}
\hline Cpd & $\begin{array}{c}\text { PAMPA } \mathbf{P}_{\mathbf{e}} \\
{\left[\mathrm{x} 10^{-6} \mathrm{~cm} / \mathrm{s}\right]}\end{array}$ & $\begin{array}{c}\text { Caco2 } \mathbf{P}_{\text {app }} \\
{\left[\mathrm{x} 10^{-6} \mathrm{~cm} / \mathrm{s}\right]}\end{array}$ & $\begin{array}{c}\text { Solubility in PBS } \\
{[\mu \mathrm{M}]}\end{array}$ & $\mathbf{F}$ & Reference \\
\hline $\mathbf{1 2 5}$ & 5.3 & 1.3 & 107 & $7 \%$ & {$[75-77]$} \\
\hline $\mathbf{1 2 6}$ & 11.0 & 7.4 & 172 & & {$[77]$} \\
\hline $\mathbf{1 2 7}$ & 2.2 & 8.0 & 8 & $51 \%$ & {$[76,77]$} \\
\hline $\mathbf{1 2 8}$ & 2.1 & 14.0 & 8 & $21 \%$ & {$[76,77]$} \\
\hline $\mathbf{1 2 9}$ & 17.2 & 19.3 & 111 & & {$[77]$} \\
\hline
\end{tabular}

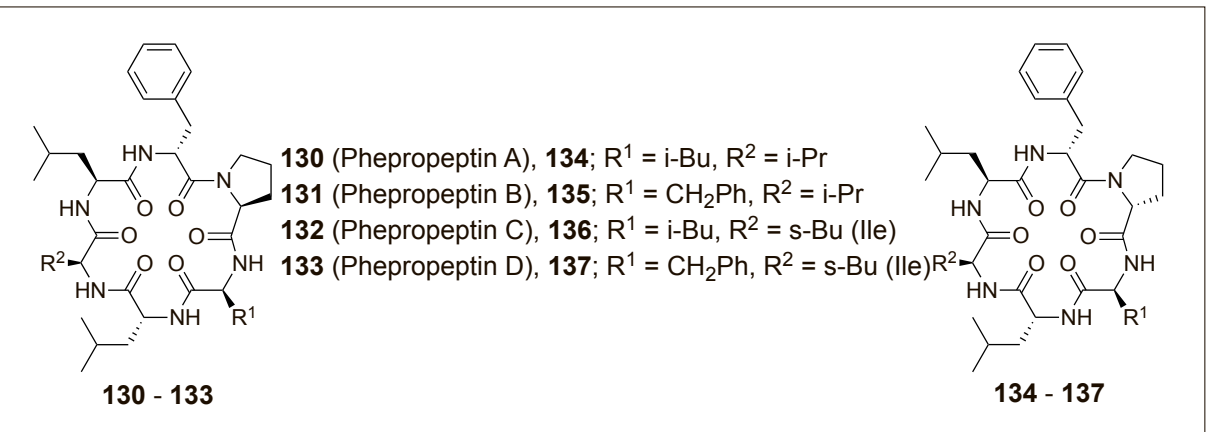

Fig. 23. Phepropeptines A-D (130-133) and their proline epimers (134-137). ${ }^{[78]}$

lar hydrogen bonds however reduced permeability; the NMR spectra of these compounds were reported to show the presence of multiple conformers. ${ }^{[77]}$

The replacement of Ala(2) by tert.-butyl glycine (leading to danamide F (127) $\left.{ }^{[76]}\right)$, Ile and Leu afforded compounds which exhibited increased $\mathrm{Caco} 2$ permeability as compared to sanguinamide A (125). All three compounds showed comparably low solubility. The conformation (hydrogen bond network) of the macrocyclic scaffold was reported to be preserved. [76,77]

$\mathrm{N}$-Methylation and increased size/ $\beta$ branching of the substituent in position 2 are found in danamide D (128) which has good oral bioavailability and Caco2 permeability. ${ }^{[76,77]}$ The improved permeability was attributed by Lokey and coworkers to the combined effects of increased aliphatic character of the side chain and removal of the exposed NH. ${ }^{[77]}$ Alteration of the residue in position 2 of $\mathbf{1 2 8}$ to Leu (removed $\beta$-branching) afforded 129 which exhibits excellent permeability in $\mathrm{Caco} 2$ and PAMPA assay as well as - compared to $\mathbf{1 2 7}$ or $\mathbf{1 2 8}$ - improved solubility. NMR data (temperature coefficient $\mathrm{T}_{\mathrm{C}} \mathrm{NH}$ ) of 129 suggest that different conformations are adopted in polar $\left(\mathrm{DMSO}-\mathrm{d}_{6}\right.$ ) and less polar $\left(\mathrm{CDCl}_{3}\right)$ environment, conferring passive permeability and solubility to the compound.[77]

Phepropeptins A-D (130-133, Fig. 23), lipophilic peptides with high cellular permeability were recently described by Lokey and coworkers to exhibit solventdependent conformational behavior.[78] A comparison with their proline epimers 134-137 revealed a more rapid cell penetration for the natural stereoisomers while the pairs of diasteromers showed similar solubility (Table 14). Solution structures obtained from NMR data and molecular dynamic simulations in $\mathrm{CDCl}_{3}$ (solvent with low dielectric constant to mimic the lipid bilayer) and DMSO (solvent with high dielectric constant to mimic polar aqueous environment) were reported for 132. In $\mathrm{CDCl}_{3}$ compound 132 adopts a conformation with three intramolecular hydrogen bonds (two transannular, one extra-annular) and in DMSO surprisingly a conformation with four intramolecular hydrogen bonds (two transannular, two extra-annular). Neither the number of the hydrogen bonds nor the polar surface area allows the solubility/permeability relation to be understood. Lokey attributed the high permeability of $\mathbf{1 3 2}$ to the ability to equilibrize between polar and nonpolar conformation depending on environment. ${ }^{[78]}$

Whitty et al. used the term 'chameleonic' behavior to describe the ability of a compound to present a mostly nonpolar surface in nonpolar environment and changing the conformation in aqueous environment to then expose polar functional groups. ${ }^{[82]}$ These authors analyzed 20 approved orally available macrocyclic drugs and concluded that some degree of chameleonic behavior is required for most oral drugs with MW $>600-700^{[82,83]}$ and proposed measures to quantify chameleonic properties. Good aqueous solubility was suggested to require a topological polar surface area TPSA (in $\AA^{2}$ ) of $\geq 0.2 \mathrm{MW}$; good passive membrane permeability to require a 3D polar surface area (molecular PSA) of $\leq 140 \AA^{2}$ in apolar environment. For compounds with TPSA $>0.2 \mathrm{MW}$ the amount of PSA to be buried $\triangle \mathrm{PSA}$ is then a least TPSA - $140 \AA^{2}$. Whitty et al. also 
pointed out the difficulty to design chameleonic properties into a specific molecule.

\subsection{Non-peptidic Macrocycles}

An example illustrating that conformational flexibility translates into oral availability stems from Polyphor's MacroFinder ${ }^{\circledR}$ library. Structures of compound 138 (Fig. 24) have been determined by NMR methods in DMSO- $\mathrm{d}_{6}$ and in $\mathrm{CD}_{3} \mathrm{OD}$ solution. In both solvents the compound adopts well-defined conformations. Characteristic NOEs indicated alltrans peptide bonds in both solvents. In DMSO-d the NH group of serine is oriented towards the arylether oxygen atom and the carbonyl group of the $\beta$-homoalanine moiety, suggesting that an intramolecular hydrogen bond could be formed. In $\mathrm{CD}_{3} \mathrm{OD}$ however the serine $\mathrm{NH}$ is exposed to the solvent. The compound was found to be well soluble (1\% DMSO DPBS buffer, $\mathrm{pH} 7.4 ; 0.93 \mathrm{~g} / \mathrm{L})$ and to show Caco2 permeability of $3.5-4.1 \times 10^{-6} \mathrm{~cm} / \mathrm{s}$ in $\mathrm{AB}$ direction (efflux ratio 11-12). In line with these data, the compound exhibited oral availability of $25-30 \%$ when dosed at 8 $\mathrm{mg} / \mathrm{kg}$ to rats. ${ }^{[84]}$

Over et al. studied factors which determine cell permeability of nonpeptidic, beyond rule of five macrocyclic compounds. ${ }^{[85]}$ A representative set of 214 macrocyclic compounds, including regio- and stereoisomers was investigated. The compounds were selected from the DOS (diversity oriented synthesis) screening collection (ca. 21'000 macrocyclic compounds ${ }^{[85]}$ ) of the Broad Institute. Solubility, lipophilicity $\left(\log \mathrm{D}_{74}\right)$ and $\mathrm{Caco} 2$ permeability were determined. $78 \%$ of the compounds were reported to show solubility values above $50 \mu \mathrm{M} ; 45 \%$ of the compounds exhibited a drug-like $\log \mathrm{D}(1-3)$. The Caco2 permeability $\mathrm{P}_{\text {app }}$ ranged from undetectable to $88 \times$ $10^{-6} \mathrm{~cm} / \mathrm{s}$ (median: $1.15 \times 10^{-6} \mathrm{~cm} / \mathrm{s}$ ) $; 75 \%$ of all compounds exhibited transport-mediated efflux (efflux ratio $>2$ ). A positive correlation between experimentally measured $\log \mathrm{D}$ values and cell permeabilities was obtained for compound groups with the same number of hydrogen bond donors. Hydrogen bond donors and acceptors were found to limit the permeability. [85]

Linking macrocyclic scaffold and substituent using polar functional groups like ureas, sulfonamides and secondary amines was associated with poor permeability. In contrast, hydrophobic groups like phenyl, pyridyl, isoxazoles, tert. amines led to increased permeability. Thus, side chains attached to the macrocyclic scaffold greatly influence the cell permeability. The influence of the coupling group is illustrated for example by the comparison of the carbamate 139 which shows a significantly higher Caco 2 permeability than the closely related urea 140 (Fig 25, Table 15). ${ }^{[85]}$
Permeability differences were reported within series of regioisomeric compounds, e.g. 1,5-triazoles showed higher permeability than the corresponding 1,4-triazoles (cf. 141 and 149, Fig. 25, Table 16). Also the configuration can have an important influence on lipophilicity, passive permeability and efflux. As an example Over et al. presented a series of stereoisomeric triazoles (Fig. 25, Table 16): The compounds 141-148 could be distributed into two groups, according to the configuration of the two stereocenters in the macrocy- clic ring. Syn diastereomeres were found to permeate better than the anti diastereomers. The syn compounds exhibited higher $\log \mathrm{D}$ values, lower efflux ratio and

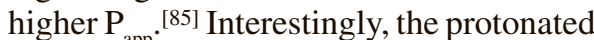
form of the syn compound $\mathbf{1 4 2}$ was found in NMR experiments to adopt different conformations in $\mathrm{CDCl}_{3}$ and in DMSO-d, in line with good solubility and permeability. ${ }^{[85]}$

Also the regioisomeric macrocyclic compounds 150 and 151 or 153 and 154 containing a cyano-substituted salicylic ac-

Table 14. ADME parameters of phepropeptins and their proline epimers. MDCK assay = permeability through a monolayer of Madin-Darby canine kidney low efflux cells, which express low levels of P-glycoproteins. These cells give a measure of passive transport with minimal interference of active efflux processes. ${ }^{[78]}$

\begin{tabular}{|c|c|c|c|c|c|c|c|}
\hline Cpd & $\operatorname{logD}_{7.4}$ & solubility & $\begin{array}{c}\text { MDCK } \\
\mathbf{P}_{\text {app }}\end{array}$ & Cpd & $\log _{7.4}$ & solubility & MDCK $\mathbf{P}_{\text {app }}$ \\
\hline & & {$[\mathrm{mg} / \mathrm{mL}]$} & $\begin{array}{c}{\left[\mathrm{x} 10^{-6}\right.} \\
\mathrm{cm} / \mathrm{s}]\end{array}$ & & & {$[\mathrm{mg} / \mathrm{mL}]$} & {$\left[\mathrm{x} 10^{-6} \mathrm{~cm} / \mathrm{s}\right]$} \\
\hline $\mathbf{1 3 0}$ & 2.08 & 0.17 & 33 & $\mathbf{1 3 4}$ & 2.37 & 0.15 & 8 \\
\hline $\mathbf{1 3 1}$ & 2.33 & 0.05 & 39 & $\mathbf{1 3 5}$ & 2.41 & 0.07 & 11 \\
\hline $\mathbf{1 3 2}$ & 2.63 & 0.06 & 40 & $\mathbf{1 3 6}$ & 2.39 & 0.07 & 15 \\
\hline $\mathbf{1 3 3}$ & 2.42 & 0.01 & 40 & $\mathbf{1 3 7}$ & 2.32 & 0.03 & 18 \\
\hline
\end{tabular}

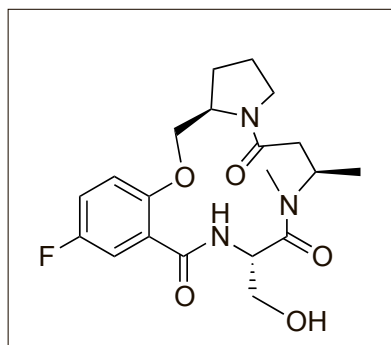

138 in DMSO- $d_{6}$ solution

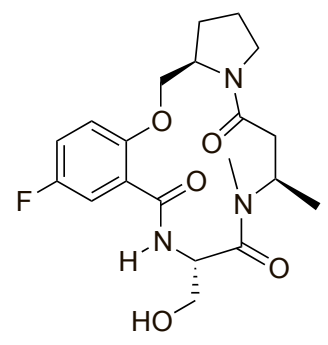

138 in $C D_{3} \mathrm{OD}$ solution
Fig. 24. The orally available MacroFinder ${ }^{\circledR}$ compound 138 exhibits 'chameleonic' behavior.

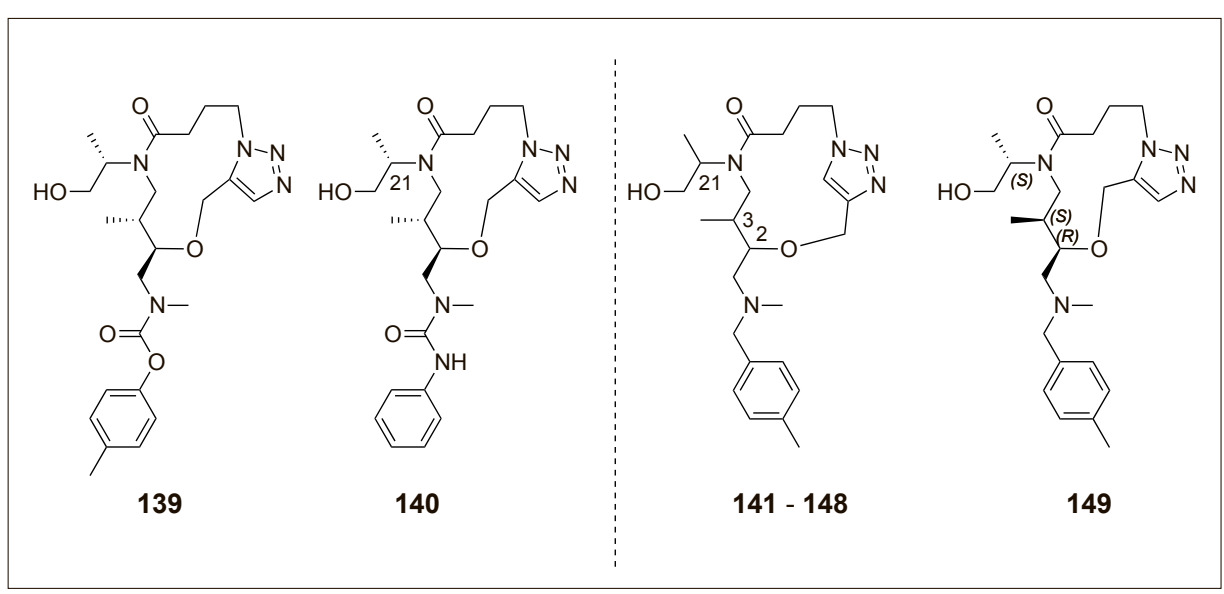

Fig. 25. Functional groups connecting macrocyclic scaffold and substituent as well as the configuration influence the cellular permeability. ${ }^{[85]}$ 
id moiety, differ in permeability. The comparison of $\mathbf{1 5 0}$ and $\mathbf{1 5 2}$ provides a further example illustrating the permeability differences of diasteromers (Fig. 26, Table 17).

\subsection{Macrocyclic Compounds as Prodrugs}

Bioreversible cyclization of the backbone of linear peptides as well as of nonpeptidic inhibitors with free amino and carboxylic acid groups was investigated to improve permeation through biological membranes and oral bioavailability.

Cyclization allows simultaneous masking of the charged and polar terminal functional groups, increasing the lipophilicity and decreasing the size of a molecule (smaller hydrodynamic radius) and its flexibility. In favorable cases, the hydrogen bonding potential of a cyclic prodrug might be reduced due to the formation of intramolecular hydrogen bonds.

Table 15. Functional groups connecting macrocyclic scaffold and substituent influence permeability; Caco2 $\mathrm{P}_{\mathrm{app}}$ : in $10^{-6} \mathrm{~cm} / \mathrm{s}$; in parentheses values determined in presence of a cocktail of inhibitors of efflux transporters. ${ }^{[85]}$

\begin{tabular}{|l|l|l|l|}
\hline Cpd & $\log D$ & $\mathbf{P}_{\text {app }} \mathbf{A B}$ & Efflux ratio \\
\hline $\mathbf{1 3 9}$ & 1.55 & $6.2(20.9)$ & $7.22(0.92)$ \\
\hline $\mathbf{1 4 0}$ & 0.6 & $0.13(0.72)$ & $45.39(2.32)$ \\
\hline
\end{tabular}

Table 16. ADME parameters of diastereomers 141 - 148 and their constitutional isomer 149; Caco2 $\mathrm{P}_{\text {app }}$ : in $10^{-6} \mathrm{~cm} / \mathrm{s}$; in parentheses values determined in presence of a cocktail of inhibitors of efflux transporters. ${ }^{[85]}$

\begin{tabular}{|c|c|c|c|c|c|c|c|c|}
\hline Cpd & & $\mathrm{C}(2)$ & $\mathrm{C}(3)$ & $\mathrm{C}(21)$ & $\log D$ & solubility & $\mathbf{P}_{\text {app }} \mathbf{A B}$ & Efflux ratio \\
\hline 141 & syn & $R$ & $S$ & $S$ & 1.1 & $>100 \mu \mathrm{M}$ & $5.72(13.16)$ & $3.15(0.68)$ \\
\hline 142 & syn & $R$ & $S$ & $R$ & 0.9 & $98 \mu \mathrm{M}$ & $5.48(10.20)$ & $2.15(0.71)$ \\
\hline 143 & syn & $S$ & $R$ & $S$ & 0.9 & $>100 \mu \mathrm{M}$ & $4.75(9.83)$ & $2.44(0.74)$ \\
\hline 144 & syn & $S$ & $R$ & $R$ & 1.2 & $>100 \mu \mathrm{M}$ & $5.66(14.09)$ & $2.96(0.55)$ \\
\hline 145 & anti & $R$ & $R$ & $S$ & 0.2 & $>100 \mu \mathrm{M}$ & $0.46(2.48)$ & $17.59(1.06)$ \\
\hline 146 & anti & $S$ & $S$ & $S$ & 0.5 & $>100 \mu \mathrm{M}$ & $0.51(2.48)$ & $17.72(0.90)$ \\
\hline 147 & anti & $S$ & $S$ & $R$ & 0.2 & $>100 \mu \mathrm{M}$ & $0.51(2.62)$ & $18.75(0.90)$ \\
\hline 148 & anti & $R$ & $R$ & $R$ & 0.4 & $99 \mu \mathrm{M}$ & $0.55(2.46)$ & $16.64(1.05)$ \\
\hline 149 & syn & $R$ & $S$ & $S$ & 2.2 & $96 \mu \mathrm{M}$ & 22.36 & 0.99 \\
\hline
\end{tabular}

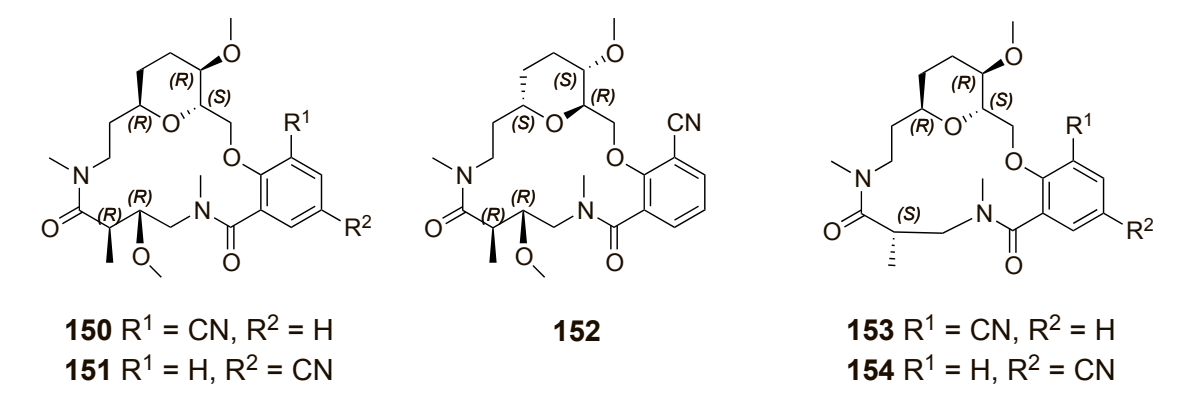

Fig. 26. Regioisomeric pairs of macrocycles (150/151; 153/154); 150 and 152 are diastereoisomers. ${ }^{[85]}$

Described prodrug-moieties include (acyloxy)alkoxy linkers, ${ }^{[86]}$ as well as substituted phenylpropionic acid-based ${ }^{[87]}$ and coumarin-based ${ }^{[88]}$ linkers (Scheme 13). The resulting cyclic prodrugs undergo a slow esterase catalyzed hydrolysis followed by a fast chemical degradation step.

Recently, Andersson et al. used (acyloxy)alkoxy linkers to convert the selective, nonpeptidic thrombin inhibitor $\mathbf{1 5 5}$ (thrombin: $\mathrm{K}=4.6 \mathrm{nM}$ ) into the cyclic prodrugs 156a and 156b (Fig. 27) and compared their in vitro ADME properties with those of the acyclic prodrug 157. [86a] All three compounds were reported to have good solubility and high passive cell permeability (Table 18). Compared with the linear analog 157, the macrocyclic prodrugs 156a and $\mathbf{1 5 6 b}$ did not exhibit increased cell permeability.

In human plasma, 156a was found to be stable for $4 \mathrm{~h}$. When incubated with human or rat hepatocytes, $\mathbf{1 5 6 a}$ was rapidly converted into 155. (The methylcarbamoyl group of the acyclic prodrug 157 was reported to be almost completely resistant to metabolism). The bioavailability of $\mathbf{1 5 5}$ after oral or intraduodenal administration of 155 or $156 a$ to rat was compared. A 5-fold higher $\mathrm{AUC}_{\text {inf }}$ for $\mathbf{1 5 5}$ was reported after oral administration of $156 \mathbf{a}$ compared to administration of $\mathbf{1 5 5}$. The oral bioavailability of $\mathbf{1 5 5}$ after administration of 156a was unfortunately only $2.5 \%$. Administration of $\mathbf{1 5 6} \mathbf{a}$ to the duodenum showed a bioavailability of $1.6 \%$, excluding acid-mediated degradation of the prodrug as explanation for the low oral bioavailability.

Borchardt and colleagues previously described the conversion of the hexapeptide 158 into a (acyloxy)alkoxy-linked cyclic prodrug 159 (Fig. 28). ${ }^{[86 \mathrm{~b}-\mathrm{e}]}$ NMR spectroscopic data indicated that 159 adopts a $\beta$-turn conformation in aqueous solution, ${ }^{[86 \mathrm{c}]}$ stabilized by an intramolecular hydrogen bond between Gly(3) NH and the carbamoyl $\mathrm{C}=\mathrm{O}$ of the pro moiety. The prodrug moiety allowed alteration of the liability of the hexapeptide to enzymatic degradation. ${ }^{[86 \mathrm{~b}]}$ As compared with 158, prodrug $159\left(\mathrm{P}_{\text {app }} \mathrm{AB}=0.13 \times 10^{-6} \mathrm{~cm} / \mathrm{s}\right)$ exhibits an at least 76-fold improved (but still poor) permeability. Compared with the intrinsic permeability of $\mathbf{1 5 8}$, determined in the presence of peptidase inhibitors $\left(\mathrm{P}_{\text {app }}\right.$ $\left.\mathrm{AB}=0.04 \times 10^{-6} \mathrm{~cm} / \mathrm{s}\right)$, the improvement was only $c a$. 3 -fold. ${ }^{866}$ ] The improved permeability seems in case of the peptide $\mathbf{1 5 8}$ to be owed to the improved stability rather than to the compact structure of the prodrug. To achieve permeability, shielding of most polar contacts or internalization by formation of intramolecular hydrogen bonds in apolar environment would be required, as found for permeable cyclic peptides. 


\section{Conclusions}

Several approaches towards diverse libraries of macrocyclic compounds have been developed over the last decade and demonstrated to provide ligands addressing a broad variety of biological targets including the notoriously difficult proteinprotein interactions. Recently, also targetoriented modular synthesis for the convergent assembly of macrolide antibiotics has been described. Truncation and modification of macrocyclic natural products serve as alternative sources for lead structures.

In medicinal chemistry programs, macrocyclization was successfully applied to improve the properties of linear lead structures, often informed by X-ray crystal structures of complexes of a linear ligand and its target protein, revealing that two substituents of the ligands were in close proximity.

Many macrocycles are 'beyond rule of five' compounds which were traditionally associated with reduced cell permeability and bioavailability. Therefore, over the last few years, significant work was dedicated to the investigation of the properties of these compounds. Studies addressing the membrane permeability of cyclic peptides revealed a strong dependence on the backbone conformation and the polarity of the side chains. Configuration and $\alpha-\mathrm{N}$ methylation are key factors determining the conformation. Peptides with mostly non-polar side chains might be passively transported; the compounds must adopt a compact conformation with minimal exposure of polar groups. More polar cyclopeptides seem to rely on active transport or facilitated diffusion; their transport depends on recognition of their spatial structure. ${ }^{[66,69]}$ The effect of an N-methylation is position-dependent and may favorably influence the permeability of a cyclopeptide scaffold but may also lead to reduced potency on target. In agreement with the findings of the studies of peptidic macrocycles also non-peptidic macrocycles exhibit significantly different cellular permeability values for stereoisomers and regioisomers. The accurate prediction of average permeability is possible based on calculated (2D) molecular descriptors; discrimination between stereo- and regioisomers, however would require methods that take into account the 3D structure. ${ }^{[70 b, 82,85]}$ The ideal bRo5 macrocyclic compound can adapt to its environment. In polar solvent or at the target protein surface, polar contacts are displayed; in apolar solvent or in the membrane bilayer, polar contacts are shielded or internalized. The formation of intramolecular hydrogen bonds and the presence of sufficient rotatable bonds in the peptide scaffold is the basis of the flexible adaptation of a compound to the polarity of its

Table 17. Caco2 permeability of regioisomers and diasteromers; $P$ : in $10^{-6} \mathrm{~cm} / \mathrm{s}$; in parentheses values determined in presence of a cocktail of inhibitors of efflux transporters. ${ }^{\left[{ }^{[5]}\right.}$

\begin{tabular}{|c|c|c|c|}
\hline $\mathbf{C p d}$ & $\mathbf{l o g} \mathbf{D}$ & $\mathbf{P}_{\text {app }} \mathbf{A B}$ & Efflux ratio \\
\hline $\mathbf{1 5 0}$ & 0.2 & $3.75(6.36)$ & $4.95(0.78)$ \\
\hline $\mathbf{1 5 1}$ & 0.1 & $0.77(1.89)$ & $12.2(1.4)$ \\
\hline $\mathbf{1 5 2}$ & 0.9 & $10.5(23.08)$ & $4.2(0.81)$ \\
\hline & & & \\
\hline $\mathbf{1 5 3}$ & 0.75 & $16.03(27.12)$ & $1.86(0.62)$ \\
\hline $\mathbf{1 5 4}$ & 0.35 & $3.17(5.93)$ & $5.13(1.03)$ \\
\hline
\end{tabular}

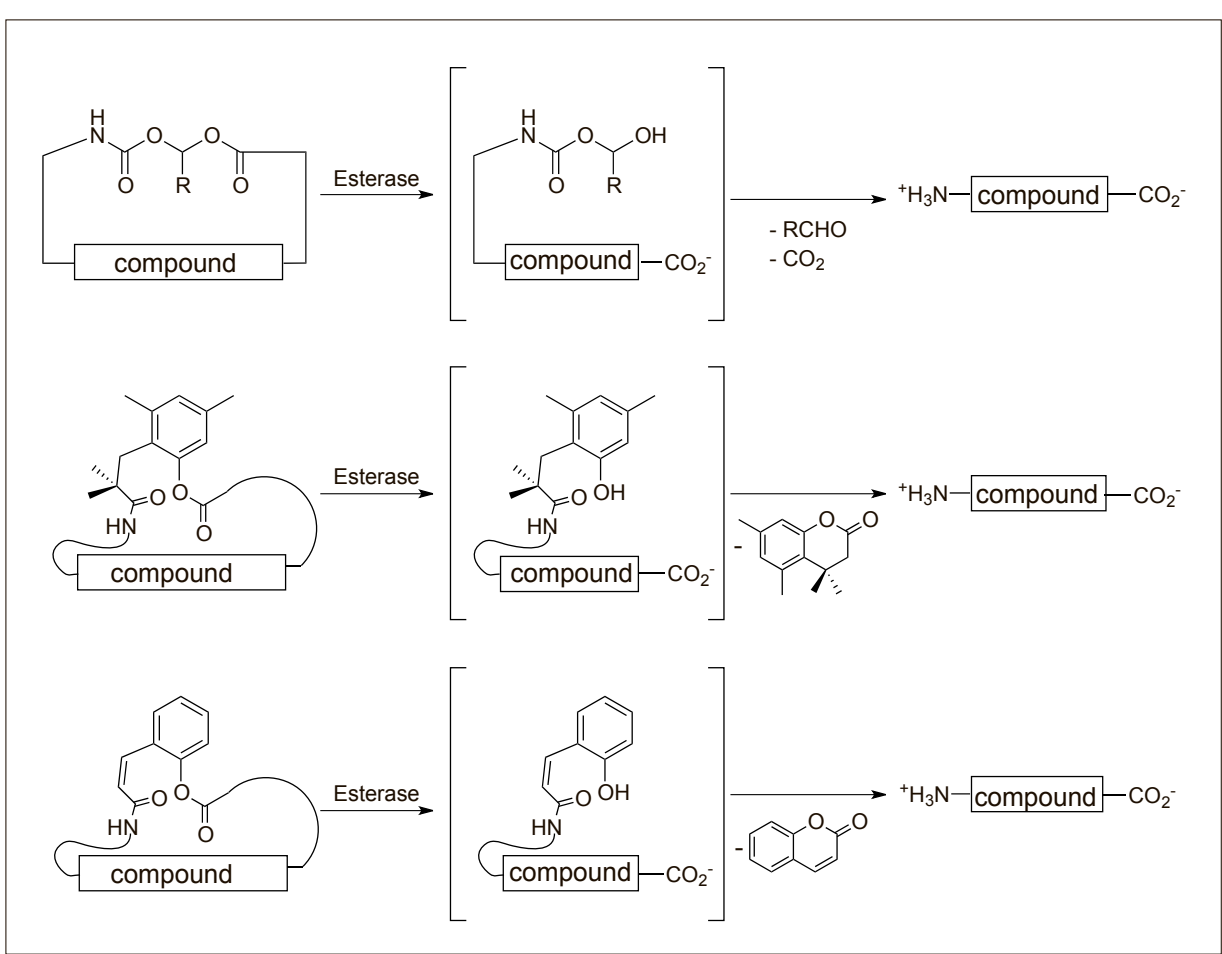

Scheme 13. Bioreversible macrocyclization of linear active compounds with zwitterionic character. ${ }^{[86-88]}$

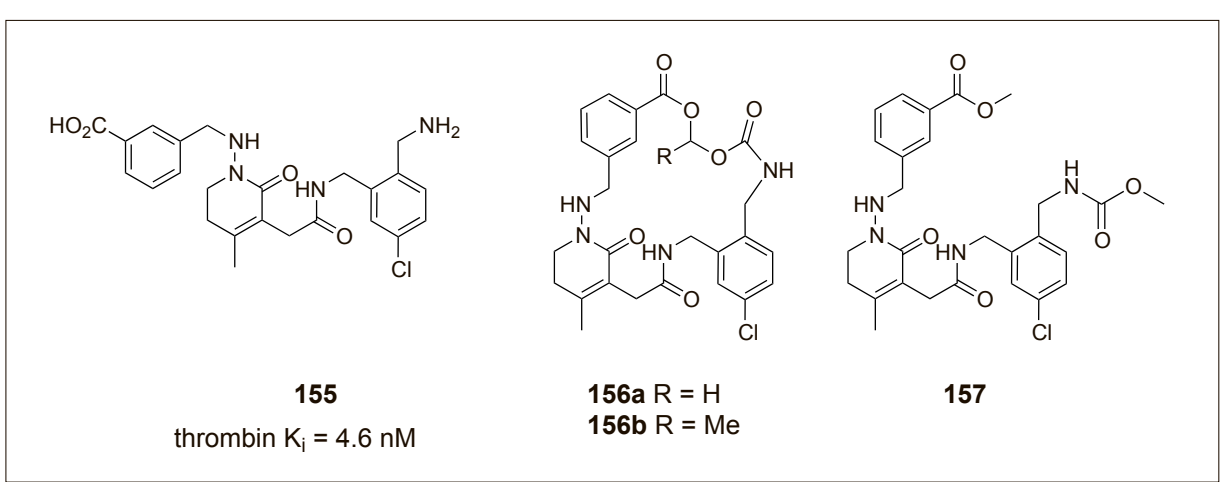

Fig. 27. (Acyloxy)alkoxy-bridged thrombin inhibitor prodrugs. ${ }^{[86 a]}$

environment, which confers permeability and aqueous solubility. This 'chameleonic' behavior ${ }^{[82]}$ has been described in a few examples including cyclosporine A, more recently sanguinamide A derivatives (129;
Fig. 22) ${ }^{[75-77]}$ and phepropeptines (e.g. 132, Fig. 23) ${ }^{[78]}$ and was also observed in nonpeptidic macrocycles like MacroFinder ${ }^{\circledR}$ compound 138 (Fig. 24) and DOS compound 142 (Fig. 25, Table 16). The two lat- 
Table 18. ADME parameters reported for inhibitor 155 and prodrugs $156 a, b$ and $157 .{ }^{\text {[86a] }}$

\begin{tabular}{|c|c|c|c|c|c|c|}
\hline Cpd & MW & TPSA & Solubility & $\log \mathbf{D}$ & $\begin{array}{c}\text { Caco-2 } \mathbf{P}_{\text {app }} \mathbf{A B} \\
{\left[\times 10^{-6} \mathrm{~cm} / \mathrm{s}\right]}\end{array}$ & $\begin{array}{c}\text { Efflux } \\
\text { ratio }\end{array}$ \\
\hline $\mathbf{1 5 5}$ & 470 & 125 & $>100$ & -0.5 & 0.1 & 2.4 \\
\hline $\mathbf{1 5 6 a}$ & 526 & 126 & 120 & 2.3 & 48 & 5.6 \\
\hline $\mathbf{1 5 6 b}$ & 540 & 126 & 340 & 2.6 & 45 & 4.8 \\
\hline $\mathbf{1 5 7}$ & 542 & 126 & 160 & 2.9 & 54 & 3.3 \\
\hline
\end{tabular}

H-Trp-Ala-Gly-Gly-Asp-Ala-OH 158

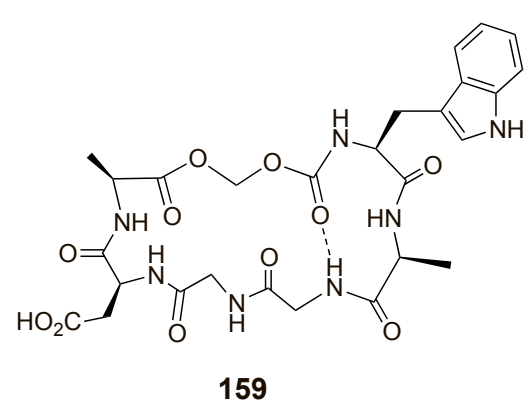

Fig. 28. Hexapeptide 158 and cyclic prodrug 159. [86b-e] $^{[3}$

ter examples illustrate that such properties can be designed into macrocycles.

\section{Acknowledgement}

The author would like to thank Drs D. Obrecht, C. Bisang and D. Benzies for their contributions and proofreading of the manuscript.

Received: June 17, 2017

[1] a) E. M. Diggers, S. P. Hale, J. Lee, N. K. Terrett, Nat. Rev. Drug Discov. 2008, 7 , 608 ; b) E. Marsault, M. L. Peterson, J. Med. Chem. 2011, 54, 1961; c) J. Mallinson, I. Collins, Future Med. Chem. 2012, 4, 1409; d) S. Vendeville, M. D. Cummings, Annu. Rep. Med. Chem. 2013, 48, 371; e) F. Giordanetto, J. Kihlberg, J. Med Chem. 2014, 57, 278; f) D. M. Ramsey, R. R. A. Kitson, J. I. Levin, C. J. Moody, S. R. McAlpine, 'Macrocycles in Drug Discovery', Ed. J. Levin, The Royal Society of Chemistry, Cambridge, 2015, p. 37; g) R. Schiess, K.-H. Altmann, 'Macrocycles in Drug Discovery', Ed. J. Levin, The Royal Society of Chemistry, Cambridge, 2015, p. 78; h) A. Ganesan, 'Macrocycles in Drug Discovery', Ed. J. Levin, The Royal Society of Chemistry, Cambridge, 2015, p. 109; i) A. Poulsen, A. D. William, B. W. Dymock, 'Macrocycles in Drug Discovery', Ed. J. Levin, The Royal Society of Chemistry, Cambridge, 2015, p. 141; j) W. M. Kazmierski, R. L. Jarvest, J. C. Plattner, X. Li, 'Macrocycles in Drug Discovery', Ed. J. Levin, The Royal Society of Chemistry, Cambridge, 2015, p. 235; k) Ph. Ermert, K. Möhle, D. Obrecht, 'Macrocycles in Drug Discovery', Ed. J. Levin, The Royal Society of Chemistry, Cambridge, 2015, p. 283; 1) S. Pena, L. Scarone. G. Serra, Future Med. Chem. 2015, 7, 355; m) P. G. Dougherty, Z. Qian, D. Pei, Biochem. J. 2017, 474, 1109 .
[2] a) R. A. Feelders, U. Yasothan, P. Kirkpatrick, Nat. Rev. Drug Discov. 2012, 11, 597; b) M. J. Yu, W. Zheng, B. M. Seletsky, B. A. Littlefield, Y. Kishi, Annu. Rep. Med. Chem. 2011, 46, 227; c) L. M. Jarvis, Chem. Eng. News 2017, 28; d) T. W. Johnson, P. F. Richardson, S. Bailey, A Brooun, B. J. Burke, M. R. Collins, J. J. Cui, J. G. Deal, Y.-L. Deng, D. Dinh, L. D. Engstrom, M. He, J. Hoffman, R. L. Hoffman, Q. Huang, R. S. Kania, J. C. Kath, H. Lam, J. L. Lam, P. T. Le, L. Lingardo, W. Liu, M. McTigue, C. L. Palmer, N. W. Sach, T. Smeal, G. L. Smith, A. E. Stewart, S. Timofeevski, H. Zhu, J. Zhu, H Y. Zou, M. P. Edwards, J. Med. Chem. 2014, 57 , 4720; e) S. Basit, Z. Ashraf, K. Lee, M. Latif, Eur. J. Med. Chem. 2017, 134, 348.

[3] A. M. Mathiowetz, S. S. F. Leung, M. P. Jacobson, 'Macrocycles in Drug Discovery', Ed. J. Levin, The Royal Society of Chemistry, Cambridge, 2015, p. 367.

[4] A. K. Yudin, Chem. Sci. 2015, 6, 30.

[5] M. L. Peterson, 'Macrocycles in Drug Discovery', Ed. J. Levin, The Royal Society of Chemistry, Cambridge, 2015, p 398.

[6] a) U. Schmidt, A. Lieberknecht, H. Griesser, J. Talbiersky, J. Org. Chem. 1982, 47, 3261; b) U. Schmidt, A. Lieberknecht, H. Griesser, J. Häusler, Liebigs Ann. Chem. 1982, 2153; c) A. G. Brown, M. J. Crimmin, P. D. Edwards, J. Chem. Soc. Perkin Trans. 1, 1992, 123; d) D. L. Boger, S. Miyazaki, S. H. Kim, J. H. Wu, S. L. Castle, O. Loiseleur, Q. Jin, J. Am. Chem. Soc. 1999, 121, 10004.

[7] For leading reference cf. C. J. White, A. K, Yudin, Nat. Chem. 2011, 3, 509.

[8] S. R. LaPlante, P. J. Edwards, L. D. Fader, A. Jakalian, O. Hucke, ChemMedChem 2011, 6, 505; LaPlante et al. proposed to classify atropisomeric compounds into three groups based on energy barriers and rotation rates. Class 1 : Energy barrier $\Delta \mathrm{E}_{\mathrm{rot}}<20 \mathrm{kcal} / \mathrm{mol}, \mathrm{t}_{1 / 2}=$ minutes or less; (compounds do not exhibit atropisomer properties) Class 2: Energy barrier $\Delta \mathrm{E}_{\text {rot }} c a$. $20-30 \mathrm{kcal} / \mathrm{mol}, \mathrm{t}_{\mathrm{t} 2}=$ minutes to months; Class 3: Energy barrier $\Delta \mathrm{E}>30 \mathrm{kcal} / \mathrm{mol}, \mathrm{t}_{1 / 2}=$ years (stable chiral compounds). Half-life is depen- dent on the medium in which the compound is dissolved. Critical in context of atropisomeric drugs: half-life in the presence of human plasma.

[9] C. J. Dinsmore, M. J. Bogusky, J. C. Culberson, J. M. Bergman, C. F. Homnick, C. B. Zartman, S. D. Mosser, M. D. Schaber, R. G. Robinson, K. S. Koblan, H. E. Huber, S. L. Graham, G. D. Hartman, J. R. Huff, T. M. Williams, J. Am. Chem. Soc. 2001, 123, 2107.

[10] I. M. Bell, S. N. Gallicchio, M. Abrams, L. S. Beese, D. C. Beshore, H. Bhimnathwala, M J. Bogusky, C. A. Buser, J. C. Culberson, J. Davide, M. Ellis-Hutchings, C. Fernandes, J. B. Gibbs, S. L. Graham, K. A. Hamilton, G D. Hartman, D. C. Heimbrook, C. F. Homnick, H. E. Huber, J. R. Huff, K. Kassahun, K. S Koblan, N. E. Kohl, R. B. Lobell, J. J. Lynch, Jr., R. Robinson, A. D. Rodrigues, J. S. Taylor, E. S. Walsh, T. M. Williams, C. B. Zartman, J. Med. Chem. 2002, 45, 2388.

[11] E. S. Priestley, D. L. Cheney, I. DeLucca, A. Wei, J. M. Luettgen, A. R. Rendina, P. C. Wong, R. R. Wexler, J. Med. Chem. 2015, 58, 6225.

[12] P. W. Glunz, L. Mueller, D. L. Cheney, V. Ladziata, Y. Zou, N. R. Wurtz, A. Wei, P. C. Wong, R. R. Wexler, E. S. Priestley, J. Med. Chem. 2016, 59, 4007.

[13] M. M. Joullié, D. J. Richard, Chem. Commun. 2004, 2011.

[14] E. K. Singh, D. M. Ramsey, S. R. McAlpine, Org. Lett. 2012, 14, 1198.

[15] S. Deng, J. Taunton, J. Am. Chem. Soc. 2002, $124,916$.

[16] a) L. T. Tan, R. T. Williamson, W. H. Gerwick, K. S. Watts, K. McGough, R. Jacobs, J. Org. Chem. 2000, 65, 419; b) F.Yokokawa, H Sameshima, T. Shioiri, Synlett 2001, SI, 986.

[17] Sing et al. described the interconversion of stable prolylamide isomers of Sanguinamide B in DMSO at $170{ }^{\circ} \mathrm{C} .{ }^{[14]}$

[18] a) J. A. Robinson, S. DeMarco, F. Gombert, K. Moehle, D. Obrecht, Drug Discov. Today 2008, 13, 944; b) D. Obrecht, E. Chevalier, K. Moehle, J. A. Robinson, Drug Discov. Today: Technol. 2012, 9, e63; c) N. Srinivas, P. Jetter, B. J. Ueberbacher, M. Werneburg, K. Zerbe, J. Steinmann, B. Van der Meijden, F. Bernardini, A. Lederer, R. L. A. Dias, P. E. Misson, H. Henze, J. Zumbrunn, F. O. Gombert, D. Obrecht, P. Hunziker, S. Schauer, U. Ziegler, A. Käch, L. Eberl, K. Riedel, S. J. DeMarco, J. A. Robinson, Science, 2010, 327, 1010; d) A. Luther, K. Moehle, E. Chevalier, G. Dale, D. Obrecht, Curr. Opin. Chem. Biol. 2017, 38, 45.

[19] C. E. Schafmeister, J. Po, G. L. Verdine, J. Am. Chem. Soc. 2000, 122, 5891.

[20] F. Bernal, A. F. Tyler, S. J. Korsmeyer, L. D. Walensky, G. L. Verdine, J. Am. Chem. Soc. 2007, 129, 2456

[21] a) T. K. Sawyer, Chem. Biol. Drug Des. 2009, 73, 3; b) T. K. Sawyer, V. Guerlavais, K. Darlak, E. Feyant, 'Macrocycles in Drug Discovery', Ed. J. Levin, The Royal Society of Chemistry, Cambridge, 2015, p. 339

[22] E. Marsault, H. R. Hoveyda, R. Gagnon, M. L. Peterson, M. Vézina, C. Saint-Louis, A. Landry, J.-F. Pinault, L. Ouellet, S. Beauchemin, S. Beaubien, A. Mathieu, K. Benakli, Z. Wang, M. Brassard, D. Lonergan, F. Bilodeau, M Ramaseshan, N. Fortin, R. Lan, S. Li, F. Galaud, V. Plourde, M. Champagne, A. Doucet, P. Bhérer, M. Gauthier, G. Olsen, G. Villeneuve, S. Bhat, L. Foucher, D. Fortin, X. Peng, S. Bernard, A. Drouin, R. Déziel, G. Berthiaume, Y. L. Dory, G. L. Fraser, P. Deslongchamps, Bioorg. Med. Chem. Lett. 2008, 18, 4731.

[23] H. R. Hoveyda, E. Marsault, R. Gagnon, A. P. Mathieu, M. Vézina, A. Landry, Z. Wang, K. Benakli, S. Beaubien, C. Saint-Louis, M. Brassard, J.-F. Pinault, L. Ouellet, S. Bhat, M. Ramaseshan, X. Peng, L. Foucher, S. Beauchemin, P. Bhérer, 
D. F. Veber, M. L. Peterson, G. L. Fraser, J. Med. Chem. 2011, 54, 8305.

[24] Tranzyme Press Release, 12 March 2012; Tranzyme Press Release, 25 May 2012.

[25] L. A. Marcaurelle, E. Comer, S. Dandapani, J. R. Duvall, B. Gerard, S . Kesavan, M. D. Lee IV, H. Lui, J. T. Lowe, J.-C. Marie, C. A Mulrooney, B. A. Pandya, A. Rowley, T. D Ryba, B.-C. Suh, J. Wei, D. W. Young, L. B. Akella, N. T. Ross, Y.-L. Zhang, D. M. Fass, S A. Reis, W.-N. Zhao, S. J. Haggarty, M. Palmer, M. A. Foley, J. Am. Chem. Soc. 2010, 132 16962.

[26] a) L. F. Peng, B. Z. Stanton, N. Maloof, X. Wang, S. L. Schreiber, Bioorg. Med. Chem. Lett. 2009, 19, 6319; b) B. Z. Stanton, L. F. Peng, N Maloof, K. Nakai, X. Wang, K. M. Herlihy, J. L. Duffner, K. M. Taveras, J. M. Hyman, S. M. Lee, A. N. Koehler, J. K. Chen, J. L. Fox, A. Mandinova, S. L. Schreiber, Nat. Chem. Biol. 2009, 5, 154.

[27] C. Dockendorff, M. M. Nagiec, M. Weiwer, S. Buhrlage, A. Ting, P. P. Nag, A. Germain, H.-J. Kim, W. Youngsaye, C. Scherer, M. Bennion, L. Xue, B. Z. Stanton, T. A. Lewis, L. MacPherson, M. Palmer, M. A. Foley, J. R Perez, S. L. Schreiber, ACS Med. Chem. Lett. 2012, 3, 808 .

[28] a) R. W. Heidebrecht, Jr., C. Mulrooney, C. P. Austin, R. H. Barker, Jr., J. A. Beaudoin, K. C.-C. Cheng, E. Comer, S. Dandapani, J. Dick, J. R. Duvall, E. H. Ekland, D. A Fidock, M. E. Fitzgerald, M. Foley, R. Guha, P. Hinkson, M. Kramer, A. K. Lukens, D. Masi, L. A. Marcaurelle, X.-Z. Su, C. J. Thomas, M. Weiwer, R. C. Wiegand, D. Wirth, M. Xia, J. Yuan, J. Zhao, M. Palmer, B. Munoz, S Schreiber, ACS Med. Chem. Lett. 2012, 3, 112 b) E. Comer, J. A. Beaudoin, N. Kato, M. E Fitzgerald, R. W. Heidebrecht, M. duPont Lee, IV, D. Masi, M. Mercier, C. Mulrooney, G. Muncipinto, A. Rowley, K. Crespo-Llado, A E. Serrano, A. K. Lukens, R. C. Wiegand, D. F Wirth, M. A. Palmer, M. A. Foley, B. Munoz, C. A. Scherer, J. R. Duvall, S. L. Schreiber, J. Med. Chem. 2014, 57, 8496

[29] a) I. B. Seiple, Z. Zhang, P. Jakubec, A. Langlois-Mercier, P. M. Wright, D. T. Hog, K. Yabu, S. R. Allu, T. Fukuzaki, P. N. Carlsen, Y. Kitamura, X. Zhou, M. L. Condakes, F. T Szczypinski, W. D. Green, A. G. Myers, Nature 2016, 533, 338; b) for discussion c.f. M.Yan, P. S. Baran, Nature 2016, 533, 326.

[30] Myers previously described a platform for the synthesis of tetracycline antibiotics, cf. M. G. Charest, C. D. Lerner, J. D. Brubaker, D. R Siegel, A. G. Myers, Science 2005, 308, 395; C. Sun, Q. Wang, J. D. Brubaker, P. M. Wright, C. D. Lerner, K. Noson, M. Charest, D. R. Siegel, Y.-M. Wang, A. G. Myers, J. Am. Chem. Soc. 2008, 130, 17913.

[31] G. P. Liao, E. M. M. Abdelraheem, C. G. Neochoritis, K. Kurpiewska, J. KalinowskaTluscik, D. C. McGowan, A. Dömling, Org. Lett. 2015, 17, 4980 .

[32] R. Hili, V. Rai, A. K. Yudin, J. Am. Chem. Soc. 2010, $132,2889$.

[33] M. C. Morejon, A. Laub, B. Westermann, D. G. Rivera, L. A. Wessjohann, Org. Lett. 2016, 18, 4096.

[34] J. R. Frost, C. C. G. Scully, A. K. Yudin, Nat. Chem. 2016, 8, 1105.

[35] N. A. Petasis, I.A. Zavialov, J. Am. Chem. Soc. 1997, 119, 445.

[36] A. M. Socha, N. Y. Tan, K. L. LaPlante, J. K. Sello, Bioorg. Med. Chem. 2010, 18, 7193.

[37] a) B. Beck, G. Larbig, B. Mejat, M. MagninLachaux, A. Picard, E. Herdtweck, A. Dömling, Org. Lett. 2003, 5, 1047; b) C. Hebach, U. Kazmaier, Chem. Commun. 2003, 596.

[38] a) T. Pirali, G. C. Tron, J. Zhu, Org. Lett. 2006, 8, 4145; b) M. Samarasimhareddy, H. P
Hemantha, V. V. Sureshbabu, Tetrahedron Lett. 2012, 53, 3104.

[39] A. Failli, H. Immer, M. Götz, Can. J. Chem. 1979, 57, 3257.

[40] B. K. W. Chung, J. L. Hickey, C. C. G. Scully, Z. Zaretsky, A. K. Yudin, Med. Chem. Commun. 2013, 4, 1124.

[41] A. V. Vasco, C. S. Pérez, F. E. Morales, H. E. Garay, D. Vasilev, J. A. Gavin, L. A. Wessjohann, D. G. Rivera, J. Org. Chem. 2015 , 80,6697

[42] S. Zaretsky, J. L. Hickey, J. Tan, D. Pichugin, M. A. St.Denis, S. Ler, B. K. W. Chung, C. C. G. Scully, A. K. Yudin, Chem. Sci. 2015, 6, 5446.

[43] Routes to access substituted aziridine aldehyde dimers starting from protected $\alpha$-amino acids or $\alpha$-hydroxy acids have been described. ${ }^{[32]}$

The conversion of serine n-butyl ester into the corresponding aziridine and subsequent DIBAL reduction of the ester afforded the unsubstituted aziridine aldehyde dimer 51. ${ }^{[32]}$

[44] a) J. L. Hickey, Z. Zaretsky, M. A. St.Denis, S. K. Chakka, M. M. Morshed, C. C. G. Scully, A. L. Roughton, A. K. Yudin, J. Med. Chem. 2016, 59, 5368; b) K. E. Low, S. Ler, K. J. Chen, R. L. Campbell, J. L. Hickey, J. Tan, C. C. G. Scully, P. L. Davies, A. K. Yudin, S. Zaretsky, J. Med. Chem. 2016, 59, 5403.

[45] X. Zhang, P. W. Glunz, J. A. Johnson, W. Jiang, S. Jacutin-Porte, V. Ladziata, Y. Zou, M. S. Phillips, N. R. Wurtz, B. Parkhurst, A. R. Rendina, T. M. Harper, D. L. Cheney, J. M. Luettgen, P. C. Wong, D. Seiffert, R. R. Wexler, E. S. Priestley, J. Med. Chem. 2016, 59, 7125.

[46] a) S. Liu, J. Desharnais, P. V. Sahasrabudhe, P. Jin, W. Li, B. D. Oates, S. Shanker, M. E. Banker, B. A. Chrunyk, X. Song, X. Feng, M. Griffor, J. Jimenez, G. Chen, D. Tumelty, A. Bhat, C. W. Bradshaw, G. Woodnutt, R. W. Lappe, A. Thorarensen, X. Qiu, J. M. Withka, L. D. Wood, Sci. Rep. 2016, 6, 26071; b) S.Liu, L. A. Dakin, L. Xing, J. M. Withka, P. V. Sahasrabudhe, W. Li, M. E. Banker, P. Balbo, S. Shanker, B. A. Chrunyk, Z. Guo, J. M. Chen, J. A. Young, G. Bai, J. T. Starr, S. W. Wright, J. Bussenius, S. Tan, A. Gopalsamy, B. A. Lefker, F. Vincent, L. H. Jones, H. Xu, L. R. Hoth, K. F. Geoghegan, X. Qiu, M. E. Bunnage, A. Thorarensen, Sci. Rep. 2016, 6, 30859; c) L. A. Dakin, 'Hit identification, binding site elucidation and structure guided design of novel macrocyclic IL-17A antagonists', oral presentation, Leysin, 2016.

[47] S. L. Alexander, T. F. Briggs, F. G. Favaloro, Jr., S. P. Hale, B. A. Seigal, K. C. Shortsleeves, C. Snedeker, M. Taylor, N. K. Terrett, D. Yan, P. W. Nowak, R. A. Denny, B. A. Chrunyk, P. V. Sahasrabudhe, J. M. Withka, WO2014/066726.

[48] J. G. Kettle, H. Alwan, M. Bista, J. Breed, N. L. Davies, K. Eckersley, S. Fillery, K. M. Foote, L. Goodwin, D. R. Jones, H. Käck, A. Lau, J. W. M. Nissink, J. Read, J. S. Scott, B. Taylor, G. Walker, L. Wissler, M. Wylot, J. Med. Chem. 2016, 59, 2346.

[49] a) T. Li, D. Saro, M. R. Spaller, Bioorg. Med. Chem. Lett. 2004, 14, 1385; b) G. Udugamasooriya, D. Saro, M. R. Spaller, Org. Lett. 2005, 7, 1203; c) D. G. Udugamasooriya, M. R. Spaller, Bioploymers 2008, 89, 653.

[50] J. E. DeLorbe, J. H. Clements, B. B. Whiddon, S. F. Martin, ACS Med. Chem. Lett. 2010, 1, 448.

[51] W. Zhang, D. DeRyckere, D. Hunter, J. Liu, M. A. Stashko, K. A. Minson, C. T. Cummings, M. Lee, T. G. Glaros, D. L. Newton, S. Sather, D. Zhang, D. Kireev, W. P. Janzen, H. S. Earp, D. K. Graham, S. V. Frye, X. Wang, J. Med. Chem. 2014, 57, 7031 .

[52] a) J. Liu, C. Yang, C. Simpson, D. DeRyckere, A. Van Deusen, M. J. Miley, D. Kireev, J. NorrisDrouin, S. Sather, D. Hunter, V. K. Korboukh,
H. S. Patel, W. P. Janzen, M. Machius, G. L. Johnson, H. S. Earp, D. K. Graham, S. V. Frye, X. Wang, ACS Med. Chem. Lett. 2012, 3, 129; b) X. Wang, J. Liu, W. Zhang, M. A. Stashko, J. Nichols, M. J. Miley, J. Norris-Drouin, Z. Chen, M. Machius, D. DeRyckere, E. Wood, D. K. Graham, H. S. Earp, D. Kireev, S. V. Frye, ACS Med. Chem. Lett. 2016, 7, 1044;

[53] a) A. Bowers, N. West, J. Taunton, S. L. Schreiber, J. E. Bradner, R. M. Williams, J. Am. Chem. Soc. 2008, 130, 11219; b) P. Bhansali, C. L. Hanigan, R. A. Casero, Jr., L. M. V. Tillekeratne, J. Med. Chem. 2011, 54, 7453;

[54] J. Almaliti, A. A. Al-Hamashi, A. T. Negmeldin, C. L. Hanigan, L. Perera, M. K. H. Pflum, R. A. Casero, Jr., L. M. V. Tillekeratne, J. Med. Chem. 2016, 59, 10642;

[55] a) A. A. Bowers, T. J. Greshock, N. West, G. Estiu, S. L. Schreiber, O. Wiest, R. M. Williams, J. E. Bradner, J. Am. Chem. Soc. 2009, 131, 2900 ; b) A. A. Bowers, N. West, T. L. Newkirk, A. E. Troutman-Youngman, S. L. Schreiber, O. Wiest, J. E. Bradner, R. M. Williams, Org. Lett. 2009, 11, 1301; c) Y. Ying, Y. Liu, S. R. Byeon, H. Kim, H. Luesch, J. Hong, Org. Lett. 2008, 10, 4021; d) Q. Wang, B. A. Rosa, B. Nare, K. Powell, S. Valente, D. Rotili, A. Mai, G. M. Marshall, M. Mitreva, PLoS Neglected Trop. Dis. 2015, 9, e0004026.

[56] D. N. Reddy, F. Ballante, T. Chuang, A. Pirolli, B. Marrocco, G. R. Marshall, J. Med. Chem. 2016, 59, 1613.

[57] a) V. A. Steadman, S. B. Pettit, K. G. Poullennec, L. Lazarides, A. J. Keats, D. K. Dean, S. J Stanway, C. A. Austin, J. A. Sanvoisin, G. M. Watt, H. G. Fliri, A. C. Liclican, D. Jin, M. H. Wong, S. A. Leavitt, Y.-J. Lee, Y. Tian, C. R. Frey, T. C. Appleby, U. Schmitz, P. Jansa, R. L. Mackman, B. E. Schultz, J. Med. Chem. 2017, 60, 1000; b) R. Sedrani, J. Kallen, L. M. Martin Cabrejas, C. D. Papageorgiou, F. Senia, S. Rohrbach, D. Wagner, B. Thai, A.-M. Jutzi Eme, J. France, L. Oberer, G. Rihs, G. Zenke, J. Wagner, J. Am. Chem. Soc. 2003, 125, 3849; c) L. M. Martin Cabrejas, S. Rohrbach, D. Wagner, J. Kallen, G. Zenke, J. Wagner, Angew. Chem. Int. Ed. 1999, 38, 2443.

[58] B. C. Doak, B. Over, F. Giordanetto, J. Kihlberg, Chem. Biol. 2014, 21, 1115.

[59] A. R. Bogdan, N. L. Davies, K. James, Org. Biomol. Chem. 2011, 9, 7727.

[60] T. Rezai, B. Yu, G. L. Millhauser, M. P. Jacobson, R. S. Lokey, J. Am. Chem. Soc. 2006, $128,2510$.

[61] NMR solvent data chart, Cambridge Isotope Laboratories, Inc.

[62] R. B. M. Koehorst, R. B. Sprujit, F. J. Vergeldt, M. A. Hemminga, Biophys. J. 2004, 87, 1445.

[63] a) C. Wu; E. R. Decker, N. Blok, J. Li, A. R. Bourgoyne, H. Bui, K. M. Keller, V. Knowles, W. Li, F. D. Stavros, G. W. Holland, T. A. Brock, R. A. F. Dixon, J. Med. Chem. 2001, 44, 1211; b) V. A. Ashwood, M. J. Field, D. C. Horwell, C. Julien-Larose, R. A. Lewthwaite, S. McCleary, M. C. Pritchard, J. Raphy, L. Singh, J. Med. Chem. 2001, 44, 2276; c) S. Sasaki, N. Cho, Y. Nara, M. Harada, S. Endo, N. Suzuki, F. Furuya, M. Fujino, J Med. Chem. 2003, 46, 113 ; d) A. Ettorre, P. D'Andrea, S. Mauro, M. Porcelloni, C. Rossi, M. Altamura, R. M. Catalioto, S. Giuliani, C. A. Maggi, D. Fattori, Biorg. Med. Chem. Lett. 2011, 21, 1807.

[64] B. Over, P. McCarren, P. Artursson, M. Foley, F. Giordanetto, G. Grönberg, C. Hilgendorf, M. D. Lee, IV, P. Matsson, G. Muncipinto, M. Pellisson, M. W. D. Perry, R. Svensson, J. R. Duvall, J. Kihlberg, J. Med. Chem. 2014, 57, 2746.

[65] W. M. Hewitt, S. S. F. Leung, C. R. Pye, A. R. Ponkey, M. Bednarek, M. P. Jacobson, R. S. Lokey, J. Am. Chem. Soc. 2015, 137, 715. 
[66] O. Ovadia, S. Greenberg, J. Chatterjee, B. Laufer, F. Opperer, H. Kessler, C. Gilon, A Hoffman, Mol. Pharmaceutics 2011, 8, 479.

[67] J. Chatterjee, F. Rechenmacher, H. Kessler, Angew. Chem. Int. Ed. 2013, 52, 254.

[68] J. G. Beck, J. Chatterjee, B. Laufer, M. U. Kiran, A. O. Frank, S. Neubauer, O. Ovadia, S. Greenberg, C. Gilon, A. Hoffman, H. Kessler, J. Am. Chem. Soc. 2012, 134, 12125.

[69] U. K. Marelli, J. Bezençon, E. Puig, B. Ernst, H. Kessler, Chem. Eur. J. 2015, 21, 8023.

[70] a) T. R. White, C. M. Renzelman, A. C. Rand, T. Rezai, C. M. McEwen, V. M. Gelev, R. A. Turner, R. G. Linington, S. S. F. Leung, A. S. Kalgutkar, J. N. Bauman, Y. Zhang, S. Liras, D. A. Price, A. M. Mathiowetz, M. P. Jacobson, R. S. Lokey, Nat. Chem. Biol. 2011, 7, 810; b) I. Lewis, M. Schaefer, T. Wagner, L. Oberer, E. Sager, P. Wipfli, T. Vorherr, Int. J. Pept. Res. Ther. 2015, 21, 205.

[71] D. S. Nielsen, R.-J. Lohman, H. N. Hoang, T. A. Hill, A. Jones, A. J. Lucke, D. P. Fairlie, ChemBioChem 2015, 16, 2289

[72] J. Chatterjee, D. Mierke, H. Kessler, J. Am. Chem. Soc. 2006, 128, 15164;

[73] a) J. Chatterjee, C. Gilon, A. Hoffman, H Kessler, Acc. Chem. Res. 2008, 41, 1331; b) L. Doedens, F. Opperer, M. Cai, J. G. Beck, M. Dedek, E. Palmer, V. C. Hruby, H. Kessler, J. Am. Chem. Soc. 2010, 132, 8115; c) E. Biron, J. Chatterjee, O. Ovadia, D. Langenegger, J. Brueggen, D. Hoyer, H. A. Schmid, R. Jelinek, C. Gilon, A. Hoffman, H. Kessler, Angew. Chem. Int. Ed. 2008, 47, 2595.
[74] D. S. Dalisay, E. W. Rogers, A. S. Edison, T. F. Molinski, J. Nat. Prod. 2009, 72, 732.

[75] D. S. Nielsen, H. N. Hoang, R.-J. Lohman, F. Diness, D. P. Fairlie; Org. Lett. 2012, 14, 5720.

[76] D. S. Nielsen, H. N. Hoang, R.-J. Lohman, T. A Hill, A. J. Lucke, D. C. Craik, D. J. Edmonds, D. A. Griffith, C. J. Rotter, R. B. Ruggeri, D. A Price, S. Liras, D. P. Fairlie, Angew. Chem. Int Ed. 2014, 53, 12059.

[77] A. T. Bockus, J. A. Schwochert, C. R. Pye, C. E. Townsend, V. Sok, M. A. Bednarek, R. S Lokey, J. Med. Chem. 2015, 58, 7409.

[78] J. Schwochert, Y. Lao, C. R. Pye, M. R. Naylor, P. V. Desai, I. C. Gonzalez Valcarcel, J. A Barrett, G. Sawada, M.-J. Blanco, R. S. Lokey, ACS Med. Chem. Lett. 2016, 7, 757.

[79] C. L. Ahlbach, K. W. Lexa, A. T. Bockus, V. Chen, P. Crews, M. P. Jacobson, R. S. Lokey, Future Med. Chem. 2015, 7, 2121.

[80] V. C. Damalanka, Y. Kim, K. R. Alliston, P. M. Weerawarna, A. C. Galasiti Kankanamalage, G. H. Lushington, N. Mehzabeen, K. P. Battaile, S. Lovell, K.-O. Chang, W. C. Groutas, J. Med. Chem. 2016, 59, 1899.

[81] A. T. Bockus, K. W. Lexa, C. R. Pye, A. S Kalgutkar, J. W. Gardner, K. C. R. Hund, W. M. Hewitt, J. A. Schwochert, E. Glassey, D. A. Price, A. M. Mathiowetz, S. Liras, M. P. Jacobson, R. S. Lokey, J. Med. Chem. 2015, 58, 4581.

[82] A. Whitty, M. Zhong, L. Viarengo, D. Beglov, D. R. Hall, S. Vajda, Drug Discovery Today 2016, 21, 712

[83] P. Matsson, J. Kihlberg, J. Med. Chem. 2017, 60,1662
[84] K. Möhle, M. Thommen, P. Ermert, D. Obrecht, unpublished results

[85] B. Over, P. Matsson, C. Tyrchan, P. Artursson, B. C. Doak, M. A. Foley, C. Hilgendorf, S E. Johnston, M. D. Lee IV, R. J. Lewis, P. McCarren, G. Muncipinto, U. Norinder, M. W. D. Perry, J. R. Duvall, J. Kihlberg, Nature Chem. Biol. 2016, 12, 1065.

[86] a) V. Andersson, F. Bergström, J. Branalt, G. Grönberg, D. Gustafsson, S. Karlsson, M Polla, J. Bergman, J. Kihlberg, J. Med. Chem. 2016, 59, 6658; b) G. M. Pauletti, S. Gangwar F. W. Okumu, T. J. Siahaan, V. J. Stella, R. T. Borchardt, Pharm. Res. 1996, 13, 1615; c) S. Gangwar, S. D. S. Jois, T. J. Siahaan, D. G. Vander Velde, V. J. Stella, R. T. Borchardt, Pharm. Res. 1996, 13, 1657; d) S. Gangwar, G. M. Pauletti, T. J. Siahaan, V. J. Stella, R. T. Borchardt, J. Org. Chem. 1997, 62, 1356; e) G. M. Pauletti, S. Gangwar, B. Wang, R. T. Borchardt, Pharm. Res. 1997, 14, 11.

[87] B. Wang, S. Gangwar, G. M. Pauletti, T. J. Siahaan, R. T. Borchardt, J. Org. Chem. 1997, 62, 1363.

[88] W. Wang, C. Camenish, D. C. Sane, H. Zhang, E. Hugger, G. L. Wheeler, R.T. Brochardt, B. Wang, J. Control. Rel. 2000, 65, 245. 